\title{
PUBLICACIONES SOBRE FILOLOGÍA INGLESA EN ESPAÑA (2007)
}

\section{RESUMEN}

Bibliografía relativa a Filología Inglesa publicada en España en 2007.

PALABRAS ClaVE: Filología Inglesa; bibliografía; España.

\section{ABSTRACT}

Bibliography on English Studies published in Spanish, 2007.

KEY WORDS: English Studies; bibliography; Spain.

ÍNDICE GENERAL
A. Literatura inglesa
B. Literatura norteamericana
C. Otras literaturas en lengua inglesa
D. Traducción
E. Cultura y cine 


\title{
A. LITERATURA INGLESA
}

\author{
IsABel MedRano \\ mmedrano@flog.uned.es \\ ANA ZAMORANO \\ aizamorano@flog.uned.es \\ UNED. Madrid
}

ÍNDICE

1. Literatura anglosajona, medieval y renacentista

2. Restauración y siglo XVIII

3. Siglo XIX

4. Siglo XX y época contemporánea

5. Miscelánea

\section{LITERATURA ANGLOSAJONA, MEDIEVAL Y RENACENTISTA}

Álvarez Recio, Leticia. «The Nostalgia for Elizabeth in T. Dekker's The Whore of Babylon (1607)». Proceedings of the 30th International Aedean Conference. Ed. María Losada Friend, Pilar Ron Vaz, Sonia Hernández Santano, Jorge Casanova. Huelva: Editorial Universidad de Huelva, 2007. CD-ROM.

BALLESTEROS GONZÁLEZ, Antonio. «A creación dramática isabelina». Literatura dramática. Una introducción histórica. Coord. Manuel F. Vieites. Capítulo de libro traducido al gallego por Dolores Torres París. Vigo: Editorial Galaxia y Xunta de Galicia (Biblioteca de Teatro e Instituto Galego das Artes Escénicas e Musicais), 2007.

Bueno Alonso, Jorge Luis. La épica de la Inglaterra anglosajona: Historia y textos desde el auge de Mercia al declive de la monarquía (760-1016). Vigo: Servizo de Publicacións da Universidade de Vigo. 2007.

—, «"Leodum Lidost on Lofgeornost”. La poesía épica de Beowulf en nuevos formatos gráficos y visuales». ES: Revista de filología inglesa, 28 (2007-2008): 47-72.

Carrasco Carrasco, Rocío y Domínguez Romero, Elena. «The Enemy from Within: Wilcox's Forbidden Planet (1956) and the Shakespearean Trace». Approaching Cultures through English. Ed. Elizabeth Woodward Smith. A Coruña: Universidade da Coruña, Servicio de Publicaciones, 2007. 111-20.

CORAL EsCOLÁ, Jordi. «Shakespeare's Pausible Community: The First Act of Titus Andronicus and its Kydian Precedent». Miscelánea: A Journal of English and American Studies, 36 (2007): 25-38.

—, «Seneca, what Seneca? The Chorus in The Spanish Tragedy». SEDERI, 17 (2007): 5-26.

-, «Vengeance Is Yours: Reclaiming the Social Bond in The Spanish Tragedy and Titus Andronicus». Atlantis, 29.2 (2007): 59-74.

-, «The Spanish Tragedy, Titus Andronicus, and the Origin of the Stage Machiavel». Proceedings of the 30th International AEDEAN Conference. Ed. María Losada Friend, Pilar Ron Vaz, Sonia Hernández Santano, Jorge Casanova. Huelva: Editorial Universidad de Huelva, 2007. CD-ROM. 
Couto Lorenzo, Gerardo. «Cultural Bias through the Centuries: Shylock and the Rule of Law». Approaching Cultures through English. Ed. Elizabeth Woodward Smith. A Coruña: Universidade da Coruña, Servicio de Publicaciones, 2007. 79-85.

Cuder Domínguez, Pilar. «Re-crafting the Heroic, Constructing a Female Hero: Margaret Cavendish and Aphra Behn». SEDERI, 17 (2007): 27-45.

CULPEPER, Jonathan. «A New Kind of Dictionary for Shakespeare's Plays: an Inmodest Proposal». SEDERI, 17 (2007): 47-74.

EscodA Agustí, Clara. «Julie Taymor's Titus (1999): Framing Violence and Activating Responsibility». Atlantis, 28.1 (2006): 57-70.

FERnÁNDEZ Rodríguez, Carmen María. «Shakespeare y la literatura femenina: The Winter's Tale, de Mary Lamb». Garoza: Revista de la Sociedad Española de Estudios Literarios de Cultura Popular, 7 (2007).

García Guerrero, M. ${ }^{a}$ Mercedes. «Con "T" de Titus a "T" de Tamora a través de la "T" de Taymor». De habitaciones propias y otros espacios conquistados. Estudios sobre mujeres y literatura en lengua inglesa en homenaje a Blanca López Román. Margarita Carretero González, M. ${ }^{a}$ Elena Rodríguez Martín y Gerardo Rodríguez Salas. Granada: Servicio de Publicaciones de la Universidad de Granada, 2006. 251- 64.

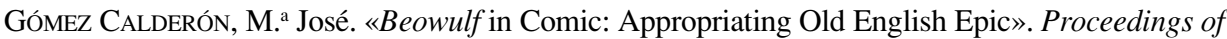
the 30th International Aedean Conference. Ed. María Losada Friend, Pilar Ron Vaz, Sonia Hernández Santano, Jorge Casanova. Huelva: Editorial Universidad de Huelva, 2007. CD-ROM.

JaRAZo Álvarez, Rubén. «Una pasión común: referencias botánicas en el Hamlet de William Shakespeare y Álvaro Cunqueiro». Garoza: Revista de la Sociedad Española de Estudios Literarios de Cultura Popular, 6 (2006).

—, «Incidencia de la literatura irlandesa medieval en la periferia española». Garoza: Revista de la Sociedad Española de Estudios Literarios de Cultura Popular, 7 (2007).

LAUREANo DomíngueZ, Lorena. «Iago's Dissonant Voice: Rhetoric and Realities in Othello». Proceedings of the 30th International Aedean Conference. Ed. María Losada Friend, Pilar Ron Vaz, Sonia Hernández Santano, Jorge Casanova. Huelva: Editorial Universidad de Huelva, 2007. CD-ROM.

LóPez-Pelaez Casellas, Jesús. «"What Good Newes from Barbary?” Nascent Capitalism, NorthAfricans and the Construction of English Identity in Thomas Heywood's Drama». Atlantis, 29.1 (June 2007): 123-40.

LORENZO, Eusebio de. «Conversaciones con Shakespeare y Marlowe, la huella permanente del Nuevo Historicismo». Estudios Ingleses de la Universidad Complutense, 14 (2006): 167-87.

Marlowe, Christopher. La masacre de París. Ed. y trad. Antonio Ballesteros González. Madrid: Publicaciones de la Asociación de Directores de Escena de España, 2007.

MONTERREY, Tomás. «Thomas Lodge's Rosalynde and the Canary Islands». SEDERI, 17 (2007): $131-40$.

MOYA, Ana y LÓPEZ, Gemma. Literatura medieval inglesa. Madrid: Síntesis, 2006.

NAYLOR, Gloria. "“Mama Day" desplaza a "Próspero" y asume el mando: deconstrucción y subversión del texto shakespeariano». Babel A.F.I.A.L.: Aspectos de filología inglesa y alemana, 16 (2007): 33-49.

Olivares Merino, Eugenio. «Mary Roper Clarke Bassett and Meredith Hanmer's Honorable Ladie of the Lande». SEDERI, 17 (2007): 75-91.

Pando Mena, Paula de. «The Image of Anne Boleyn as a Propagandistic Construction in Shakespeare's Henry VIII, John Banks's Virtue Betray'd and Calderón's La Cisma de Inglaterra». Proceedings of the 30th International Aedean Conference. Ed. María Losada Friend, Pilar Ron Vaz, Sonia Hernández Santano, Jorge Casanova. Huelva: Editorial Universidad de Huelva, 2007. CD-ROM. 
-, «John Bancroft's Henry II and the Humanization of English Tragedy». Proceedings of the 30th International Aedean Conference. Ed. María Losada Friend, Pilar Ron Vaz, Sonia Hernández Santano, Jorge Casanova. Huelva: Editorial Universidad de Huelva, 2007. CD-ROM.

Portillo García, Rafael. «Adaptaciones, componendas y traiciones: Cuatro nuevos montajes de Shakespeare». Proceedings of the 30th International Aedean Conference. Ed. María Losada Friend, Pilar Ron Vaz, Sonia Hernández Santano, Jorge Casanova. Huelva: Editorial Universidad de Huelva, 2007. CD-ROM.

PujANTE, A. Luis y CAMPILlo, Laura, eds. Shakespeare en España. Textos 1764-1916. Introducción y notas de Ángel-Luís Pujante. Granada y Murcia: Universidad de Granada y Universidad de Murcia, 2007.

ShaKeSPEARE, William. Ricardo III. Trad. y ed. Ángel-Luís Pujante. Madrid: Espasa-Calpe, 2007. SAlvador Bello, Mercedes. «The Coronation and The Death of Edgar in the Anglo-Saxon Chronicle : An Illustration of Late Tenth-Century Panegyric Tradition?». Proceedings of the 30th International Aedean Conference. Ed. María Losada Friend, Pilar Ron Vaz, Sonia Hernández Santano, Jorge Casanova. Huelva: Editorial Universidad de Huelva, 2007. CD-ROM.

SÁNCHEZ SALOR, Eustaquio. «Nebrija reformed in English: Johannes Hawkins (1631)». Anuario de estudios filológicos, 30 (2007): 353-71.

SMale, Mervyn. «La mujer en Shakespeare: algunas consideraciones». De habitaciones propias y otros espacios conquistados. Estudios sobre mujeres y literatura en lengua inglesa en homenaje a Blanca López Román. Margarita Carretero González, M. ${ }^{a}$ Elena Rodríguez Martín y Gerardo Rodríguez Salas. Granada: Servicio de Publicaciones de la Universidad de Granada, 2006. 238-50.

Torre Moreno, M. ${ }^{a}$ José de la. «El valor político de la función de la reina Wealhtheow como "peace-weaver": poder ritual, logocentrismo y diplomacia». De habitaciones propias y otros espacios conquistados. Estudios sobre mujeres y literatura en lengua inglesa en homenaje a Blanca López Román. Margarita Carretero González, M. ${ }^{a}$ Elena Rodríguez Martín y Gerardo Rodríguez Salas. Granada: Servicio de Publicaciones de la Universidad de Granada, 2006. 15969.

—, «La invisibilidad del cuerpo femenino en Beowulf: transferencias metonímicas y simbólicas del poder femenino orientadadas a su ocultación y demonización». Cuerpos de mujeres: miradas, representaciones e identidades. Coord. Ana María Muñoz Muñoz, Carmen Gregorio Gil y Adelina Sánchez Espinosa. Granada: Universidad de Granada, 2007. 73-90.

ZUNINO GARRIDO, M. ${ }^{a}$ de la Cinta. «"We shalbe fitte for greater matters": Rhetorical Connections between the Boys of St. Paul's and John Lyly's Drama». Proceedings of the 30th International Aedean Conference. Ed. María Losada Friend, Pilar Ron Vaz, Sonia Hernández Santano, Jorge Casanova. Huelva: Editorial Universidad de Huelva, 2007. CD-ROM.

\section{RESTAURACIÓN Y SIGLO XVIII}

Alvarez Faedo, María José. «Lord Carteret y Cervantes: análisis del contexto socio-histórico que propició la primera iniciativa inglesa de editar el Quijote en español y ofrecer una biografía de su autor». Cervantes y el Quijote: Actas del coloquio internacional, Oviedo 27-30 de octubre de 2004 organizado por la Cátedra Emilio Alarcos. Coord. Emilio Martínez Mata. Oviedo: 2007. 227-238.

Couce Rivas, Margarita. «El mundo colonial en Aphra Behn y Sor Juana Inés de la Cruz». Proceedings of the 30th International Aedean Conference. Ed. María Losada Friend, Pilar Ron Vaz, Sonia Hernández Santano, Jorge Casanova. Huelva: Editorial Universidad de Huelva, 2007. CD-ROM. 
Fernández RodrígueZ, Carmen. «Feeding Fancies with the Pen: The Female Artist in Fanny Burney's The Wanderer (1814)». Approaching Cultures through English. Ed. Elizabeth Woodward Smith. A Coruña: Universidade da Coruña, Servicio de Publicaciones, 2007. 139-47.

FilgueIRA FigueIRA, Marina. «El carácter aristocrático del teatro de la Restauración inglesa. Desmitificación y popularización de un género». Garoza: Revista de la Sociedad Española de Estudios Literarios de Cultura Popular, 6 (2006).

García García, Luciano. «A Caroline View of Spaniards and Portuguese on the Stage: The Dramatic Representation of Iberia in James Shirley (1596-1666)». Revista canaria de estudios ingleses, 54 (2007): 37-54.

Johnson, Samuel. La historia de Rasselas, príncipe de Abisinia. Ed., trad. e introd. M. ${ }^{a}$ Luisa Pascual Garrido. Córdoba: Berenice, 2007.

LaSA ÁlvareZ, Begoña. «Literary Patrons and Women Writers at the End of the Eighteenth and Beginning of the Nineteenth Century: A Demanding Relationship». Approaching Cultures through English. Ed. Elizabeth Woodward Smith. A Coruña: Universidade da Coruña, Servicio de Publicaciones, 2007. 197-205.

Lorenzo Modia, María Jesús. «Ventriloquizing Female Authorship: The Case of EighteenthCentury Women's Magazines and Periodicals». Proceedings of the 30th International Aedean Conference. Ed. María Losada Friend, Pilar Ron Vaz, Sonia Hernández Santano, Jorge Casanova. Huelva: Editorial Universidad de Huelva, 2007. CD-ROM.

LosAdA FRIEND, María. «Reescribir a Chatterton: la pervivencia y transformación del suicidio romántico inglés». Estudios sobre literatura y suicidio. Coord. Pablo Luis Zambrano Carballo, 2006. 77-122.

—, «Otras lecturas románticas sobre Chatterton». Cuadernos de Ilustración y Romanticismo: Revista del Grupo de Estudios del siglo XVIII, 14 (2006): 43-64.

MARTínEZ DueÑAS, José Luis. «El género epistolar y el discurso narrativo en Tristram Shandy y en Humpry Clinker». Alicante: Biblioteca Virtual Miguel de Cervantes, 2006. 276-83.

NúÑEZ PuENTE, Carolina. «Orientalism in the English Eighteenth Century: The "Other Woman" of Women Writers' Texts». Approaching Cultures through English. Ed. Elizabeth Woodward Smith. A Coruña: Universidade da Coruña, Servicio de Publicaciones, 2007. 279-87.

PARDo GARcía, Pedro Javier. «El siglo de oro del Quijote en la literatura inglesa, 1740-1840». La huella de Cervantes y del Quijote en la cultura anglosajona. Ed. José Manuel Barrio Marco y María José Crespo Allué. Valladolid: Universidad de Valladolid, 2007. 133-58.

PEPYS, Samuel. Diario (1660-1669). Selección, traducción, introducción y notas Joaquín Martínez Lorente. Madrid: Espasa-Calpe, 2007.

Trofimova Violetta, AKalin Esin. «The Representation of the Other in Aphra Behn's Works». Revista canaria de estudios ingleses, 54 (2007): 25-36.

\section{SigLo XIX}

Altuna García de SalazAR, Asier. «Patriotismo y domesticidad: una cuestión de género en el romanticismo angloirlandés con referente español». Análisis de género en los estudios irlandeses. Ed. María Elena Jaime de Pablos. Almería: Servicio de Publicaciones de la Universidad de Almería, 2007. 49-62.

—, «Re-Writing Nineteenth-Century Translational Boundaries: James Clarence Mangan and Spain».Re-writing Boundaries. Ed. Asier Altuna y Cristina Andreu. Barcelona: Promocions i Publicacions Universitàries, 2007. 151-60.

Borham Puyal, Miriam. «The Reading of the Quixotic Self in Eaton Stannard Barrett's The Heroine». Proceedings of the 30th International Aedean Conference. Ed. María Losada 
Friend, Pilar Ron Vaz, Sonia Hernández Santano, Jorge Casanova. Huelva: Editorial Universidad de Huelva, 2007. CD-ROM.

CANADY SALGADO, Jacobo. «Fancy a haiku? Brief outline for a comparative study between Japanese Haiku and English Romantic Poetry». Proceedings of the 30th International Aedean Conference. Ed. María Losada Friend, Pilar Ron Vaz, Sonia Hernández Santano, Jorge Casanova. Huelva: Editorial Universidad de Huelva, 2007. CD-ROM.

CARIDAD BARREIRO, M. ${ }^{a}$ Mercedes. «Superstición popular y tragedia en El brazo marchito». Garoza: Revista de la Sociedad Española de Estudios Literarios de Cultura Popular, 7 (2007).

CONSTÁN VALVERDE, Sergio. «La verdad de Las Máscaras: Oscar Wilde en la obra de Pérez de Ayala». Proceedings of the 30th International Aedean Conference. Ed. María Losada Friend, Pilar Ron Vaz, Sonia Hernández Santano, Jorge Casanova. Huelva: Editorial Universidad de Huelva, 2007. CD-ROM.

CORTÉs PÉREZ, Catuxa. «"Votaries of the Muse": Thomas Hardy's "An Imaginative Woman" as a Parody of the Romantic Stereotypes». The Short Story in English: Crossing Boundaries. Ed. Gema Soledad Castillo García, María Rosa Cabellos Castilla, Juan Antonio Sánchez Jiménez y Vincent Carlisle Espínola. Alcalá de Henares: Servicio de Publicaciones de la Universidad de Alcalá, 2006. 254-64.

DAÑOBEITIA FERNÁNDEZ, Maria Luisa. «El delantal de la señora Gargery: apunte breve en torno a Great Expectations». De habitaciones propias y otros espacios conquistados. Estudios sobre mujeres y literatura en lengua inglesa en homenaje a Blanca López Román. Margarita Carretero González, M. ${ }^{a}$ Elena Rodríguez Martín y Gerardo Rodríguez Salas. Granada: Servicio de Publicaciones de la Universidad de Granada, 2006. 47-60.

DíEz FABRE, Silvia. «La mujer-monstruo en la novela de Somerville and Ross The Real Charlotte». Análisis de género en los estudios irlandeses. Ed. María Elena Jaime de Pablos. Almería: Servicio de Publicaciones de la Universidad de Almería, 2007. 25-38.

FERNÁNDEZ MÉNDEZ, Cristina. «Gender Relations between Male Colonisers and Colonised Females in Stevenson's The Beach of Falesá: The Subversion of the Transcultural Romance Plot». Approaching Cultures through English. Ed. Elizabeth Woodward Smith. A Coruña: Universidade da Coruña, Servicio de Publicaciones, 2007. 131-38.

GonZÁLEZ Moreno, Beatriz. «Mapping Coleridge's Morphean Space». Proceedings of the 30th International Aedean Conference. Ed. María Losada Friend, Pilar Ron Vaz, Sonia Hernández Santano, Jorge Casanova. Huelva: Editorial Universidad de Huelva, 2007. CD-ROM.

—, Lo sublime, lo gótico y lo romántico. La experiencia estética en el Romanticismo inglés. Ciudad Real: Universidad de Castilla-La Mancha, 2007.

Martínez García, Montserrat. «Bridging Cultures and Languages: Towards the Creation of a Hybrid Identity in Walter Scott's Waverley». Proceedings of the 30th International Aedean Conference. Ed. María Losada Friend, Pilar Ron Vaz, Sonia Hernández Santano, Jorge Casanova. Huelva: Editorial Universidad de Huelva, 2007. CD-ROM

MEZquita FernándeZ, María Antonia. «Poetas y visiones: William Blake y Claudio Rodríguez». Proceedings of the 30th International Aedean Conference. Ed. María Losada Friend, Pilar Ron Vaz, Sonia Hernández Santano, Jorge Casanova. Huelva: Editorial Universidad de Huelva, 2007. CD-ROM.

Miquel Baldellou, Marta. "Victorian Angels of the House vs. Fallen Angels, the American New Woman vs. the Decadent: Young Females Coming of Age through Transatlantic SelfDevelopment in Margaret Mitchell's Gone with the Wind and W. M. Thackeray's Vanity Fair». Proceedings of the 30th International Aedean Conference. Ed. María Losada Friend, Pilar Ron Vaz, Sonia Hernández Santano, Jorge Casanova. Huelva: Editorial Universidad de Huelva, 2007. CD-ROM. 
MonTERRey, Tomás. «De la mímesis al símbolo: "Ozymandias" como un poema de transición». Proceedings of the 30th International Aedean Conference. Ed. María Losada Friend, Pilar Ron Vaz, Sonia Hernández Santano, Jorge Casanova. Huelva: Editorial Universidad de Huelva, 2007. CD-ROM.

Ramos GaY, Ignacio. Oscar Wilde y el teatro de boulevard francés. Valencia: Universidad de Valencia, 2007.

—, «Dandismo y Gastronomía en Oscar Wilde y Alfred de Musset». Proceedings of the 30th International Aedean Conference. Ed. María Losada Friend, Pilar Ron Vaz, Sonia Hernández Santano, Jorge Casanova. Huelva: Editorial Universidad de Huelva, 2007. CD-ROM.

SÁNCHEZ EsPINOSA, Adelina. «Diosas a la carta para artistas decadentes: una lectura feminista de The Well-Beloved». De habitaciones propias y otros espacios conquistados. Estudios sobre mujeres y literatura en lengua inglesa en homenaje a Blanca López Román. Margarita Carretero González, M. ${ }^{a}$ Elena Rodríguez Martín y Gerardo Rodríguez Salas. Granada: Servicio de Publicaciones de la Universidad de Granada, 2006. 61-73.

—, «Cuerpos asediados, cuerpos camuflados: Thomas Hardy y la crisis del género de la narrativa finisecular victoriana». Cuerpos de mujeres: miradas, representaciones e identidades. Coord. Ana María Muñoz Muñoz, Carmen Gregorio Gil y Adelina Sánchez Espinosa. Granada: Universidad de Granada, 2007. 265-86.

VÁzquez De Prada Merino, María Teresa. «El Quijote en The Old Curiosity Shop». ES: Revista de filología inglesa, 28 (2007-2008): 225-39.

\section{Siglo XX y CONTEMPORÁNEA}

Aguilera Linde, Mauricio D. «Ulises en la (pos)modernidad». Estudios en Honor de Rafael Fente Gómez. Ed. Miguel Ángel Martínez-Cabeza Lombardo, Neil McClaren y Luis Quereda Rodríguez-Navarro. Granada: Editorial Universidad de Granada, 2007. 485-98.

AleXe, María y ARdelean Carmen. «The Self and the Magic Power Within: The Influence of D.H. Lawrence's Short Stories on Romanian Post-modernism». The Short Story in English: Crossing Boundaries. Ed. Gema Soledad Castillo García, María Rosa Cabellos Castilla, Juan Antonio Sánchez Jiménez y Vincent Carlisle Espínola. Alcalá de Henares: Servicio de Publicaciones de la Universidad de Alcalá, 2006. 10-19.

Aliaga Rodrigo, Esther «Robert McLiam Wilson's Ripley Bogle: The Burden of Geography». Rewriting Boundaries. Ed. Asier Altuna y Cristina Andreu. Barcelona: Promocions i Publicacions Universitàries, 2007. 39-40.

—, «Glenn Patterson and Robert McLiam Wilson: Two Contemporary Northern Irish Writers and the Question of National Identity». Postcolonial and Gender Perspectives in Irish Studies. Ed. Marisol Morales Ladrón. A Coruña: Netbiblo, 2007. 85-101.

Alonso Giráldez, José Miguel. «El lenguaje de la frustración y el deseo en Ulysses de James Joyce». Estudios Joyceanos en Gran Canaria: Joyce «In His Palms». Coord. Santiago Henríquez Jiménez y Carmen Martín Santana, Madrid: Huerga y Fierro Editores, 2007. 13-27.

ANDRÉs CUEVAS, Isabel M. ${ }^{a}$ Virginia Woolf and Her World: Unmasking the Presence of Carnival in the Novels of Virginia Woolf. Granada: Editorial Universidad de Granada, 2006.

—, «Sobre ramas sagradas y reyes bufones: el destronamiento de la autoridad contemporánea en Mrs. Dalloway». De habitaciones propias y otros espacios conquistados. Estudios sobre mujeres y literatura en lengua inglesa en homenaje a Blanca López Román. Ed. Margarita Carretero González, M. ${ }^{a}$ Elena Rodríguez Martín y Gerardo Rodríguez Salas. Granada: Servicio de Publicaciones de la Universidad de Granada, 2006. 89-104. 
—, «The Lamb, the Puppet, and the Dying God: the Role of the Scapegoat in Virginia Woolf's Mrs. Dalloway». Proceedings of the 30th International Aedean Conference. Ed. María Losada Friend, Pilar Ron Vaz, Sonia Hernández Santano, Jorge Casanova. Huelva: Editorial Universidad de Huelva, 2007. CD-ROM.

-, «Eating Out Borders: The Role of Carnival and Cannibalization in Virginia Woolf's The Voyage Out». Estudios en honor de Rafael Fente Gómez. Ed. Miguel Ángel Martínez-Cabeza Lombardo, Neil McClaren, Luis Quereda Rodríguez-Navarro Granada: Servicio de Publicaciones de la Universidad de Granada, 2007. 419-30.

—, «"A Little Figure with a Golden Teapot on his Head": The Carnivalesque Significance of Percival in Virginia Woolf's The Waves». Entre la creación y el aula. Homenaje a Manuel Villar Raso. Ed. Pilar Villar Argáiz, Rosa Morillas Sánchez y Mauricio Aguilera Linde. Granada: Servicio de Publicaciones de la Universidad de Granada, 2007. 191-200.

-, «Orlando in Wonderland: The Carnivalesque Turn in Orlando's Androgyny». In-between: Essays \& Studies in Literary Criticism, 14.2 (2007): 213-223.

- «Monstruos, animales y otras féminas: la representación grotesca del cuerpo femenino en las novelas de Virginia Woolf». Cuerpos de mujeres: miradas, representaciones e identidades. Ed. Ana María Muñoz Muñoz, Carmen Gregorio Gil y Adelina Sánchez Espinosa. Granada: Universidad de Granada, 2007. 189-204.

Aragay, Mireia, Klein, Hildegard, Monforte, Enric y Zozaya, Pilar, eds. British Theatre of the 1990s: Interviews with Directors, Playwrights, Critics and Academics. Basingstoke: Palgrave Macmillan, 2007.

Arizti, Bárbara, Martínez-Falquina, Silvia, eds. e intro. On the Turn: The Ethics of Fiction in Contemporary Narrative in English. Newcastle: Cambridge Scholars Publishing, 2007.

Asensio ARóstegui, María del Mar. «Crossing Generic Boundaries in Jeannette Winterson's The Poetics of Sex». The Short Story in English: Crossing Boundaries. Ed. Gema Soledad Castillo García, María Rosa Cabellos Castilla, Juan Antonio Sánchez Jiménez y Vincent Carlisle Espínola. Alcalá de Henares: Servicio de Publicaciones de la Universidad de Alcalá, 2006. 52-64.

—, «Postmodernist (Dis)continuities: Jeannette Winterson's Silence on Wyndham Lewis». Wyndham Lewis the Radical. Essays on Literature and Modernity. Ed. Carmelo Cunchillos Jaime. Bern: Peter Lang, 2007. 243-74.

Bando Domínguez, Juan. «The Midnight Verdict: La reescritura de Seamus Heany de las fuentes medievales europeas». Re-writing Boundaries. Ed. Asier Altuna y Cristina Andreu. Barcelona: Promocions i Publicacions Universitàries, 2007.161-70.

BASTIDA RodRíguEZ, Patricia. «Experimenting with the Short Story: Formal Challenges and Generic Ambiguity in the Fiction of Michèle Roberts». The Short Story in English: Crossing Boundaries. Ed. Gema Soledad Castillo García, María Rosa Cabellos Castilla, Juan Antonio Sánchez Jiménez y Vincent Carlisle Espínola. Alcalá de Henares: Servicio de Publicaciones de la Universidad de Alcalá, 2006. 97-110.

CALDERÓN Quindós, M. Teresa. «My Boundary is Myself: A Cognitive Look into Seamus Heany's "From the Republic of Conscience"». Re-writing Boundaries. Ed. Asier Altuna y Cristina Andreu. Barcelona: Promocions i Publicacions Universitàries, 2007. 217-24.

Caneda Cabrera, M. Teresa. "'This Country and this Race Produced me': Identidad personal e histeria colectiva en A Portrait of the Artist As a Young Man». The Scallop of Saint James: An Old Pilgrim's Hoard. Reading Joyce from the Peripheries / Leyendo a Joyce desde las periferias. Ed. Susana Domínguez Pena, Margarita Estévez Saá y Anne MacCarthy. Weston, Florida: Netbiblo, 2006. 123-32.

—, «"The Sameness of Difference": Joyce's Kailedoscopic Odyssey(s) throughout Europe». James Joyce Quarterly, 44.1 (Fall 2006): 139-50. 
—, «The Reconfiguration of Joyce across Cultures: Two Different Portraits of A Portrait». Papers on Joyce 13 (2007): 83-98.

CARRERA DE LA RED, María José. «"Soul, mind and carcass": Autography in Samuel Beckett's Texts for Nothing (XI)». Re-writing Boundaries. Ed. Asier Altuna y Cristina Andreu. Barcelona: Promocions i Publicacions Universitàries, 2007.171-80.

CARretero GonZÁLEZ, Margarita. «Mujeres de sangre, mujeres de savia: aspectos sociales y biológicos de la construcción de los géneros en The Lord of the Rings». De habitaciones propias y otros espacios conquistados. Estudios sobre mujeres y literatura en lengua inglesa en homenaje a Blanca López Román. Ed. Margarita Carretero González, M. ${ }^{a}$ Elena Rodríguez Martín y Gerardo Rodríguez Salas. Granada: Servicio de Publicaciones de la Universidad de Granada, 2006. 105-16.

CAStillo, Francisco Javier. «Los espejos de la memoria: algunas notas sobre la obra de Patrick Leigh Fermor». NERTER, 10 (2006-2007): 12- 18.

Cerezo Moreno, Marta «Female Sacrifice and Gender Violence in A.S. Byatt's Babel Tower: An Ethical Perspective». The Ethical Component in Experimental British Fiction since the 1960's. Ed. Jean-Michel Ganteau and Susana Onega. Newcastle: Cambridge Scholars Publishing, 2007.

Cissell, Matthew M. «The Ludic Element in Joyce». The Scallop of Saint James: An Old Pilgrim's Hoard. Reading Joyce from the Peripheries / Leyendo a Joyce desde las periferias. Ed. Susana Domínguez Pena, Margarita Estévez Saá y Anne MacCarthy. Weston, Florida: Netbiblo, 2006. 103-12.

Clark, David y Vidal Rodríguez-Sabio, María. «Joyce como material didáctico: el ejemplo de 'Clay'». The Scallop of Saint James: An Old Pilgrim's Hoard. Reading Joyce from the Peripheries / Leyendo a Joyce desde las periferias. Ed. Susana Domínguez Pena, Margarita Estévez Saá y Anne MacCarthy. Weston, Florida: Netbiblo, 2006. 113-22.

ConchA, Ángeles de la. «Unravelling Conventions; or, the Ethics of Deconstruction in Ian McEwan's Atonement». The Ethical Component in Experimental British Fiction since the 1960's. Ed. Susana Onega and Jean-Michel Ganteau. Newcastle: Cambridge Scholars Publishing, 2007. 191-208.

Cunchillos JAIME, Carmelo. ed. Wyndham Lewis the Radical. Essays on Literature and Modernity. Bern: Peter Lang, 2007. 243-74.

DíAz-BILD, Aída. «At Swim, Two Boys: In Search of the Nation of Freedom». Estudios Irlandeses, 2 (2007): 14-31.

Domínguez García, Beatriz. «La novela de concienciación en la narrativa de Kate Atkinson». Proceedings of the 30th International Aedean Conference. Ed. María Losada Friend, Pilar Ron Vaz, Sonia Hernández Santano, Jorge Casanova. Huelva: Editorial Universidad de Huelva, 2007. CD-ROM.

Domínguez Pena, Mla. Susana. «Patrón de comportamiento de la figura del sacerdote en la narración breve de S. O'Faolain». Estudios Joyceanos en Gran Canaria: Joyce «In His Palms». Coord. Santiago Henríquez Jiménez y Carmen Martín Santana, Madrid: Huerga y Fierro Editores, 2007.

-, Estévez SaÁ, Margarita y Maccarthy, Anne, eds. The Scallop of Saint James, An Old Pilgrim's Hoard: Reading Joyce from the Peripheries / Leyendo a Joyce desde las Periferias. Weston, Florida: Netbiblo, 2006.

Elices Agudo, Juan Francisco. «Postcolonial Cartographies: The Reinterpretation of the Land in Brian Friel and Michael Ondaatje». Re-writing Boundaries. Ed. Asier Altuna y Cristina Andreu. Barcelona: Promocions i Publicacions Universitàries, 2007. 45-54.

Estévez SAÁ, José Manuel. «"Nubecillas” en la obra de James Joyce y Joseph O’Connor». The Scallop of Saint James: An Old Pilgrim's Hoard. Reading Joyce from the Peripheries / Leyen- 
do a Joyce desde las periferias. Ed. Susana Domínguez Pena, Margarita Estévez Saá y Anne MacCarthy. Weston, Florida: Netbiblo, 2006. 233-42.

—, «La lección de Dermot Bolger: Releer Ulises a los 90». Estudios Joyceanos en Gran Canaria: Joyce «In His Palms». Coord. Santiago Henríquez Jiménez y Carmen Martín Santana, Madrid: Huerga y Fierro Editores, 2007.

—, «El significado de la tierra en la literatura campesina en lengua inglesa: John Berger». Garoza, 7 (2007).

—, «From the Country to the City: The Peasant's Loss of Identity in John Berger's Trilogy». Proceedings of the 30th International Aedean Conference. Ed. María Losada Friend, Pilar Ron Vaz, Sonia Hernández Santano, Jorge Casanova. Huelva: Editorial Universidad de Huelva, 2007. CD-ROM.

Estévez SaÁ, Margarita. «"Real People with Hidden Symptoms": Portraits of the Artist as Women in Twentieth-Century Literature in English». Proceedings of the 30th International Aedean Conference. Ed. María Losada Friend, Pilar Ron Vaz, Sonia Hernández Santano, Jorge Casanova. Huelva: Editorial Universidad de Huelva, 2007. CD-ROM.

—, «El fantasma de Lucia en/y la obra de James Joyce». Estudios Joyceanos en Gran Canaria: Joyce «In His Palms». Coord. Santiago Henríquez Jiménez y Carmen Martín Santana, Madrid: Huerga y Fierro Editores, 2007. 77-90.

—, «Caracterización e identidad femenina en la obra de Muriel Spark». Garoza: Revista de la Sociedad Española de Estudios Literarios de Cultura Popular, 7 (2007).

—, "A Little Figure with a Golden Teapot on his Head": The Carnivalesque Significance of Percival in Virginia Woolf's The Waves». Entre la creación y el aula. Homenaje a Manuel Villar Raso. Ed. Pilar Villar Argáiz, Rosa Morillas Sánchez y Mauricio Aguilera Linde. Granada: Servicio de Publicaciones de la Universidad de Granada, 2007.

FALCES SIERRA, Marta. «Intertextual Relations between The Love Song of J. Alfred Prufrock and Pandemica y Celeste». Estudios en Honor de Rafael Fente Gómez. Ed. Miguel Ángel Martínez-Cabeza Lombardo, Neil McClaren y Luis Quereda Rodríguez-Navarro. Granada: Editorial Universidad de Granada, 2007. 475-84.

FERNÁNDEZ SÁNCHEZ, José Francisco «"For Truth is a Manly Thing": imágenes de masculinidad en las novelas de Bernard MacLaverty». Análisis de género en los estudios irlandeses. Ed. María Elena Jaime de Pablos. Almería: Servicio de Publicaciones de la Universidad de Almería, 2007. 39-48.

Filardo Llamas, Laura e Iglesias Botrán, Ana María. «Re-writing Boundaries: The Case of Brenda Murphy's Double Narrative Identity». Re-writing Boundaries. Ed. Asier Altuna y Cristina Andreu. Barcelona: Promocions i Publicacions Universitàries, 2007. 181-90.

FLoYD, Alan. «The Paradoxes and Estereotypes of The Third Man». Approaching Cultures through English. Ed. Elizabeth Woodward Smith. A Coruña: Universidade da Coruña, Servicio de $\mathrm{Pu}-$ blicaciones, 2007. 157-65.

GARCía LEÓn, Rafael. «La obra de James Joyce: "The Same thing Anew"». The Scallop of Saint James: An Old Pilgrim's Hoard. Reading Joyce from the Peripheries / Leyendo a Joyce desde las periferias. Ed. Susana Domínguez Pena, Margarita Estévez Saá y Anne MacCarthy. Weston, Florida: Netbiblo, 2006. 5-14.

—, «Richard Ford's Gatherings from Spain and Joyce: A Possible Source for Some Spanish Words in Ulysses». Papers on Joyce XII (2006): 85-92.

—, «Joyce y la alegoría del mundo como escenario». Estudios Joyceanos en Gran Canaria: Joyce «In His Palms». Coord. Santiago Henríquez Jiménez y Carmen Martín Santana, Madrid: Huerga y Fierro Editores, 2007. 91-100.

GARCíA TORTOSA, Francisco. «Ulises: novela de diversión y de estudio». Introducción a The Scallop of Saint James: An Old Pilgrim's Hoard. Reading Joyce from the Peripheries / Leyendo a 
Joyce desde las periferias. Ed. Susana Domínguez Pena, Margarita Estévez Saá y Anne MacCarthy. Weston, Florida: Netbiblo, 2006.

—, «La hija del judío y los judíos en Ulises». Estudios Joyceanos en Gran Canaria: Joyce «In His Palms». Coord. Santiago Henríquez Jiménez y Carmen Martín Santana. Madrid: Huerga y Fierro Editores, 2007. 101-18.

—, «El misterio del primer Ulysses catalán: la odisea de Joan Francesc Vidal Jové». Estudios Joyceanos en Gran Canaria: Joyce «In His Palms». Eds. Santiago Henríquez y Carmen Martín Santana. Madrid: Huerga y Fierro, 2007. 159-73.

GonZÁlez CHACón, María del Mar. «"Re-imagining ourselves from scratch”: Marina Carr's Unmapped Territories in Ariel». Re-writing Boundaries. Ed. Asier Altuna y Cristina Andreu. Barcelona: Promocions i Publicacions Universitàries, 2007. 191-98.

—, «La compañía Charabanc (Marie Jones), Anne Devlin y Christina Reid: estudio postcolonial del teatro norirlandés contemporáneo». Postcolonial and Gender Perspectives in Irish Studies. Ed. Marisol Morales Ladrón. A Coruña: Netbiblo, 2007. 157-78.

GonzÁlez RodríGuez, María Luz. «La textualización del cuerpo femenino en los relatos de Alice Munro». Revista de Filología de la Universidad de la Laguna, 25 (2007): 277-85.

GREGOR, Keith. «"Reescribiendo el guión": hacia una política del teatro contemporáneo norirlandés escrito por mujeres». Análisis de género en los estudios irlandeses. Ed. María Elena Jaime de Pablos. Almería: Servicio de Publicaciones de la Universidad de Almería, 2007. 63-78.

Henríquez Jiménez, Santiago J., Martín SAntana, Carmen, coord. Estudios Joyceanos en Gran Canaria: Joyce «In His Palms", Madrid: Huerga y Fierro Editores, 2007.

—, «Vitalidad de la literatura irlandesa posterior al cuadrinomio Oscar Wilde, William Butler Yeats, James Joyce y Samuel Beckett». Estudios Joyceanos en Gran Canaria: Joyce «In His Palms». Coord. Santiago Henríquez Jiménez y Carmen Martín Santana, Madrid: Huerga y Fierro Editores, 2007.

Hernáez Lerena, M. ${ }^{a}$ Jesús. «Are Lewis's Short Stories Pathological?». Wyndham Lewis the Radical. Essays on Literature and Modernity. Ed. Carmelo Cunchillos Jaime. Bern: Peter Lang, 2007. 71-91.

—, «The Unethical Storyteller. Wyndham Lewis and Humanity Unredeemed». Proceedings of the 30th International Aedean Conference. Ed. María Losada Friend, Pilar Ron Vaz, Sonia Hernández Santano, Jorge Casanova. Huelva: Editorial Universidad de Huelva, 2007. CDROM.

Herrero Martín, Rosana. «Infantilising Staging of Postcolonial Adulthood: A Study of Tom Murphy's A Crucial Week in the Life of a Grocer's Assistant and Sebastian Barry's Boss Grady's Boys». Postcolonial and Gender Perspectives in Irish Studies. Ed. Marisol Morales Ladrón. A Coruña: Netbiblo, 2007. 179- 99.

HIDALGO, Pilar. «The Elegiac Moment in English Literature; from Julian Barnes's England, England to Martin Amis's Experience». Estudios en Honor de Rafael Fente Gómez. Ed. Miguel Ángel Martínez-Cabeza Lombardo, Neil McClaren y Luis Quereda Rodríguez-Navarro. Granada: Editorial Universidad de Granada, 2007. 405-18.

Hierro Gutiérrez, María. «La maternidad en soledad: Blessings de Shenesha Jackson». Proceedings of the 30th International Aedean Conference. Ed. María Losada Friend, Pilar Ron Vaz, Sonia Hernández Santano, Jorge Casanova. Huelva: Editorial Universidad de Huelva, 2007. CD-ROM.

JaIME DE PABlos, María Elena «Mujer y naturaleza en The Lake de George Moore». Análisis de género en los estudios irlandeses. Ed. María Elena Jaime de Pablos. Almería: Servicio de Publicaciones de la Universidad de Almería, 2007. 79-94.

JARAZO ÁlVAREZ, Rubén. «James Joyce en la prensa gallega: un artículo de Álvaro de Cunqueiro». The Scallop of Saint James: An Old Pilgrim's Hoard. Reading Joyce from the Peripheries / 
Leyendo a Joyce desde las periferias. Ed. Susana Domínguez Pena, Margarita Estévez Saá y Anne MacCarthy. Weston, Florida: Netbiblo, 2006. 215-22.

—, «Un viaje a Irlanda en la literatura gallega: Lord Dunsany y Álvaro Cunqueiro». Estudios Joyceanos en Gran Canaria: Joyce «In His Palms». Coord. Santiago Henríquez Jiménez y Carmen Martín Santana, Madrid: Huerga y Fierro Editores, 2007.

KLEIN, Hildegard. «La nueva estética en la escena londinense al final del milenio: un teatro experimental y provocador». De habitaciones propias y otros espacios conquistados. Estudios sobre mujeres y literatura en lengua inglesa en homenaje a Blanca López Román. Ed. Margarita Carretero González, M. ${ }^{a}$ Elena Rodríguez Martín y Gerardo Rodríguez Salas. Granada: Servicio de Publicaciones de la Universidad de Granada, 2006. 219-33.

LARA RALLO, Carmen «A. S. Byatt y la intertextualidad pictórica: la presencia de Rembrandt y Vermeer en la tetralogía». Proceedings of the 30th International Aedean Conference. Ed. María Losada Friend, Pilar Ron Vaz, Sonia Hernández Santano, Jorge Casanova. Huelva: Editorial Universidad de Huelva, 2007. CD-ROM.

LÁZARO, Luis Alberto. «El misterio del primer Ulisses catalán: la odisea de Joan Francesc Vidal Jové». Estudios Joyceanos en Gran Canaria: Joyce «In His Palms». Coord. Santiago Henríquez Jiménez y Carmen Martín Santana, Madrid: Huerga y Fierro Editores, 2007. 159-73.

Ledo FernándeZ, Mónica. «The Parish in Patrick Kavanagh: Towards a New Mythology». Approaching Cultures through English. Ed. Elizabeth Woodward Smith. A Coruña: Universidade da Coruña, Servicio de Publicaciones, 2007. 207-16.

Llantada Díaz, María Francisca. Form and Meaning in Dorothy M. Richardson's Pilgrimage. Heidelberg: Universitätsverlag Winter, 2007.

LLORENS CubEDo, Dídac. «T. S. Eliot and Salvador Espriu: timeless literature». Proceedings of the 30th International Aedean Conference. Ed. María Losada Friend, Pilar Ron Vaz, Sonia Hernández Santano, Jorge Casanova. Huelva: Editorial Universidad de Huelva, 2007. CDROM.

Lojo Rodríguez, Laura María. «Virginia Woolf's Short Fiction: Towards a Feminine Poetics». The Short Story in English: Crossing Boundaries. Ed. Gema Soledad Castillo García, María Rosa Cabellos Castilla, Juan Antonio Sánchez Jiménez y Vincent Carlisle Espínola. Alcalá de Henares: Servicio de Publicaciones de la Universidad de Alcalá, 2006. 556-69.

—, «The Politics of Gender: Eavan Boland's Construction of Subjectivity». Approaching Cultures through English. Ed. Elizabeth Woodward Smith. A Coruña: Universidade da Coruña, Servicio de Publicaciones, 2007. 217-25.

LóPEZ, Gemma, Seductions in Narrative: Subjectivity and Desire in the Works of Angela Carter and Jeanette Winterson. Youngstown, New York: Cambria Press, 2007.

LóPEZ FernándeZ, M. ${ }^{a}$ Deseada. «Walking with a Thesis: Detective Fiction as a Subtext in Iain Sinclair's White Chappel, Scarlet Tracings». Proceedings of the 30th International Aedean Conference. Ed. María Losada Friend, Pilar Ron Vaz, Sonia Hernández Santano, Jorge Casanova. Huelva: Editorial Universidad de Huelva, 2007. CD-ROM.

Losada Friend, María y Olivares Allepuz, Bendición. «Re-escribiendo fronteras a través del viaje interior: La configuración de la identidad irlandesa en The Gingerbread Woman de Jennifer Johnston». Re-writing Boundaries. Ed. Asier Altuna y Cristina Andreu. Barcelona: Promocions i Publicacions Universitàries, 2007. 55- 66.

LOSADA PÉREZ, Ana María. "Excavating the Self”: Irish Landscape and Subjectivity in Seamus Haney's Early Poetry». Approaching Cultures through English. Ed. Elizabeth Woodward Smith. A Coruña: Universidade da Coruña, Servicio de Publicaciones, 2007. 235-42.

MacCANDless, Ian y MARTíneZ ToRres, Francisco. «La melodía infinita y "Stream of Consciousness": Posibles influencias de Richard Wagner en James Joyce». The Scallop of Saint James: An Old Pilgrim's Hoard. Reading Joyce from the Peripheries / Leyendo a Joyce desde las pe- 
riferias. Ed. Susana Domínguez Pena, Margarita Estévez Saá y Anne MacCarthy. Weston, Florida: Netbiblo, 2006. 183-92.

MaldonAdo Acevedo, Ana. «Time Passes, Yes, and We Grow Old: Old Age in Virginia Woolf's The Waves». Proceedings of the 30th International Aedean Conference. Ed. María Losada Friend, Pilar Ron Vaz, Sonia Hernández Santano, Jorge Casanova. Huelva: Editorial Universidad de Huelva, 2007. CD-ROM.

MCLAREN, Neil. «Comments on the Place of Education in D. H. Lawrence's Work». Estudios en Honor de Rafael Fente Gómez. Ed. Miguel Ángel Martínez-Cabeza Lombardo, Neil McClaren y Luis Quereda Rodríguez-Navarro. Granada: Editorial Universidad de Granada, 2007. 391404.

MartíneZ-DueÑas EsPejo, José Luis. «The Pillars of the Earth/Los pilares de la tierra: notas sobre textualidad histórica y ficción». Alicante: Biblioteca Virtual Miguel de Cervantes, 2007.

Martínez RodríGuez, Carmen M. " " "Like an Angry Stone Image”. Acción y parálisis femenina en Dubliners». The Scallop of Saint James: An Old Pilgrim's Hoard. Reading Joyce from the Peripheries / Leyendo a Joyce desde las periferias. Ed. Susana Domínguez Pena, Margarita Estévez Saá y Anne MacCarthy. Weston, Florida: Netbiblo, 2006. 91-102.

Medina CASADO, Carmelo. «Los demonios de la perversión, depravación y obscenidad. La censura legal a la obra de Joyce». The Scallop of Saint James: An Old Pilgrim's Hoard. Reading Joyce from the Peripheries / Leyendo a Joyce desde las periferias. Ed. Susana Domínguez Pena, Margarita Estévez Saá y Anne MacCarthy. Weston, Florida: Netbiblo, 2006. 29-47.

MiQuel Baldellou, Marta. «Feasting on Memory in Fasting Times: retrieving personal identity from collective remembrance and vice versa in Nuala O'Faolain's My Dream of You».Babel A.F.I.A.L: Aspectos de filología inglesa y alemana, 16 (2007): 85-106.

-, «Women in the Twilight and Identity in the Making: The Concept of Transition in Eavan Boland's Poetry». Estudios irlandeses, 2 (2007): 128-34.

Montero Ameneiro, Lidia María. «"A bird on its wings over water”: Two Days in Aragon de Molly Keane». Estudios Joyceanos en Gran Canaria: Joyce «In His Palms». Coord. Santiago Henríquez Jiménez y Carmen Martín Santana, Madrid: Huerga y Fierro Editores, 2007.

Montesdeoca Cubas, María del Pino. «Only connect: conexiones entre Howards End de E. M. Forster y On Beauty de Zadie Smith». Revista de Filología de la Universidad de la Laguna, 25 (2007): 435-41.

MORALES LADRÓN, Marisol. «De puertas adentro: narrativa interior y violencia doméstica en The Woman who Walked into Doors de Roddy Doyle». Análisis de género en los estudios irlandeses. Ed. María Elena Jaime de Pablos. Almería: Servicio de Publicaciones de la Universidad de Almería, 2007. 95-106.

Morato Agrafofo, Yolanda. «Cuando tu enemigo es 'el enemigo': desencuentros literarios entre James Joyce y Windham Lewis». The Scallop of Saint James: An Old Pilgrim's Hoard. Reading Joyce from the Peripheries / Leyendo a Joyce desde las periferias. Ed. Susana Domínguez Pena, Margarita Estévez Saá y Anne MacCarthy. Weston, Florida: Netbiblo, 2006. 193-202.

Mulligan, Maureen. «Irish Music and the Musical Background to Joyce». Estudios Joyceanos en Gran Canaria: Joyce «In His Palms». Coord. Santiago Henríquez y Carmen Martín Santana. Madrid: Huerga y Fierro, 2007. 185-94.

MuÑoz LunA, Rosa. «The Colour of Mental Illness in Sylvia Plath's The Bell Jar». Proceedings of the 30th International Aedean Conference. Ed. María Losada Friend, Pilar Ron Vaz, Sonia Hernández Santano, Jorge Casanova. Huelva: Editorial Universidad de Huelva, 2007. CD-ROM.

MuÑOZ VALdIVIESO, Sofía. «Re-Constructing Post-War Britain as a Hybrid National Narrative in Andrea Levy's Small Island». Proceedings of the 30th International Aedean Conference. Ed. María Losada Friend, Pilar Ron Vaz, Sonia Hernández Santano, Jorge Casanova. Huelva: Editorial Universidad de Huelva, 2007. CD-ROM. 
Nicolás Román, Susana. «Influencias brechtianas en el teatro de Edward Bond: un análisis comparativo de Human Cannon y The Mother». Anuario de estudios filológicos, 29 (2006): 237-45.

—, «Influencias en la obra teatral de Sarah Kane: la problemática de su clasificación». Proceedings of the 30th International Aedean Conference. Ed. María Losada Friend, Pilar Ron Vaz, Sonia Hernández Santano, Jorge Casanova. Huelva: Editorial Universidad de Huelva, 2007. CD-ROM.

OLIVA CRUZ, Juan Ignacio. «Intertextualidades y ecos joyceanos en la escritura confesional angloindia». Estudios Joyceanos en Gran Canaria: Joyce «In His Palms». Coord. Santiago Henríquez Jiménez y Carmen Martín Santana, Madrid: Huerga y Fierro Editores, 2007. 195-206.

Palacios Pablos, Andrés. "Borders", a Core Reference to the Irish Identity and its Creative Psyche: Brian Moore's Literary Imagination». Re-writing Boundaries. Ed. Asier Altuna y Cristina Andreu. Barcelona: Promocions i Publicacions Universitàries, 2007. 67-74.

Penna, Rosa Elena. «Las cuevas de Barabar/Marabar: realidad, ficción y simbolismos a través de $A$ Pasage to India». El viaje literario y... la cueva: imágenes de la memoria. Ed. Santiago Henríquez Jiménez. Las Palmas de Gran Canaria: Cabildo de Gran Canaria, 2007. 233-50.

PÉREZ SIMÓN, Andrés. «El monólogo de Molly Bloom: la transferencia semiótica desde la narrativa al teatro». The Scallop of Saint James: An Old Pilgrim's Hoard. Reading Joyce from the Peripheries / Leyendo a Joyce desde las periferias. Ed. Susana Domínguez Pena, Margarita Estévez Saá y Anne MacCarthy. Weston, Florida: Netbiblo, 2006. 133-40.

PÉREZ VIDES, Auxiliadora. «Beyond the Limits of Illegitimacy: Mary Leland's The Killeen». Rewriting Boundaries. Ed. Asier Altuna y Cristina Andreu. Barcelona: Promocions i Publicacions Universitàries, 2007.121-26.

Petisco, Sonia. «El monólogo de Molly Bloom: Disolución del alma». Estudios Joyceanos en Gran Canaria: Joyce «In His Palms». Coord. Santiago Henríquez Jiménez y Carmen Martín Santana. Madrid: Huerga y Fierro Editores, 2007. 207-14.

Porcel García, María Isabel. «Chez Joyce: su biblioteca en francés». The Scallop of Saint James: An Old Pilgrim's Hoard. Reading Joyce from the Peripheries / Leyendo a Joyce desde las periferias. Ed. Susana Domínguez Pena, Margarita Estévez Saá y Anne MacCarthy. Weston, Florida: Netbiblo, 2006. 15-28.

—, «La influencia de Valery Larbaud en James Joyce». Estudios Joyceanos en Gran Canaria: Joyce «In His Palms». Coord. Santiago Henríquez Jiménez y Carmen Martín Santana, Madrid: Huerga y Fierro Editores, 2007. 215-23.

Pozo Montaño, M. ángeles. «Edna O’Brien o el retrato periodístico de la artista escarlata». The Scallop of Saint James: An Old Pilgrim's Hoard. Reading Joyce from the Peripheries / Leyendo a Joyce desde las periferias. Ed. Susana Domínguez Pena, Margarita Estévez Saá y Anne MacCarthy. Weston, Florida: Netbiblo, 2006. 223-32.

—, «The Short Stories of James Joyce and Edna O'Brien: Echoes of Dubliners in Lantern Slides». The Short Story in English: Crossing Boundaries. Ed. Gema Soledad Castillo García, María Rosa Cabellos Castilla, Juan Antonio Sánchez Jiménez y Vincent Carlisle Espínola. Alcalá de Henares: Servicio de Publicaciones de la Universidad de Alcalá, 2006. 736-46.

Praga Terente, Inés. "“Those Five Brave Glenties Women": ecos lorquianos en Dancing at Lughnasa». Análisis de género en los estudios irlandeses. Ed. María Elena Jaime de Pablos. Almería: Servicio de Publicaciones de la Universidad de Almería, 2007. 107-20.

RÁEz-PAdilla, Juan. 'And Somewhere the Dove Rose': Seamus Heaney y su Fase Aérea en la crítica literaria». Estudios irlandeses, 2 (2007): 162-72.

Redondo Olmedilla, José Carlos. «Creative Writing and Inspiration Mapping: Martin Amis and Kazuo Ishiguro Compared». Proceedings of the 30th International Aedean Conference. Ed. María Losada Friend, Pilar Ron Vaz, Sonia Hernández Santano, Jorge Casanova. Huelva: Editorial Universidad de Huelva, 2007. CD-ROM. 
Río Álvaro, Constanza del. «William Trevor's Felicia's Journey: Inherited Dissent or Fresh Departure from Tradition?». Estudios irlandeses, 2 (2007): 1-13.

- , «Negotiating Boundaries: The Ethics of Reconciliation in Kate O'Riordan's The Boy in the Moon (1997)». Re-writing Boundaries. Ed. Asier Altuna y Cristina Andreu. Barcelona: Promocions i Publicacions Universitàries, 2007. 97-104.

Río Molina, Benigno del. «From Iconophagy to Anthropophagy: Cannibalising Images in Ulysses». Papers on Joyce XII (2006): 25-44.

—, «Mr. Deasy y el Caballero del Verde Gabán: Un estudio comparativo entre Ulises y Don Quijote». Proceedings of the 30th International Aedean Conference. Ed. María Losada Friend, Pilar Ron Vaz, Sonia Hernández Santano, Jorge Casanova. Huelva: Editorial Universidad de Huelva, 2007. CD-ROM.

—, «Moneda y palabra: De Ezra Pound al "Nestor" de Joyce». Estudios Joyceanos en Gran Canaria: Joyce «In His Palms». Coord. Santiago Henríquez Jiménez y Carmen Martín Santana, Madrid: Huerga y Fierro Editores, 2007. 43-56.

Román, Susana N. «Phaedra's Love de Sarah Kane: Sex, Love, and Religion». Proceedings of the 30th International Aedean Conference. Ed. María Losada Friend, Pilar Ron Vaz, Sonia Hernández Santano, Jorge Casanova. Huelva: Editorial Universidad de Huelva, 2007. CDROM.

Romero GonZÁLEZ, Tanya. «La intertextualidad en Atonement de Ian McEwan». Proceedings of the 30th International Aedean Conference. Ed. María Losada Friend, Pilar Ron Vaz, Sonia Hernández Santano, Jorge Casanova. Huelva: Editorial Universidad de Huelva, 2007. CD-ROM.

Romero JóDAR, Andrés. «A Stranger in a Strange Land: An Existentialist Reading of Fredrick Clegg in The Collector by John Fowles». Atlantis: Revista de la Asociación Española de Estudios Anglo-Norteamericanos, 28.1 (2006): 45-55.

SACIDO Romero, Jorge. "II Am not a Sausage Machine': Conrad's Anxiety and Resistance in 'The Partner'». The Short Story in English: Crossing Boundaries. Ed. Gema Soledad Castillo García, María Rosa Cabellos Castilla, Juan Antonio Sánchez Jiménez y Vincent Carlisle Espínola. Alcalá de Henares: Servicio de Publicaciones de la Universidad de Alcalá, 2006. 799-814.

—, y Lojo RodríGuEZ, Laura M.a «¿Qué teme Virginia Woolf? La figura del judío en dos relatos de la autora». Proceedings of the 30th International Aedean Conference. Ed. María Losada Friend, Pilar Ron Vaz, Sonia Hernández Santano, Jorge Casanova. Huelva: Editorial Universidad de Huelva, 2007. CD-ROM.

SALIS, Loredana. «Post-modern Perspectives: Discourses of Insularity and the Philoctetes Myth in Sherca by Sydney Bernard Smith». Re-writing Boundaries. Ed. Asier Altuna y Cristina Andreu. Barcelona: Promocions i Publicacions Universitàries, 2007. 199-208.

SÁnChez CAlle, Pilar. «Portrait of a Lady: "Parturition" by Mina Loy». Proceedings of the 30th International Aedean Conference. Ed. María Losada Friend, Pilar Ron Vaz, Sonia Hernández Santano, Jorge Casanova. Huelva: Editorial Universidad de Huelva, 2007. CD-ROM.

SÁnChez-Palencia CARAzo, Carolina. "The way you wear your hat': Performativity and selfinvention in Jackie Kay's Trumpet and Duncan Tucker's Transamerica. Proceedings of the 30th International Aedean Conference. Ed. María Losada Friend, Pilar Ron Vaz, Sonia Hernández Santano, Jorge Casanova. Huelva: Editorial Universidad de Huelva, 2007. CD-ROM.

—, «4.48 Psychosis: Sarah Kane's "bewildered fragments”». Proceedings of the 30th International Aedean Conference. Ed. María Losada Friend, Pilar Ron Vaz, Sonia Hernández Santano, Jorge Casanova. Huelva: Editorial Universidad de Huelva, 2007. CD-ROM.

SimONS, Jefferey. «Orality, Literacy, Joyce». The Scallop of Saint James: An Old Pilgrim's Hoard. Reading Joyce from the Peripheries / Leyendo a Joyce desde las periferias. Ed. Susana Domínguez Pena, Margarita Estévez Saá y Anne MacCarthy. Weston, Florida: Netbiblo, 2006. 65-78. 
—, «The Literate Gusts of "Aeolus"». Estudios Joyceanos en Gran Canaria: Joyce «In His Palms». Coord. Santiago Henríquez Jiménez y Carmen Martín Santana, Madrid: Huerga y Fierro Editores, 2007. 225-38.

SiXto Rey, Susana. «Parálisis gótica en Dubliners de James Joyce. Análisis de tres relatos». The Scallop of Saint James: An Old Pilgrim's Hoard. Reading Joyce from the Peripheries / Leyendo a Joyce desde las periferias. Ed. Susana Domínguez Pena, Margarita Estévez Saá y Anne MacCarthy. Weston, Florida: Netbiblo, 2006. 79-90.

TABARÉs PÉREZ, Patricia. «Scottish Perceptions of Ireland in Carol Ann Duffy's Lyric Poetry». Rewriting Boundaries. Ed. Asier Altuna y Cristina Andreu. Barcelona: Promocions i Publicacions Universitàries, 2007. 237-46.

TEJedor CABrera, José María. «Algunas ventanas en Joyce». The Scallop of Saint James: An Old Pilgrim's Hoard. Reading Joyce from the Peripheries / Leyendo a Joyce desde las periferias. Ed. Susana Domínguez Pena, Margarita Estévez Saá y Anne MacCarthy. Weston, Florida: Netbiblo, 2006. 48-64.

—, «Variations on the Quincunx in "Grace"». Papers on Joyce 13 (2007): 61-82.

TERRAZAS, Melania. «Intricate Models of Conflict in Wyndham Lewis's Fiction». Wyndham Lewis the Radical. Essays on Literature and Modernity. Ed. Carmelo Cunchillos Jaime. Bern: Peter Lang, 2007. 109-36.

Toro SANTOS, Antonio Raúl de. «La literatura irlandesa en España». Estudios Joyceanos en Gran Canaria: Joyce «In His Palms». Coord. Santiago Henríquez Jiménez y Carmen Martín Santana, Madrid: Huerga y Fierro Editores, 2007.

Vericat PÉREZ-MíngueZ, Fabio. «Medical Lyricism as Cultural Distance: T.S. Eliot and the (Feminine) Body». Proceedings of the 30th International Aedean Conference. Ed. María Losada Friend, Pilar Ron Vaz, Sonia Hernández Santano, Jorge Casanova. Huelva: Editorial Universidad de Huelva, 2007. CD-ROM.

VILlaR ARGÁIz, Pilar. «La experiencia femenina de Eavan Boland como un "amorous exchange" entre supuestos binarios». De habitaciones propias y otros espacios conquistados. Estudios sobre mujeres y literatura en lengua inglesa en homenaje a Blanca López Román. Ed. Margarita Carretero González, M. ${ }^{a}$ Elena Rodríguez Martín y Gerardo Rodríguez Salas. Granada: Servicio de Publicaciones de la Universidad de Granada, 2006. 171-87.

-, Eavan Boland's Evolution as an Irish Woman Poet: An Outsider within an Outsider's Culture. Lewiston, Queenston, Lampeter: The Edwin Mellen Press, 2007.

-, The Poetry of Eavan Boland: A Postcolonial Reading. Bethesda, Dublin: Academica Press, 2007.

—, «Liminal Spaces in Eavan Boland's Diasporic Poems: "In-between” Irishness and Englishness». Re-writing Boundaries. Ed. Asier Altuna y Cristina Andreu. Barcelona: Promocions i Publicacions Universitàries, 2007. 83-96.

—, «Angela's Ashes: A Vision of Ireland that Sells in America». Entre la creación y el aula: Estudios en honor de Profesor Manuel Villar Raso. Ed. Pilar Villar Argáiz, Rosa Morillas Sánchez, Mauricio Aguilera Linde. Granada: Editorial Universidad de Granada, 2007. 129-144.

—, «Real, Imaginary and Silent Landscapes in Seamus Deane's Reading in the Dark: Deconstructing the Dream of an "Authentic" Ireland». Estudios en Honor de Rafael Fente Gómez. Ed. Miguel Ángel Martínez-Cabeza Lombardo, Neil McClaren y Luis Quereda RodríguezNavarro. Granada: Editorial Universidad de Granada, 2007. 311-24.

—, «Recording the "Unpoetic": Eavan Boland's Silences». Irish University Review: A Journal of Irish Studies, 37.2 (2007): 472-491.

—, «The Subaltern in Eavan Boland's Poetry». New Voices in Irish Criticism: The Theoretical Turn (Studies in Irish Literature). Ed. Cathy McGlynn and Paula Murph. Lewiston, Queenston, Lampeter: Edwin Mellen Press, 2007. 37-54- 
—, «Eavan Boland's Revisionary Stance on Nationalism: a "Post-nationalist" or a "Post-colonial" Writer?». Essays on Modern Irish Literature. Ed. John Strachan y Alison Younger. Sunderland: The University of Sunderland Press, 2007. 107-20.

—, «Sexualidad, creatividad artística e identidad femenina en la poesía de Eavan Boland». Cuerpos de mujeres: miradas, representaciones e identidades. Ed. Ana María Muñoz Muñoz, Carmen Gregorio Gil y Adelina Sánchez Espinosa. Granada: Universidad de Granada, 2007. 381-402.

Villar Flor, Carlos, Domínguez Carballo, Noelia. «Lewisian Footprints in Evelyn Waugh's Early Satires». Wyndham Lewis the Radical. Essays on Literature and Modernity. Ed. Carmelo Cunchillos Jaime. Bern: Peter Lang, 2007. 187-218.

Zunino Garrido, M. ${ }^{a}$ de la Cinta. "Biblical Echoes in Chamber Music». Estudios Joyceanos en Gran Canaria: Joyce «In His Palms». Coord. Santiago Henríquez Jiménez y Carmen Martín Santana, Madrid: Huerga y Fierro Editores, 2007. 239-52.

WALlHEAD SALWAY, Celia M. «Lo "sutilmente gótico" y la mujer madura como víctima en A.S. Byatt: "Baglady" (Elementals) y "Raw Material" (Little Black Book of Stories)». De habitaciones propias y otros espacios conquistados. Estudios sobre mujeres y literatura en lengua inglesa en homenaje a Blanca López Román. Ed. Margarita Carretero González, M. ${ }^{a}$ Elena Rodríguez Martín y Gerardo Rodríguez Salas. Granada: Servicio de Publicaciones de la Universidad de Granada, 2006. 145-56.

\section{MiscelÁNEA}

Alonso GiRÁLDEZ, José Miguel. «Cervantes, Borges y Joyce. Tres en compañía». The Scallop of Saint James: An Old Pilgrim's Hoard. Reading Joyce from the Peripheries / Leyendo a Joyce desde las periferias. Ed. Susana Domínguez Pena, Margarita Estévez Saá y Anne MacCarthy. Weston, Florida: Netbiblo, 2006. 169-82.

Altuna, Asier y Andreu, Cristina, eds. Re-writing Boundaries. Barcelona, 2007.

Amador Moreno, Carolina P. «The Crossing of Boundaries in Donegal Writing». Re-writing Boundaries. Ed. Asier Altuna y Cristina Andreu. Barcelona: Promocions i Publicacions Universitàries, 2007. 209-16.

Antón PACHeCO, Ana. «Adapting old cuentos que todos conocen: Don Juan Tenorio in the borderland». Estudios ingleses de la Universidad Complutense, 15 (2007): 105-17.

Barbeito, J. Manuel, FeiJóo, Jaime, FigueroA, Antón and SACido, Jorge, eds. National Identities and European Literatures. Bern: Peter Lang, 2008.

Barrio Marco, José Manuel, Crespo AlluÉ, María José, eds. La huella de Cervantes y del Quijote en la cultura anglosajona. Valladolid: Universidad de Valladolid, 2007.

Barros del Río, M. ${ }^{a}$ Amor. «Nuevas tendencias en el "bildungsroman" femenino irlandés». Análisis de género en los estudios irlandeses. Ed. María Elena Jaime de Pablos. Almería: Servicio de Publicaciones de la Universidad de Almería, 2007. 13-24.

—, «Espacios femeninos en la novela de la República escrita por mujeres». Postcolonial and Gender Perspectives in Irish Studies. Ed. Marisol Morales Ladrón. A Coruña: Netbiblo, 2007. 103-23.

Benito de LA Iglesia, Tamara. «The Anti/Post-colonial Trace in Some Stories of the Northern Irish Troubles». Postcolonial and Gender Perspectives in Irish Studies. Ed. Marisol Morales Ladrón. A Coruña: Netbiblo, 2007. 125-38.

BRITO, Manuel. «Historia y logos en la memoria de los hombres: Gloucester y las Islas Canarias». El viaje literario y... la cueva: imágenes de la memoria. Ed. Santiago J. Henríquez Jiménez. Las Palmas de Gran Canaria: Cabildo de Gran Canaria, 2007. 35-51. 
CARRERA, Isabel. «La teorización postcolonial de Irlanda». Postcolonial and Gender Perspectives in Irish Studies. Ed. Marisol Morales Ladrón. A Coruña: Netbiblo, 2007. 3-19.

Carretero González, Margarita, RodríGuez Martín, M. ${ }^{a}$ Elena y RodríGuez Salas, Gerardo, eds. De habitaciones propias y otros espacios conquistados. Estudios sobre mujeres y literatura en lengua inglesa en homenaje a Blanca López Román. Granada: Servicio de Publicaciones de la Universidad de Granada, 2006.

Castillo García, Gema Soledad, Cabellos Castilla, María Rosa, Sánchez Jiménez, Juan Antonio, CArlisle Espínola, Vincent, eds. The Short Story in English: Crossing Boundaries. Alcalá de Henares: Servicio de Publicaciones de la Universidad de Alcalá, 2006.

ConchA, Ángeles de la. «Cultura y violencia de género. Literatura y mito en la génesis de un conflicto secular». Circunstancia: Revista de ciencias sociales del Instituto Universitario de Investigación Ortega y Gasset, 12 (2007). Número monográfico «La lucha por erradicar la violencia de género». Ed. Mercedes Bengoechea. Revista electrónica.

COUSILLAS RoDRíGUEZ, Manuel. «Interacción de la literatura popular irlandesa y gallega». Garoza: Revista de la Sociedad Española de Estudios Literarios de Cultura Popular, 7 (2007).

Domínguez Pena, Susana, Estévez SAÁ, Margarita, y MacCARThy, Anne, eds. The Scallop of Saint James: An Old Pilgrim's Hoard. Weston, FL.: Netbiblo, 2006.

—, Ireland in the Coming Time. New Insights on Irish Literature. Weston, FL.: Netbiblo. 2006.

EstéveZ SAÁ, Margarita. «"The Seanchai”: Short Fiction by Irish Women Writers from the Republic». Postcolonial and Gender Perspectives in Irish Studies. Ed. Marisol Morales Ladrón. A Coruña: Netbiblo, 2007. 139-54.

FERnÁndez LóPeZ, Dolores, Domínguez Pérez, Mónica y RodríGueZ-Gallego, Fernando, coord. Campus stellae: haciendo camino en la investigación literaria. 2 vols. Santiago de Compostela: Universidade de Santiago de Compostela, 2006. 69-79.

GonZÁLEZ ARIAS, Luz Mar. «Acts of Union: El discurso del amor en el texto poético de autoras irlandesas (1980-2005)». Postcolonial and Gender Perspectives in Irish Studies. Ed. Marisol Morales Ladrón. A Coruña: Netbiblo, 2007. 65-82.

GoNZÁLEZ MuÑoz, Fernando. «Aspectos de la proyección de la mitología antigua en la literatura inglesa posterior al Renacimiento». Cuadernos de literatura griega y latina. 6 (2007):14963.

González Rodríguez, María Luz, LóPez-Peláez Casellas, Jesús, LóPez-Peláez Casellas, Milagros, Oliva CRUZ, Juan Ignacio. «Identity Revisited». Revista canaria de estudios ingleses, 54 (2007): 13-24.

HenRíquez JimÉnEZ, Santiago J., ed. El viaje literario y... la cueva: imágenes de la memoria. Las Palmas de Gran Canaria: Cabildo de Gran Canaria, 2007.

—, «El viaje literario y... la cueva: actualidad de los textos y de la crítica inglesa de viajes más recientes sobre el patrimonio español y Canarias». El viaje literario y... la cueva: imágenes de la memoria. Ed. Santiago Henríquez Jiménez. Las Palmas de Gran Canaria: Cabildo de Gran Canaria, 2007. 173-92.

JAIME DE PABLos, María Elena, ed. Análisis de género en los estudios irlandeses. Almería: Servicio de Publicaciones de la Universidad de Almería, 2007.

JARAZo Álvarez, Rubén «Introduction to Paleography: Applying the Study of Ancient Texts to Welsh Literature». Approaching Cultures through English. Ed. Elizabeth Woodward Smith. A Coruña: Universidade da Coruña, Servicio de Publicaciones, 2007. 181-96.

LaRA Rallo, Carmen. Las voces y los ecos. Perspectivas sobre la intertextualidad. Málaga: Anejos de Analecta Malacitana, 63 (2007).

LÓPEZ-BURGOS, María Antonia. «Ventas, posadas y fondas en los relatos de viajeras inglesas de otros tiempo». De habitaciones propias y otros espacios conquistados. Estudios sobre mujeres y literatura en lengua inglesa en homenaje a Blanca López Román. Margarita Carretero Gon- 
zález, M. ${ }^{a}$ Elena Rodríguez Martín y Gerardo Rodríguez Salas. Granada: Servicio de Publicaciones de la Universidad de Granada, 2006. 23-33.

—, «Las cuevas de Granada en la literatura de viajeros británicos e irlandeses de otros tiempos». El viaje literario y... la cueva: imágenes de la memoria. Ed. Santiago Henríquez Jiménez. Las Palmas de Gran Canaria: Cabildo de Gran Canaria, 2007. 193- 210.

Martínez-Cabeza Lombardo, Miguel Ángel, McLaren, Neil, Quereda RodrígueZ-Navarro, Luis eds. Estudios en Honor de Rafael Fente Gómez. Granada: Editorial Universidad de Granada, 2007.

McLAREN, Neil. «Comments on the Place of Education in D.H.Lawrence's Work». Estudios en Honor de Rafael Fente Gómez. Ed. Miguel Ángel Martínez-Cabeza Lombardo, Neil McLaren y Luis Quereda Rodríguez-Navarro. Granada: Editorial Universidad de Granada, 2007. 391- 404.

MonTERREY, Tomás. «Writers at the Gallery: Painting and Postmodernist English Short-Story Telling». The Short Story in English: Crossing Boundaries. Ed. Gema Soledad Castillo García, María Rosa Cabellos Castilla, Juan Antonio Sánchez Jiménez y Vincent Carlisle Espínola. Alcalá de Henares: Servicio de Publicaciones de la Universidad de Alcalá, 2006. 625-35.

Morales LADrón, Marisol, ed. Postcolonial and Gender Perspectives in Irish Studies. A Coruña: Netbiblo, 2007.

—, «Prólogo: Postcolonialismo y género en los estudios irlandeses». Postcolonial and Gender Perspectives in Irish Studies. Ed. Marisol Morales Ladrón. A Coruña: Netbiblo, 2007. xvii-xxx.

Muldigan, Maureen. «Troglodytes in Myth and Literature: The Image of the Cave». El viaje literario y... la cueva: imágenes de la memoria. Ed. Santiago Henríquez Jiménez. Las Palmas de Gran Canaria: Cabildo de Gran Canaria, 2007. 211-32.

Oliva Cruz, Juan Ignacio, González Rodríguez, María Luz y LóPez-Peláez Casellas, Jesús. «Identity and Literature». Revista canaria de estudios ingleses, 54 (2007): 9-12.

Palacios GonzÁlez, Manuela. «Northern Ireland: The Poetry In Between». Postcolonial and Gender Perspectives in Irish Studies. Ed. Marisol Morales Ladrón. A Coruña: Netbiblo, 2007. 45-64.

Pascual, Nieves, Alonso-Gallo, Laura y Collado-RodríGuez, Francisco, eds. Masculinities, Femininities and the Power of the Hybrid in U.S. Narratives: Essays on Gender Borders. Heidelberg: Universitätsverlag, 2007.

Proust-García, Karine. «George Sand and Lord Byron in the classroom: teaching the culture of romantic love through letter writing». Approaching Cultures through English. Ed. Elizabeth Woodward Smith. A Coruña: Universidade da Coruña, Servicio de Publicaciones, 2007. 307-16.

RAMÓN TORRIJOS, María del Mar. «Dentro y fuera de la norma: representación textual de la mujer detective en la literatura anglo-norteamericana». Garoza: Revista de la Sociedad Española de Estudios Literarios de Cultura Popular, 7 (2007): 17.

Río Molina, Benigno del. «"Hades" como danza de la muerte». The Scallop of Saint James: An Old Pilgrim's Hoard. Reading Joyce from the Peripheries / Leyendo a Joyce desde las periferias. Ed. Susana Domínguez Pena, Margarita Estévez Saá y Anne MacCarthy. Weston, Florida: Netbiblo, 2006. 155-68.

Rodríguez Guerrero-Strachan, Santiago. «Melancholy and the Fantastic Short Story». The Short Story in English: Crossing Boundaries. Ed. Gema Soledad Castillo García, María Rosa Cabellos Castilla, Juan Antonio Sánchez Jiménez y Vincent Carlisle Espínola. Alcalá de Henares: Servicio de Publicaciones de la Universidad de Alcalá, 2006. 756-64.

RodRíGuEZ GoNZÁLEZ, Carla. «La negación de la diferencia étnica en la literatura escocesa contemporánea». ES: Revista de filología inglesa, 28 (2007-2008): 171-87.

Toro SANTOS, Antonio Raúl de. La literatura irlandesa en España. A Coruña: Netbiblo, 2007.

—, British and Irish Writers in the Spanish Periodical Press. A Coruña: Netbiblo. 2007. 
__, y Alonso GiRÁLDEZ, José Miguel. «New Representations of Irishness in Contemporary Irish Poetry: George Watson and Seamus Heaney's Concept of "Sense of Place" in Northern Ireland». Approaching Cultures through English. Ed. Elizabeth Woodward Smith. A Coruña: Universidade da Coruña, Servicio de Publicaciones, 2007. 103-10.

SÁnchez EsPinosa, Adelina, Rodríguez Salas, Gerardo, VIllar Argáiz, Pilar, Andrés Cuevas, Isabel María. «La evolución del discurso feminista sobre la maternidad en tres momentos de la literatura en lengua inglesa». Los feminismos como herramientas de cambio social. Coord. Esperanza Bosch Fiol, Victoria Aurora Ferrer Pérez, Capilla Navarro Guzmán, vol. 2, (De la violencia contra las mujeres a la construcción del pensamiento feminista). Palma de Mallorca: Universitat de les Illes Balears, 2007. 235-50.

VÁzquez Marruecos, José Luis y VÁzquez y del Árbol, Esther. Poesía escocesa. Antología bilingüe. Granada: Servicio de Publicaciones de la Universidad de Granada, 2007.

VILLACAÑAS, Beatriz. Literatura irlandesa. Madrid: Síntesis, 2007.

VILlar Argáiz, Pilar. «The Exiled Irish Writer: An Orientalist?». Proceedings of the 30th International Aedean Conference. Ed. María Losada Friend, Pilar Ron Vaz, Sonia Hernández Santano, Jorge Casanova. Huelva: Editorial Universidad de Huelva, 2007. CD-ROM.

-, Morillas SÁnchez, Rosa y Aguilera Linde, Mauricio, eds. Entre la creación y el aula. Homenaje a Manuel Villar Raso. Granada: Servicio de Publicaciones de la Universidad de Granada, 2007.

WallHEAD, Celia. "Vladimir Nabokov and Auto(biography): The Meaning of "Real" in The Real Life of Sebastian Knight». Estudios en Honor de Rafael Fente Gómez. Ed. Miguel Ángel Martínez-Cabeza Lombardo, Neil McClaren y Luis Quereda Rodríguez-Navarro. Granada: Editorial Universidad de Granada, 2007. 453-62. 


\section{B. LITERATURA NORTEAMERICANA}

NiEVES DE Mingo IZQuiERDo

UNED. Madrid

ndemingo@bec.uned.es

Acosta Bustamante, Leonor. «The postmodern encounter with the exotic in Rikki Ducornet's short stories». Proceedings of the 30th International Aedean Conference. Ed. María Losada Friend, Pilar Ron Vaz, Sonia Hernández Santano, Jorge Casanova. Huelva: Editorial Universidad de Huelva, 2007. CD-ROM.

Aguilera Linde, Mauricio. «Ulises en la (post)modernidad anglonorteamircana». Estudios en Honor de Rafael Fente Gómez. Ed. Miguel Ángel Martínez Cabeza, Neil Mc Laren y Luis Quereda. Granada: Editorial Universidad de Granada, 2007. 485-98.

—, y ToRres ZúNIIGA, Laura. «"The first thing I see. Desire is". Tennessee Williams y sus personajes femeninos». De habitaciones propias y otros espacios conquistados. Estudios sobre mujeres y literatura en lengua inglesa en homenaje a Blanca López Román. Ed. Margarita Carretero González, M. ${ }^{a}$ Elena Rodríguez Martín y Gerardo Rodríguez Salas. Granada: Publicaciones Universidad de Granada, 2006. 191-206.

AlAmEdA HERnÁndEZ, Ángela. «Colony vs. Metropolis: Opposing Discursive Representations of a Colony's National Identity in the Printed Press». Odisea: Revista de estudios ingleses, 8 (2007): 19-33.

AlmeIDA, Diana. «Intertextuality and Female Identity in Eudora Welty's The Golden Apples». The Short Story in English: Crossing Boundaries. Ed. Gema Soledad Castillo García, María Rosa Cabellos Castilla, Juan Antonio Sánchez Jiménez y Vincent Carlisle Espínola. Alcalá de Henares: Servicio de Publicaciones de la Universidad de Alcalá, 2006. 20-31.

Altuna, Asier y Andreu, Cristina, eds. Re-writing Boundaries. Barcelona: Promocions i Publicacions Universitàries, 2007.

Alvarez Amorós, José Antonio. «Reaching Out for Fictional Reality: Para-Derridean Forms of Différance in Henry James's The Coxon Fund». Contemporary Debates on the Short Story. Ed. José R. Ibáñez, José Francisco Fernández y Carmen M. Bretones. Brussels: P.I.E. Peter Lang, 2007. 49-88.

Álvarez CALleja, Maria Antonia. «Conexiones literarias interculturales: tratamiento cómico de la violencia en Beryl Bainbridge y John Hawkes». ES: Revista de filología inglesa, 27 (20062007): 7-22.

ÁlvAREZ LóPEZ, Ester. «Culinary Metaphors and Chicano Culture in Elaine Romero's The Fat-Free Chicana and The Snow Cap Queen». Critical Essays on Chicano Studies. Ed. Ramón Espejo, Juan Ignacio Guijarro, Jesús Lerate de Castro, Pilar Marín y María Ángeles Toda Iglesia. Brussels: P.I.E. Peter Lang, 2007. 37-50.

ANDRÉs, Rodrigo. Herman Melville: poder y amor entre hombres. Valencia. Biblioteca Javier Coy d'Estudis Nord-Americans: Publicacions de la Universitat de València, 2007.

Andrés Cuevas, Isabel María. «The Duplicity of the City in O. Henry: The Defeat of the City and Squaring the Circle». The Short Story in English: Crossing Boundaries. Ed. Gema Soledad Castillo García, María Rosa Cabellos Castilla, Juan Antonio Sánchez Jiménez y Vincent Carlisle Espínola. Alcalá de Henares: Servicio de Publicaciones de la Universidad de Alcalá, 2006. 32-42.

ARMENGOL, Josep M. ${ }^{\mathrm{a}}$ «Gendering men: Re-visions of Violence as a Test of Manhood in American Literature». Atlantis, 29.2 (2007): 75-92. 
ARzúa Azurmendi, Carmen. «All Serious Daring Starts from Within: Crossing Inner and Regional Boundaries in Eudora Welty's The Optimist's Daughter». The Short Story in English: Crossing Boundaries. Ed. Gema Soledad Castillo García, María Rosa Cabellos Castilla, Juan Antonio Sánchez Jiménez y Vincent Carlisle Espínola. Alcalá de Henares: Servicio de Publicaciones de la Universidad de Alcalá, 2006. 43-51.

Bados Cidia, Concepción. «Chicano/Chicana Theater: Representing and Performing Women in Mexican-American Families». Family Reflections. The Contemporary American Family in the Arts. Ed. Carmen Flys Junquera y Maurice A. Lee. Alcalá de Henares: Servicio de Publicaciones Universidad de Alcalá, 2007. 305-20.

BAelo Allué, Sonia. «Youth culture in Bret Easton Ellis's Less Than Zero: moral decadence in the world of conspicuous consumerism». Proceedings of the 30th International Aedean Conference. Ed. María Losada Friend, Pilar Ron Vaz, Sonia Hernández Santano, Jorge Casanova. Huelva: Editorial Universidad de Huelva, 2007. CD-ROM.

Barrio Marco, Jose Manuel y Crespo Allué, Maria José, coords. La huella de Cervantes y del Quijote en la cultura anglosajona. Valladolid: Universidad de Valladolid, 2007.

—, «El Quijote y la prosa en Norteamérica, su influencia en Washington Irving: The Sketch Book». La huella de Cervantes y del Quijote en la cultura anglosajona. Coord. José Manuel Barrio Marco y María José Crespo Allué. Valladolid: Universidad de Valladolid, 2007. 321-34.

-, «Kevin Brockmeier's The Ceiling: The Real and Claustrophobic Fantasy of a Broken Couple». The Short Story in English: Crossing Boundaries. Ed. Gema Soledad Castillo García, María Rosa Cabellos Castilla, Juan Antonio Sánchez Jiménez y Vincent Carlisle Espínola. Alcalá de Henares: Servicio de Publicaciones de la Universidad de Alcalá, 2006. 86-96.

BARros Grela, Eduardo. «La "literatura de latinos" en Estados Unidos: ¿un discurso falsificado?». Garoza: Revista de la Sociedad Española de Estudios Literarios de Cultura Popular, 7 (2007): 1.

BEIRANTE, Rute. «Media-mediated Family in Bobbie Ann Mason's Shiloh and Other Stories». Family Reflections. The Contemporary American Family in the Arts. Ed. Carmen Flys Junquera y Maurice A. Lee. Alcalá de Henares: Servicio de Publicaciones Universidad de Alcalá, 2007. 293-304.

—, «Dialogues across the Atlantic Ocean: Melville's Short Fiction and Portuguese Literature or the Silence of the Scriveners». The Short Story in English: Crossing Boundaries. Ed. Gema Soledad Castillo García, María Rosa Cabellos Castilla, Juan Antonio Sánchez Jiménez y Vincent Carlisle Espínola. Alcalá de Henares: Servicio de Publicaciones de la Universidad de Alcalá, 2006. 111-22.

Blanco Outon, Cristina (póstumo). «A Wife's Story and A Pair of Tickets: Family Diaspora in Bharati Mukherjee and Amy Tan». Family Reflections. The Contemporary American Family in the Arts. Ed. Carmen Flys Junquera y Maurice A. Lee. Alcalá de Henares: Servicio de Publicaciones Universidad de Alcalá, 2007. 187-200.

BLAVE-Gómez, Raquel. «The Language of Contempt: Asphalt Anti-heroes in Lara Stapleton's "Motherlove"». The Short Story in English: Crossing Boundaries. Ed. Gema Soledad Castillo García, María Rosa Cabellos Castilla, Juan Antonio Sánchez Jiménez y Vincent Carlisle Espínola. Alcalá de Henares: Servicio de Publicaciones de la Universidad de Alcalá, 2006. $133-41$.

Benito, Jesús y Manzanas, Ana M. ${ }^{\mathrm{a}}$ «Introductory esssay». Border Transits. Literature and Culture across the Line. Ed. Ana M. ${ }^{a}$ Manzanas. Amsterdam/New York: Rodopi, 2007. 1-21.

BRITO, Manuel .«Instances of the Journey Motif through Language and Selfhood in some Modernist American Poets». Modernism Revisited: Transgressing Boundaries and Strategies of Renewal in American Poetry. Ed. Viorica Patea y Paul Scott Derrick. Amsterdam \& New York: Rodopi, 2007. 175-88. 
-, «Language Working to Uncover the Social and the Cultural: The Example of Rodrigo Toscano». Critical Essays on Chicano Studies. Ed. Ramón Espejo, Juan Ignacio Guijarro, Jesús Lerate de Castro, Pilar Marín y María Ángeles Toda Iglesia. Brussels: P.I.E. Peter Lang, 2007. 51-64.

—, «New Considerations Propounded in Little Magazines of American Innovative Poetry». Revista canaria de estudios ingleses, 55 (2007): 141-52.

Brufau Alvira, Nuria. «Chicanas, Identities and Translators». The Short Story in English: Crossing Boundaries. Ed. Gema Soledad Castillo García, María Rosa Cabellos Castilla, Juan Antonio Sánchez Jiménez y Vincent Carlisle Espínola. Alcalá de Henares: Servicio de Publicaciones de la Universidad de Alcalá, 2006.142-60.

Burillo Gadea, María Rosa. «The West as a Main Subject in Contemporary American ShortStory Writing». The Short Story in English: Crossing Boundaries. Ed. Gema Soledad Castillo García, María Rosa Cabellos Castilla, Juan Antonio Sánchez Jiménez y Vincent Carlisle Espínola. Alcalá de Henares: Servicio de Publicaciones de la Universidad de Alcalá, 2006.161-72.

CAÑAdAS RodríGUEZ, Emilio. «Community and Morals in Tim Gautreaux's Welding with Children». The Short Story in English: Crossing Boundaries. Ed. Gema Soledad Castillo García, María Rosa Cabellos Castilla, Juan Antonio Sánchez Jiménez y Vincent Carlisle Espínola. Alcalá de Henares: Servicio de Publicaciones de la Universidad de Alcalá, 2006. 173-182.

—, «Echoes, Postmodernism and Plagiarism in Kathy Acker's Don Quixote». La huella de Cervantes y del Quijote en la cultura anglosajona. Coord. José Manuel Barrio Marco y María José Crespo Allué. Valladolid: Universidad de Valladolid, 2007. 467-78.

CARR, Peter. «Re-borderisation in the South-Western Novels of Ana Castillo and Cormac McCarthy». Revista de estudios norteamericanos, 12 (2007).

Castillo García, Gema Soledad, Cabellos Castilla, María Rosa, Sánchez JimÉnez, Juan Antonio y Carlisle Espínola, Vincent eds. The Short Story in English: Crossing Boundaries. Alcalá de Henares: Servicio de Publicaciones de la Universidad de Alcalá, 2006.

—, «Writing and Translating the Puerto Rican Short Story: Rosario Ferré». The Short Story in English: Crossing Boundaries. Ed. Gema Soledad Castillo García, María Rosa Cabellos Castilla, Juan Antonio Sánchez Jiménez y Vincent Carlisle Espínola. Alcalá de Henares: Servicio de Publicaciones de la Universidad de Alcalá, 2006. 198-214.

Castro Dopacio, Maria Jesus. «The Feminization of Domestic Architecture in Pat Mora's House of Houses». Critical Essays on Chicano Studies. Ed. Ramón Espejo, Juan Ignacio Guijarro, Jesús Lerate de Castro, Pilar Marín y María Ángeles Toda Iglesia. Brussels: P.I.E. Peter Lang, 2007. 65-76.

Ceballos Muñoz, Alfonso. «Gay Men Only, Please!: The "performance" of Gay Identity in Terrence McNally's Love! Valour! Compassion!». Revista de estudios norteamericanos, 12 (2007).

CID, Teresa. «The Dead Body of a Little Girl Is Not a Painting: Reading Katherine Vaz after 9/11». The Short Story in English: Crossing Boundaries. Ed. Gema Soledad Castillo García, María Rosa Cabellos Castilla, Juan Antonio Sánchez Jiménez y Vincent Carlisle Espínola. Alcalá de Henares: Servicio de Publicaciones de la Universidad de Alcalá, 2006. 215-29.

Collado-RodríGuez, Francisco. «From Theory to Practice: Blank Fiction, Ethics, and Hybridism in Palahniuk's Stranger than Fiction and Invisible Monsters». Masculinities, Femininities and the Power of the Hybrid in U.S. Narratives: Essays on Gender Borders. Ed. Nieves Pascual, Laura Alonso-Gallo y Francisco Collado-Rodríguez. Heidelberg: Universitätsverlag, 2007.

-, «Temporal Rearrangement and the Sense of Meaning in Mason's Zigzagging Down a Wild Trail». The Short Story in English: Crossing Boundaries. Ed. Gema Soledad Castillo García, María Rosa Cabellos Castilla, Juan Antonio Sánchez Jiménez y Vincent Carlisle Espínola. Alcalá de Henares: Servicio de Publicaciones de la Universidad de Alcalá, 2006. 242-53. 
-, Alonso-Gallo, Laura y Pascual, Nieves. «Fighting Limits: Masculinities, Femininities and the Hybrid at the turn of the Millennium». Masculinities, Femininities and the Power of the Hybrid in U.S. Narratives: Essays on Gender Borders. Ed. Nieves Pascual, Laura Alonso-Gallo y Francisco Collado-Rodríguez. Heidelberg: Universitätsverlag, 2007.

COTA-TORRES, Édgar. «Dispelling the Border Myth: Zonkey Writers and the Black Legend». Border Transits. Literature and Culture across the Line. Ed. Ana M. ${ }^{a}$ Manzanas. Amsterdam/New York: Rodopi, 2007. 53-62.

Cotto Benítez, Ruth Amarilis. La influencia del Spanglish en la literatura norteamericana. Madrid: Sanz y Torres, 2007.

Darias Beautell, Eva y Hernáez Lerena, M. ${ }^{a}$ Jesús, eds. Canon Disorders: Gendered Perspectives on Literature and Film in Canada and the United States. Logroño: Universidad de la Rioja/Universidad de La Laguna, 2007.

Davis, Rocío G. Begin Here: Reading Asian North American Autobiographies of Childhood. Honolulu: University of Hawai Press, 2007.

—, «Daughters of the House: Paradigms of the Absent Mother in Patti Kim's A Cab Called Reliable and Lois-Ann Yamanaka's Blu's Hanging». Family Reflections. The Contemporary American Family in the Arts. Ed. Carmen Flys Junquera y Maurice A. Lee. Alcalá de Henares: Servicio de Publicaciones Universidad de Alcalá, 2007. 171-86.

-, Aurell, Jaume y Delgado, Ana Beatriz, eds. Ethnic Life Writing and Histories: Genres, Performance, and Culture. Hamburg: LIT Verlag, 2007.

Delgado, Berta. «Where Is the Battle? Class, Race and Identity in Daniel Cano's "Somewhere Outside Duc Pho"». The Short Story in English: Crossing Boundaries. Ed. Gema Soledad Castillo García, María Rosa Cabellos Castilla, Juan Antonio Sánchez Jiménez y Vincent Carlisle Espínola. Alcalá de Henares: Servicio de Publicaciones de la Universidad de Alcalá, 2006. 291-300.

DoвrotT, Gretchen. «Home Sweet Home: The Mother/Daughter Dyad in Flannery O'Connor's Short Fiction». The Short Story in English: Crossing Boundaries. Ed. Gema Soledad Castillo García, María Rosa Cabellos Castilla, Juan Antonio Sánchez Jiménez y Vincent Carlisle Espínola. Alcalá de Henares: Servicio de Publicaciones de la Universidad de Alcalá, 2006. 31224.

Domínguez MiguelA, Antonia. «Redefining the Father Figure in Contemporary Chicana Literature». Critical Essays on Chicano Studies. Ed. Ramón Espejo, Juan Ignacio Guijarro, Jesús Lerate de Castro, Pilar Marín y María Ángeles Toda Iglesia. Brussels: P.I.E. Peter Lang, 2007. 77-90.

—, «Barrio Dreams: re-appropriations of "Home" in Urban Puerto Rican Narratives». Proceedings of the 30th International Aedean Conference. Ed. María Losada Friend, Pilar Ron Vaz, Sonia Hernández Santano, Jorge Casanova. Huelva: Editorial Universidad de Huelva, 2007. CDROM.

DuRÁN, Isabel. «The Brown/Mestiza Metaphor, or the Impertinence against Borders». Border Transits. Literature and Culture across the Line. Ed. Ana M. ${ }^{a}$ Manzanas. Amsterdam/New York: Rodopi, 2007. 147-80.

DuRÁN, Javier. «Border Voices: Life Writings and Self-Representation of the U.S.-Mexico Frontera». Border Transits. Literature and Culture across the Line. Ed. Ana M. ${ }^{a}$ Manzanas. Amsterdam/New York. Rodopi, 2007. 61-78.

EDMOND, Jacob. «Antologías. Traspasando fronteras: encuentros y colaboración entre las poéticas de vanguardia de Rusia y los Estados Unidos». Nerter, 10 (2006-2007): 34-40.

Espejo, Ramón, Guijarro, Juan-Ignacio, Lerate De CAStro, Jesús, Marín, Pilar, y Toda Iglesia, María Ángeles, eds. Critical Essays on Chicano Studies. Brussels: P.I.E. Peter Lang, 2007.

EsPínOLA, Lourdes. «Borges-Alice Walker: Where Roads Cross, Unite, and Fork». The Short Story in English: Crossing Boundaries. Ed. Gema Soledad Castillo García, María Rosa Ca- 
bellos Castilla, Juan Antonio Sánchez Jiménez y Vincent Carlisle Espínola. Alcalá de Henares: Servicio de Publicaciones de la Universidad de Alcalá, 2006. 336-44.

FeIJóo, Sara. «Little Red Riding Hood and the Chomskyan Wolf: a Debate on Poverty of the Stimulus Arguments». BELLS 16 (2007). Revista electrónica.

FERNÁNDEZ, Salvador C. «The Bandit and the Preacher: 19th-Century Protagonists in Southwest Literature». Critical Essays on Chicano Studies. Ed. Ramón Espejo, Juan Ignacio Guijarro, Jesús Lerate de Castro, Pilar Marín y María Ángeles Toda Iglesia. Brussels: P.I.E. Peter Lang, 2007. 103-12.

FERNÁNDEZ DEL AMO, M. ${ }^{a}$ Mercedes. Diversidad y género en la literatura afroamericana. Granada: C.S.V., 2007.

FERNANDEZ BAHILlO, Hector O. «Archer Milton Huntington y Cervantes: esbozos de un hispanista norteamericano». La huella de Cervantes y del Quijote en la cultura anglosajona. Coord. José Manuel Barrio Marco y María José Crespo Allué. Valladolid: Universidad de Valladolid, 2007. 353-66.

FERNÁNDEZ MORALES, Marta. «Foucauldian Biopower in Contemporary Anglo-American Theatre: Margaret Edson and Nell Dunn». BELLS: Barcelona English Language and Literature Studies, 15 (2006).

FERNÁNDEZ RodRÍGUEZ, Carolina. «Towards a Half-bred Poetics: the Role of Dramatic Irony in the Short Stories of the Chicano Borderlands». Odisea: revista de estudios ingleses, 8 (2007): 6979.

FERnANDEZ SuÁrez, José Ramón. «El Quijote y A Connecticut yankee de Mark Twain». La huella de Cervantes y del Quijote en la cultura anglosajona. Coord. José Manuel Barrio Marco y María José Crespo Allué. Valladolid: Universidad de Valladolid, 2007. 383-96.

FILARDo Llamas, Laura y GUTIERREZ RodríGUEZ, Marta. «Lectures on Lolita: la influencia cervantina en Vladimir Nabokov». La huella de Cervantes y del Quijote en la cultura anglosajona. Coord. José Manuel Barrio Marco y María José Crespo Allué. Valladolid: Universidad de Valladolid, 2007. 407-20.

Flys JunQueRA, Carmen. «The Detective has a Family?». Family Reflections. The Contemporary American Family in the Arts. Ed. Carmen Flys Junquera y Maurice A. Lee. Alcalá de Henares: Servicio de Publicaciones Universidad de Alcalá, 2007. 275-92.

—, «Fluid Boundaries in Judith Ortiz Cofer's Silent Dancing». Contemporary Debates on the Short Story. Ed. José R. Ibáñez, José Francisco Fernández, Carmen M. Bretones. Brussels: P.I.E. Peter Lang, 2007.155-84.

—, «Shifting Borders and Intersecting Territories: Rudolfo Anaya». Border Transits. Literature and Culture across the Line. Ed. Ana M. ${ }^{a}$ Manzanas. Amsterdam/New York. Rodopi: 2007. 95-113.

-, y LEE, Maurice A., eds. Family Reflections. The Contemporary American Family in the Arts. Alcalá de Henares: Servicio de Publicaciones Universidad de Alcalá, 2007.

FrA-LóPEZ, Patricia. «Fitzgerald's Professional Women: Jenny Prince in Jacob's Ladder and Helen Avery in Magnetism as Antecedents of Rosemary Hoyt in Tender is the Night». A Distant Drummer. Foreign Perspectives on F. Scott Fitzgerald. Ed. Jamal Assadi y William Freedman. Bern: Peter Lang, 2007.

Fraile Marcos, Ana M.a, ed. Richard Wright's Native Son. Amsterdam: Rodopi, 2007.

—, «Native Son Beyond the Page». Native Son Beyond the Page. Richard Wright's Native Son. Ed. Ana M. ${ }^{a}$ Faile Marcos. Amsterdam/New York: Rodopi: 2007.

—, «Native Son's "ideology of form": The (African) American Jeremiad and American Exceptionalism». Native Son Beyond the Page. Richard Wright's Native Son. Ed. Ana María Fraile Marcos. Amsterdam/New York: Rodopi, 2007. 119-42.

FRÍAS RUdOLFI, María. Ethics and Ethnicity in the Literature of the United States. Valencia: Universidad de Valencia, 2007. 
—, «"Life for me ain't been no crystal stair": Female-headed Households or Demythologizing the Pathology of African American Families». Family Reflections. The Contemporary American Family in the Arts. Ed. Carmen Flys Junquera y Maurice A. Lee. Alcalá de Henares: Servicio de Publicaciones Universidad de Alcalá, 2007. 231-54.

-, «Zora Neale Hurston's Sweat. From Oppressive Domesticity to Subversive Domestic Violence». The Short Story in English: Crossing Boundaries. Ed. Gema Soledad Castillo García, María Rosa Cabellos Castilla, Juan Antonio Sánchez Jiménez y Vincent Carlisle Espínola. Alcalá de Henares: Servicio de Publicaciones de la Universidad de Alcalá, 2006. 368-77.

García Lorenzo, María M. «Desde el asiento de la conductora: reconstrucción de espacios y vínculos femeninos en la narrativa norteamericana». Relatos de viajes, miradas de mujeres. Ed. Mar Gallego y Eloy Navarro. Sevilla: Alfar, 2007. 71-93.

GARRIGÓs GONZÁLEZ, Cristina. «Las mujeres quijotes y los efectos perniciosos de la lectura en The Female Quixote de Charlotte Lennox y Female Quixotism de Tabitta Tenney». La huella de Cervantes y del Quijote en la cultura anglosajona. Coord. José Manuel Barrio Marco y María José Crespo Allué. Valladolid: Universidad de Valladolid, 2007. 457-66.

—, «Neither Fish nor Bird, but Frid and Bish: Richard Power's The Time of Our Singing». Proceedings of the 30th International Aedean Conference. Ed. María Losada Friend, Pilar Ron Vaz, Sonia Hernández Santano, Jorge Casanova. Huelva: Editorial Universidad de Huelva, 2007. CD-ROM.

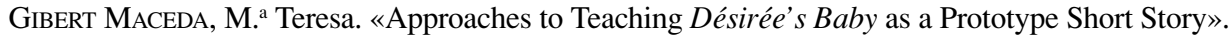
The Short Story in English: Crossing Boundaries. Ed. Gema Soledad Castillo García, María Rosa Cabellos Castilla, Juan Antonio Sánchez Jiménez y Vincent Carlisle Eespínola. Alcalá de Henares: Servicio de Publicaciones de la Universidad de Alcalá, 2006. 428-36.

GINÉS GIBERT, Montserrat. «Quijotescos empeños: Mark Twain y el sur». La huella de Cervantes y del Quijote en la cultura anglosajona. Coord. José Manuel Barrio Marco y María José Crespo Allué. Valladolid: Universidad de Valladolid, 2007. 375-82.

Goicoechea de Jorge, María y LóPEZ-VARela, Asunción. «Androids, Gynoids and Cyborgs: Applying Bem's Theory of Psychological Androgyny to CyberFeminist Reader-Response Criticism». Masculinities, Femininities and the Power of the Hybrid in U.S. Narratives: Essays on Gender Borders. Ed. Nieves Pascual, Laura Alonso-Gallo y Francisco Collado-Rodríguez. Heidelberg: Universitätsverlag, 2007.

GonZÁLEZ, Jesús A. «"Happy Accidents”. An Interview with Paul Auster». Revista de estudios norteamericanos, 12 (2007).

GonzÁlez CAlvo, Olga. "Caroline Kirkland’s Guide to West Living: A New Home - Who'll Follow? Or, Glimpses of Western Life». Proceedings of the 30th International Aedean Conference. Ed. María Losada Friend, Pilar Ron Vaz, Sonia Hernández Santano, Jorge Casanova. Huelva: Editorial Universidad de Huelva, 2007. CD-ROM.

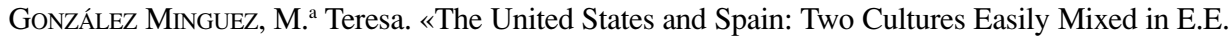
Cummings' Works». Proceedings of the 30th International Aedean Conference. Ed. María Losada Friend, Pilar Ron Vaz, Sonia Hernández Santano, Jorge Casanova. Huelva: Editorial Universidad de Huelva, 2007. CD-ROM.

GoNZÁLEZ RodRÍGUEZ, Luisa María. «La mise en abyme como imagen del agotamiento de las versiones de realidad en Menelaiad de John Barth». Proceedings of the 30th International Aedean Conference. Ed. María Losada Friend, Pilar Ron Vaz, Sonia Hernández Santano, Jorge Casanova. Huelva: Editorial Universidad de Huelva, 2007. CD-ROM.

Gutiérrez Arranz, José María. «Periplos bestiales: Escamandro, Pegaso, Enigma... Bestias en Faulkner y Norfolk». Odisea: revista de estudios ingleses, 8 (2007): 89-100.

HENRíQuez BETANCOR, María. «"Too bad mihijita was morena”: Anzaldúa’s Autobiographical Encounters with Her Mother». Canon Disorders: Gendered Perspectives on Literature and Film 
in Canada and the United States. Ed. Eva Darias Beautell y María Jesús Hernáez Lerena. Logroño: Universidad de La Rioja: Servicio de Publicaciones, 2007. 139-60.

HerRerA-SobeK, María. «The Dysfunctional Family in Lucha Corpi's Detective Novels». Family Reflections. The Contemporary American Family in the Arts. Ed. Carmen Flys Junquera y Maurice A. Lee. Alcalá de Henares: Servicio de Publicaciones Universidad de Alcalá, 2007. 321-34.

Hierro Gutiérrez, María. «La maternidad en soledad: Blessings de Shenesha Jackson». Proceedings of the 30th International Aedean Conference. Ed. María Losada Friend, Pilar Ron Vaz, Sonia Hernández Santano, Jorge Casanova. Huelva: Editorial Universidad de Huelva, 2007. CD-ROM.

IbÁÑEZ, José R., FernándeZ, José Francisco, Bretones, Carmen M., eds. Contemporary Debates on the Short Story. Brussels: Peter Lang, 2007.

IbARROLA-ARMENDARIZ, Aitor. «Families Broken and Rebuilt: A Native American Journey from the Real to the Fictional and Back». Family Reflections. The Contemporary American Family in the Arts. Ed.Carmen Flys Junquera y Maurice A. Lee. Alcalá de Henares: Servicio de Publicaciones Universidad de Alcalá, 2007. 211-30.

-, «Harriet Wilson's Our Nig. An Idiosyncratic Attempt to Locate the Color Line in term of Class, Gender and Geography». Border Transits. Literature and Culture across the Line. Ed. Ana M. ${ }^{a}$ Manzanas. Amsterdam/New York. Rodopi: 2007. 23-33.

—, «Pat Conroy's The Prince[ss?] of Tides: The Relation of Region and Religion to Gender Issues». Masculinities, Femininities and the Power of the Hybrid in U.S. Narratives: Essays on Gender Borders. Ed. Nieves Pascual, Laura Alonso-Gallo y Francisco Collado-Rodríguez. Heidelberg: Universitätsverlag, 2007.

Jensen CASADO, Elvira. «Transgressing and Transcending the American Identity with August Wilson's Bones People, Ghosts and Aunt Ester». Odisea: revista de estudios ingleses, 8 (2007): 101-8.

JiMÉNEZ PLACER, Susana María. «Granny Weatherall's Death: The Absence of Sings». The Short Story in English: Crossing Boundaries. Ed. Gema Soledad Castillo García, María Rosa Cabellos Castilla, Juan Antonio Sánchez Jiménez y Vincent Carlisle Espínola. Alcalá de Henares: Servicio de Publicaciones de la Universidad de Alcalá, 2006. 496-509.

LÁZARO LARRAZ, Maria Luisa. «La incuestionable impronta cervantina en la narrativa de Paul Auster». La huella de Cervantes y del Quijote en la cultura anglosajona. Coord. José Manuel Barrio Marco y María José Crespo Allué. Valladolid: Universidad de Valladolid, 2007. 437-44.

LlÁCER, Eusebio V. «Fantasy and Reality in Bierce's War Short Stories». The Short Story in English: Crossing Boundaries. Ed. Gema Soledad Castillo García, María Rosa Cabellos Castilla, Juan Antonio Sánchez Jiménez y Vincent Carlisle Espínola. Alcalá de Henares: Servicio de Publicaciones de la Universidad de Alcalá, 2006. 532-43.

López Liquete, M. ${ }^{a}$ Felisa. (Post)colonial American Mirrors. Bilbao: Servicio Editorial Universidad del País Vasco, 2007.

LoYo, Hilaria. «Forms of Beset Manhood in An American Tragedy: From Dreier to von Sternberg and Stevens». Masculinities, Femininities and the Power of the Hybrid in U.S. Narratives: Essays on Gender Borders. Ed. Nieves Pascual, Laura Alonso-Gallo y Francisco Collado-Rodríguez. Heidelberg: Universitätsverlag, 2007.

Manuel Cuenca, Carme. La reconstrucción del sur en la narrativa de George W. Cable y Thomas N. Page. Valencia: Publicacions Universitat de Valencia. Biblioteca Javier Coy d'Estudis Nord-Americans, 2006.

—, «Bigger's Rebellious Complaint: Biblical Imagery in Native Son». Native Son Beyond the Page. Richard Wright's Native Son. Ed. Ana María Fraile Marcos. Amsterdam/New York: Rodopi, 2007. 157-70. 
ManZANAS, Ana M. a ed. Border Transits. Literature and Culture across the Line. Amsterdam/New York: Rodopi, 2007.

—, «Border Dynamics: From Terminus to Terminator». Border Transits. Literature and Culture across the Line. Ed. Ana M. ${ }^{a}$ Manzanas. Amsterdam/New York: Rodopi, 2007. 1-8.

—, «Circles and Crosses: Reconsidering Lines of Demarcation». Border Transits. Literature and Culture across the Line. Ed. Ana M. ${ }^{a}$ Manzanas. Amsterdam/New York: Rodopi, 2007. 9-34.

-, y Benito SÁnchez, Jesús. «"Con la Iglesia hemos topado", amigo Tecumseh: Una lectura de Truth and Bright Water, de Thomas King». Don Quijote por tierras extranjeras: estudios sobre la recepción internacional de la novela cervantina. Coord. Hans Christian Hagendorn. Cuenca: Ediciones de la Universidad de Castilla-La Mancha, 2007. 233-44.

Marín RuIZ, Ricardo. «From the Telling to the Performing: Presence of Elements of the Short Story in Ernest Hemingway's The Fifth Column». The Short Story in English: Crossing Boundaries. Ed. Gema Soledad Castillo García, María Rosa Cabellos Castilla, Juan Antonio Sánchez Jiménez y Vincent Carlisle Espínola. Alcalá de Henares: Servicio de Publicaciones de la Universidad de Alcalá, 2006. 602-12.

Martín Castillejos, Ana M. «Johnny Panic and the Bible of Dreams: Landscape and Symbolism in the Short Stories of Sylvia Plath». The Short Story in English: Crossing Boundaries. Ed. Gema Soledad Castillo García, María Rosa Cabellos Castilla, Juan Antonio Sánchez Jiménez y Vincent Carlisle Espínola. Alcalá de Henares: Servicio de Publicaciones de la Universidad de Alcalá, 2006. 613-24.

Martín GonZÁLEZ, Matilde «Engendering Experimental Poetry: Women Poetry Anthologies and Feminist Theories». Masculinities, Femininities and the Power of the Hybrid in U.S. Narratives: Essays on Gender Borders. Ed. Nieves Pascual, Laura Alonso-Gallo y Francisco Collado-Rodríguez. Heidelberg: Universitätsverlag, 2007.

—, «Publishing and Disclosing Experimentation in American Poetry: Women Representing Properly». Approaching Cultures through English. Ed. Elizabeth Woodward Smith. A Coruña: Universidade da Coruña, Servicio de Publicaciones, 2007. 243-51.

MARTín PÁRRAGA, Javier. «La huella cervantina en la narrativa de Kurt Vonnegut». La huella de Cervantes y del Quijote en la cultura anglosajona. Coord. José Manuel Barrio Marco y María José Crespo Allué. Valladolid: Universidad de Valladolid, 2007. 429-36.

MarTíN-RodrígueZ, Manuel. «Mapping the Trans/Hispanic Atlantic: Nuyol, Miami, Tenerife, Tangier». Border Transits. Literature and Culture across the Line. Ed. Ana M. ${ }^{a}$ Manzanas. Amsterdam/New York. Rodopi, 2007. 205-224.

Martín Salván, Paula. «An Ascetic Book: Don DeLillo's The Body Artist». Proceedings of the 30th International Aedean Conference. Ed. María Losada Friend, Pilar Ron Vaz, Sonia Hernández Santano, Jorge Casanova. Huelva: Editorial Universidad de Huelva, 2007. CDROM.

Martínez Falquina, Silvia. «Gender Diversity in Native America: A Postindian Re/Vision of Borders». Masculinities, Femininities and the Power of the Hybrid in U.S. Narratives: Essays on Gender Borders. Ed. Nieves pascual, Laura Alonso-Gallo y Francisco Collado-Rodríguez. Heidelberg: Universitätsverlag, 2007.

MARTínez Vela, Ana. «La transformación de la mujer europea en mujer norteamericana de frontera en la novela The Pioneers de James Fenimore Cooper». De habitaciones propias y otros espacios conquistados. Estudios sobre mujeres y literatura en lengua inglesa en homenaje a Blanca López Román. Ed. Margarita Carretero González, M. ${ }^{a}$ Elena Rodríguez Martín y Gerardo Rodríguez Salas. Granada: Publicaciones Universidad de Granada, 2006. 35-46.

Mas Alcaraz, Julio, trad. La diferencia entre Pepsi y Coca-Cola: Antología de Poesía Norteamericana Contemporánea. Madrid: Ediciones Vitruvio, 2007. 
Mateos-Aparicio Martín-Albo, Ángel. «Don Quijote visita Nueva York: interpretando el Quijote en City of Glass, de Paul Auster». Don Quijote por tierras extranjeras: estudios sobre la recepción internacional de la novela cervantina. Coord. Hans Christian Hagendorn. Cuenca: Ediciones de la Universidad de Castilla-La Mancha, 2007. 245-56.

—, «Martians USA: El planeta rojo visto por la imaginación de Edgar Rice Burroughs». Proceedings of the 30th International Aedean Conference. Ed. María Losada Friend, Pilar Ron Vaz, Sonia Hernández Santano, Jorge Casanova. Huelva: Editorial Universidad de Huelva, 2007. CD-ROM.

Millares VAquero, Mario. «En un Lugar de Harlem: Cervantes a través de Langston Hughes». La huella de Cervantes y del Quijote en la cultura anglosajona. Coord. José Manuel Barrio Marco y María José Crespo Allué. Valladolid: Universidad de Valladolid, 2007. 421-28.

—, «The Negro Artist and the Racial Mountains: Langston Hughes responde a George Schuyler». Proceedings of the 30th International Aedean Conference. Ed. María Losada Friend, Pilar Ron Vaz, Sonia Hernández Santano, Jorge Casanova. Huelva: Editorial Universidad de Huelva, 2007. CD-ROM.

—, «Poet on Poet: Countee Cullen and Langston Hughes. Hughes (Two Versions for an AestheticLiterary Theory». Anglogermanica online: Revista electrónica periódica de filología alemana e inglesa, 5 (2007).

MiQuel BALdellou, Marta. «Growing up through Silence: Instances of Transatlantic Female Constraint in Anita Desai's Fasting Feasting». ES: Revista de filología inglesa, 27 (20062007):107-18.

Montes Granado, Consuelo. «Code-Switching in Sandra Cisneros' Short Stories». Proceedings of the 30th International Aedean Conference. Ed. María Losada Friend, Pilar Ron Vaz, Sonia Hernández Santano, Jorge Casanova. Huelva: Editorial Universidad de Huelva, 2007. CDROM.

Morillas SÁnchez, Rosa y Díaz Marín, Cecilia. «Deseo y violencia en The World According to Bensenhaver». De habitaciones propias y otros espacios conquistados. Estudios sobre mujeres y literatura en lengua inglesa en homenaje a Blanca López Román. Ed. Margarita Carretero González, M. ${ }^{a}$ Elena Rodríguez Martín y Gerardo Rodríguez Salas. Granada: Publicaciones Universidad de Granada, 2006. 117-32.

NADAL, Marita. «Freedom and Temporal Openness versus Inevitability and Narrative Closure in Flannery O'Connor's Short Stories». The Short Story in English: Crossing Boundaries. Ed. Gema Soledad Castillo García, María Rosa Cabellos Castilla, Juan Antonio Sánchez Jiménez y Vincent Carlisle Espínola. Alcalá de Henares: Servicio de Publicaciones de la Universidad de Alcalá, 2006. 636-46.

NARbona Carrión, María Dolores. Vida y obra de Elizabeth Stuart Phelps y selección de textos. Málaga: Servicio de Publicaciones de la Universidad de Málaga, 2006.

-, ed. Sophie Treadwell: Contexto Teatral, biografía, crítica y traducción de su obra Machinal. Málaga: Servicio de Publicaciones de la Universidad de Málaga, 2007.

—, «The Conflict Between the American Dream and Chicano Traditions: Josefina López's Simply María or The American Dream». Critical Essays on Chicano Studies. Ed. Ramón Espejo, Juan Ignacio Guijarro, Jesús Lerate de Castro, Pilar Marín y María Ángeles Toda Iglesia. Brussels: P.I.E. Peter Lang, 2007.179-90.

—, «Elizabeth Stuart Phelps (1844-1911): the Presence of Medical Subjects in her Literary Works». Revista de estudios norteamericanos, 12 (2007).

—, «La literatura norteamericana escrita por mujeres en tiempos de guerra: la aportación de las obras de Elizabeth Stuart Phelps». Mujeres, simbolismo y vida: estudios sobre mujeres. Coord. María de los Angeles Durán López y María Viedma García. Universidad de Málaga: Servicio de Publicaciones, 2007. 299-315. 
NAVARro TeJero, Antonia. «La representación estereotipada del género en la ficción chicana e india de los años 90». Critical Essays on Chicano Studies. Ed. Ramón Espejo, Juan Ignacio Guijarro, Jesús Lerate de Castro, Pilar Marín y María Ángeles Toda Iglesia. Brussels: P.I.E. Peter Lang, 2007. 191-200.

NAVAS OCAÑA, María Isabel. Historia de la teoría y la crítica literaria en Gran Bretaña y Estados Unidos. Madrid: Verbum, 2007.

NúÑEZ PuENTE, Carolina. «Gendering the Short-Story: "Annunciation” by Meridel Le Sueur». The Short Story in English: Crossing Boundaries. Ed. Gema Soledad Castillo García, María Rosa Cabellos Castilla, Juan Antonio Sánchez Jiménez y Vincent Carlisle Espínola. Alcalá de Henares: Servicio de Publicaciones de la Universidad de Alcalá, 2006. 660-73.

Oliver-Rotger, Maria Antonia. «Ethnographies of Transnational Migration in Rubén Martínez's Crossing Over». Border Transits. Literature and Culture across the Line. Ed. Ana M. ${ }^{a}$ Manzanas. Amsterdam/New York. Rodopi, 2007. 181-204.

Palacios Pablos, Andrés. «Brian Moore's Short Stories: An Instance of Advancing Recurrent Autobiographic Subject Matter». The Short Story in English: Crossing Boundaries. Ed. Gema Soledad Castillo García, María Rosa Cabellos Castilla, Juan Antonio Sánchez Jiménez y Vincent Carlisle Espínola. Alcalá de Henares: Servicio de Publicaciones de la Universidad de Alcalá, 2006. 695-706.

Pascual, Nieves, Alonso-Gallo, Laura y Collado-Rodríguez, Francisco, eds. Masculinities, Femininities and the Power of the Hybrid in U.S. Narratives: Essays on Gender Borders. Heidelberg: Universitätsverlag, 2007.

-, «The Anorexic Cyborg». Masculinities, Femininities and the Power of the Hybrid in U.S. Narratives: Essays on Gender Borders. Ed. Nieves Pascual, Laura Alonso-Gallo y Francisco Collado-Rodríguez. Heidelberg: Universitätsverlag, 2007.

PATEA, Viorica. «New Readings in American Romanticism». Revista canaria de estudios ingleses, 54 (2007): 209-14.

—, «Romantic epistemology and the short story: Poe's poetics of unity and fragmentation». Proceedings of the 30th International Aedean Conference. Ed. María Losada Friend, Pilar Ron Vaz, Sonia Hernández Santano, Jorge Casanova. Huelva: Editorial Universidad de Huelva, 2007. CD-ROM.

Perea Villena, María Jesús. «The American Dream versus Determinism in O. Henry's Short Stories». The Short Story in English: Crossing Boundaries. Ed. Gema Soledad Castillo García, María Rosa Cabellos Castilla, Juan Antonio Sánchez Jiménez y Vincent Carlisle Espínola. Alcalá de Henares: Servicio de Publicaciones de la Universidad de Alcalá, 2006. 717-26.

PÉREZ Riu, Carmen: «Women's Self-portrait as Self-discovery: Negotiating the Gap between Seeing and Being Seen in Drusila Modejeska's The Orchard (1994)». ES: Revista de filología inglesa, 27 (2006-2007):151-62.

RAMÓN TORRIJOS, M. ${ }^{\text {a }}$ del Mar. «Dentro y fuera de la norma, representación textual de la mujer detective en la literatura angloamericana». Garoza: revista de la Sociedad Española de Estudios Literarios de Cultura Popular, 7 (2007): 17.

Rigal Aragón, Margarita y GonZÁlez Moreno, Beatriz. «Poe's Narratives: Tales or Short Stories». The Short Story in English: Crossing Boundaries. Ed. Gema Soledad Castillo García, María Rosa Cabellos Castilla, Juan Antonio Sánchez Jiménez y Vincent Carlisle Espínola. Alcalá de Henares: Servicio de Publicaciones de la Universidad de Alcalá, 2006. 747-55.

Rio, David, IbARraran, Amaia, SANTAMARÍA, José Miguel y LÓPEZ, M. ${ }^{a}$ Felisa, eds. Exploring the American Literary West: International Perspectives. Bilbao: Universidad del País Vasco, 2006.

-, Robert Laxalt, the Voice of the Basques in American Literature. Trad. Kristin Addis. Reno: Center for Basque Studies. University of Nevada, 2007. 
Rodríguez Gómez, Paula María. «An Archetypal Reading of the Cage Symbol in Henry James's Major Phase». Revista canaria de estudios ingleses, 54 (2007): 69-86.

RodríGUEZ GonZÁLEZ, Dulce M. ${ }^{\mathrm{a}}$ «The Dismantling of the Oedipal Dyad in Two American Women Poets: The Dynamics of Maternal Desire». Canon Disorders: Gendered Perspectives on Literature and Film in Canada and the United Status. Ed. Eva Darias Beautell y María Jesús Hernáez Lerena. Logroño: Universidad de La Rioja: Servicio de Publicaciones, 2007. 119-38.

—, «From a Politics of Greediness to a Logic of Generosity: The Journey of Maternal Attachment in Alicia Ostriker's Poem "Listen"». Proceedings of the 30th International Aedean Conference. Ed. María Losada Friend, Pilar Ron Vaz, Sonia Hernández Santano, Jorge Casanova. Huelva: Editorial Universidad de Huelva, 2007. CD-ROM.

RodríGuez Mosteiro, Ana María. «Characters Looking for Their Own Place: Sandra Cisneros and Her Idea of a Frontier». The Short Story in English: Crossing Boundaries. Ed. Gema Soledad Castillo García, María Rosa Cabellos Castilla, Juan Antonio Sánchez Jiménez y Vincent Carlisle Espínola. Alcalá de Henares: Servicio de Publicaciones de la Universidad de Alcalá, 2006. 765-74.

Rodríguez Ramírez, María del Carmen. «Minimalism to the Maximum: Short Story as the Starting Point in Memento». The Short Story in English: Crossing Boundaries. Ed. Gema Soledad Castillo García, María Rosa Cabellos Castilla, Juan Antonio Sánchez Jiménez y Vincent Carlisle Espínola. Alcalá de Henares: Servicio de Publicaciones de la Universidad de Alcalá, 2006. 775-85.

Romero JóDAR, Andrés. «Somewhere over the Rainbow: Representation of Identities in Neil Gaiman's The Sandman». Revista canaria de estudios ingleses, 54 (2007):149-68.

Rosselló Hernández, Vicente R. «In the Name of the Father: Reflexive Sadomasochism and the Symbolic Order in Chuck Palahniuk's Choke; or, "What Would Jesus Not Do"». Proceedings of the 30th International Aedean Conference. Ed. María Losada Friend, Pilar Ron Vaz, Sonia Hernández Santano, Jorge Casanova. Huelva: Editorial Universidad de Huelva, 2007. CD-ROM.

SANTAULARIA, Isabel. «"The Great Good Place" No More. Integrating and Dismantling Opositional Discourse in some Recent Examples of Serial Killer Fiction». Atlantis, 29 (2007): 55-67.

SANTOS VIla, Sonia. «"The Child was a Deaf Mute": Quijotismo y ternura en Chickamauga de Ambrose Bierce». La huella de Cervantes y del Quijote en la cultura anglosajona. Coord. José Manuel Barrio Marco y María José Crespo Allué. Valladolid: Universidad de Valladolid, 2007. 397-406.

SERrano Moya, Elena. «Sherman Alexie's Short Stories and his Cinematographic Elements in Them». The Short Story in English: Crossing Boundaries. Ed. Gema Soledad Castillo García, María Rosa Cabellos Castilla, Juan Antonio Sánchez Jiménez y Vincent Carlisle Espínola. Alcalá de Henares: Servicio de Publicaciones de la Universidad de Alcalá, 2006. 852-67.

Simal GonzÁlez, Begoña. «The Cariboo Café as a Border Text: the Holographic Model». Border Transits. Literature and Culture across the Line. Ed. Ana M. ${ }^{a}$ Manzanas. Amsterdam/New York. Rodopi: 2007. 81-93.

—, «Sisters in Arms: The Ethnic Doppelgänger in Amy Tan's The Hundred Secret Senses». Family Reflections. The Contemporary American Family in the Arts. Ed. Carmen Flys Junquera y Maurice A. Lee. Alcalá de Henares: Servicio de Publicaciones Universidad de Alcalá, 2007. 157-70.

—, «"A Wall of Barbed Lies”: Absent Borders in María Cristina Mena's Short Fiction». Border Transits. Literature and Culture across the Line. Ed. Ana M. ${ }^{a}$ Manzanas. Amsterdam/New York: Rodopi, 2007. 147-80.

Sola BuIL, Ricardo J. «Blind Josef Pronek: A Room with No View». The Short Story in English: Crossing Boundaries. Ed. Gema Soledad Castillo García, María Rosa Cabellos Castilla, Juan Antonio Sánchez Jiménez y Vincent Carlisle Espínola. Alcalá de Henares: Servicio de Publicaciones de la Universidad de Alcalá, 2006. 878-90. 
Soто, Isabel. «To Hear Another Language: Lifting the Veil between Langston Hughes and Federico García Lorca». Border Transits. Literature and Culture across the Line. Ed. Ana M. ${ }^{a}$ Manzanas. Amsterdam/New York: Rodopi, 2007: 101-17.

—, «Langston Hughes: The Empowerment of Dislocation». Montage: Eessays on the Art and Life of Langston Hughes. Ed. John Edgar Tidwell y Cheryl R. Ragar. Columbia: University of Missouri Press, 2007. 169-80.

SuÁreZ-Toste, Ernesto. «Memories of a Country Mouse: Elizabeth Bishop's Short Stories». The Short Story in English: Crossing Boundaries. Ed. Gema Soledad Castillo García, María Rosa Cabellos Castilla, Juan Antonio Sánchez Jiménez y Vincent Carlisle Espínola. Alcalá de Henares: Servicio de Publicaciones de la Universidad de Alcalá, 2006. 931-40.

—, «Spontaneous, not Automatic: William Carlos Williams versus Surrealist Poetics». DQR Studies in Literature, Modernism Revisited. Transgressing Boundaries and Strategies of Renewal in American Poetry. Ed. Viorica Patea y Paul Scott Derrick Amsterdam/New York: Rodopi, 2007. 161-73.

—, «Metaphor and creativity in Nancy Willard's Poetry». Proceedings of the 30th International Aedean Conference. Ed. María Losada Friend, Pilar Ron Vaz, Sonia Hernández Santano, Jorge Casanova. Huelva: Editorial Universidad de Huelva, 2007. CD-ROM.

TAYLOR, Gloria. «"Mama Day" desplaza a "Próspero" y asume el mando: deconstrucción y subversión del texto Shakespeariano». Babel A.F.I.A.L., 16 (2007): 33-49.

TodA IgLESIA, María Ángeles. «¿Cuántas cervezas? Dos versiones de un cuento de Alicia Gaspar de Alba». Critical Essays on Chicano Studies. Ed. Ramón Espejo, Juan Ignacio Guijarro, Jesús Lerate de Castro, Pilar Marín y María Ángeles Toda Iglesia. Brussels: P.I.E. Peter Lang, 2007. 245-54.

URdialEs SHAW, Martín. «Reading, Riddling and Relaying: The Legacies of Female Voices in Tillie Olsen's Tell Me a Riddle». The Short Story in English: Crossing Boundaries. Ed. Gema Soledad Castillo García, María Rosa Cabellos Castilla, Juan Antonio Sánchez Jiménez y Vincent Carlisle Espínola. Alcalá de Henares: Servicio de Publicaciones de la Universidad de Alcalá, 2006. 961-72.

VALIENTE NÚÑEZ, Javier. «Native American Testimonio and the Theorization of a Postcolonial Project: towards a Native American Liberation Theology and Philosophy in the Battle of the Hundred Slain Episode of Black Elk Speaks». Proceedings of the 30th International Aedean Conference. Ed. María Losada Friend, Pilar Ron Vaz, Sonia Hernández Santano, Jorge Casanova. Huelva: Editorial Universidad de Huelva, 2007. CD-ROM.

VALLINA SAMPEIRO, Francisco Javier. «Deshumanización y destino en las narrativas bélicas de Joseph Heller y Norman Mailer: Coincidencias entre Catch-22 y The Naked and the Dead». Odisea: Revista de estudios ingleses, 8 (2007): 199-213.

—, «Wasteland Scenery and Technological Suicide in Kurt Vonnegut's Apocalyptic Narrative: Admonishment and Exhortation». Revista de estudios norteamericanos, 12 (2007).

VAQUeRA, Santiago: «Postcards from the Border: In Tijuana, Revolución is an Avenue». Border Transits. Literature and Culture across the Line. Ed. Ana M. ${ }^{a}$ Manzanas. Amsterdam/New York: Rodopi, 2007. 79-100.

VÁzquez Del Árbol, Ester y Vázquez Marruecos, José Luis. Poesía Norteamericana. Antología Bilingüe (Con ilustraciones del pintor José Félix Jiménez Muñoz). Granada: Editorial Universidad de Granada. 2007.

VericAt PÉREZ-MíngueZ, Fabio. «Medical Lyricism as Cultural Distance: T.S. Eliot and the (Feminine) Body». Proceedings of the 30th International Aedean Conference. Ed. María Losada Friend, Pilar Ron Vaz, Sonia Hernández Santano, Jorge Casanova. Huelva: Editorial Universidad de Huelva, 2007. CD-ROM. 
VILlar Raso, Manuel. A Glimpse on Chicano Literature: an Anthology. Granada: Editorial Universidad de Granada, 2007.

Villalobos, Jose Pablo: «Up against the Border: A Literary Response». Border Transits. Literature and Culture across the Line. Ed. Ana M. ${ }^{a}$ Manzanas. Amsterdam/New York: Rodopi, 2007. 3552. 


\section{OTRAS LITERATURAS EN LENGUA INGLESA}

NiEVES DE Mingo IZquiERdo

UNED. Madrid ndemingo@bec.uned.es

ÍNDICE

1. Estudios sobre literatura africana

2. Estudios sobre literatura asiática

3. Estudios sobre literatura australiana y neocelandesa

4. Estudios sobre literatura canadiense

5. Estudios sobre literatura caribeña

\section{ESTUDIOS SOBRE LITERATURA AFRICANA}

Dachs Ventura, Agnés. «Accessing Another Culture: South African Tales for Children». Approaching Cultures through English. Ed. Elizabeth Woodward Smith. A Coruña: Universidade da Coruña, Servicio de Publicaciones, 2007. 93-101.

DAsYLVA, Ademola O. «Cross-cultural Influences and Correspondences in Contemporary Nigerian Drama». ES: Revista de filología inglesa, 27 (2006-2007): 25-38.

GARCíA-RAmíreZ, Paula. «Corruption and Survival in Chinua Achebe's Short Stories». The Short Story in English: Crossing Boundaries. Ed. Gema Soledad Castillo García, María Rosa Cabellos Castilla, Juan Antonio Sánchez Jiménez y Vincent Carlisle Espínola. Alcalá de Henares: Servicio de Publicaciones de la Universidad de Alcalá, 2006. 389-406.

LóPEZ-PelÁEZ CASELlas, Jesús. «"What good news from Barbary” Nascent capitalism, NorthAfricans and the Construction of English Identity in Thomas Heywood's Drama». Atlantis, 29.1 (2007): 123-38.

\section{ESTUDIOS SOBRE LITERATURA ASIÁTICA}

Fresno Calleja, Paloma. «Debunking Myths of Authenticity: Vilsoni Hereniko and Teresia Tewaia's Last Virgin in Paradise». Proceedings of the 30th International Aedean Conference. Ed. María Losada Friend, Pilar Ron Vaz, Sonia Hernández Santano, Jorge Casanova. Huelva: Editorial Universidad de Huelva, 2007. CD-ROM.

Gnanamony, Robert. «Reign of Terror in the Grand Guignol Days of Partition: A Select Reading of Alok Bhalla's Edition of Stories About the Partition of India». Revista canaria de estudios ingleses, 54 (2007): 119-38.

Martos Huesos, María Elena. «The Subaltern Ethnographer: Blurring the Boundaries through Amitav Ghosh's Writing». Miscelánea: A Journal of English and American studies, 36 (2007): 55-66.

Miquel BALDELlou, Marta. «Growing up through Silence: Instances of Transatlantic Female Constraint in Anita Desai's Fasting Feasting. ES: Revista de filología inglesa, 27 (2006-2007): $107-18$. 
Morgan, Nina y Horks, Heather. «Hegemonía espectral y otros fantasmas en la literatura asiática y asiática-anglófona». Anthropos, 216 (2007): 138-49.

MurALI, S. «Life Lines: Water, Life and the Indian Experience. Cultural Meanings, Social Significance and Literary Implications». ES: Revista de filología inglesa, 27 (2006-2007):119-34.

SALES SALVADOR, Dora. «The Translator as an Agent of Intercultural Transference and Mediation: Translating India». The Short Story in English: Crossing Boundaries. Ed. Gema Soledad Castillo García, María Rosa Cabellos Castilla, Juan Antonio Sánchez Jiménez y Vincent Carlisle Espínola: Alcalá de Henares. Servicio de Publicaciones de la Universidad de Alcalá, 2006. 815-28.

\section{ESTUDIOS SOBRE LITERATURA AUSTRALIANA Y NEOCELANDESA}

CuRnow, Wynstan. «Escribir en los confines del universo». Nerter, 10 (2007): 30-33.

Herrero, M. Dolores. «Merlinda Bobis's White Turtle: Crossing to the Other Side, Bridging the Gap between Different Worlds and Cultures». The Short Story in English: Crossing Boundaries. Ed. Gema Soledad Castillo García, María Rosa Cabellos Castilla, Juan Antonio Sánchez Jiménez y Vincent Carlisle Espínola. Alcalá de Henares: Servicio de Publicaciones de la Universidad de Alcalá, 2006. 451-67.

LóPEZ PÉREZ, Ana Belén. «The Inner Space and the Building of Female Identity: The Case of Katherine Mansfield's Short Stories». The Short Story in English: Crossing Boundaries. Ed. Gema Soledad Castillo García, María Rosa Cabellos Castilla, Juan Antonio Sánchez Jiménez y Vincent Carlisle Espínola. Alcalá de Henares: Servicio de Publicaciones de la Universidad de Alcalá, 2006. 556-69.

LóPEZ SÁNCHEZ-VizCAÍNO, M. ${ }^{a}$ Jesús. «Literature Keeps its Secrets: Silence and Alterity in J.M. Coetzee's Foe». Proceedings of the 30th International Aedean Conference. Ed. María Losada Friend, Pilar Ron Vaz, Sonia Hernández Santano, Jorge Casanova. Huelva: Editorial Universidad de Huelva, 2007. CD-ROM.

Oliete AldeA, Elena. «Colouring the Black and White Australian Past in Sally Morgan's My Place». Babel A.F.I.A.L., 16 (2007): 129-49.

PÉREZ Riu, Carmen. «Women's Self-portrait as Self-discovery: Negotiating the Gap between Seeing and Being Seen in Drusila Modejeska's The Orchard (1994)». ES: Revista de filología inglesa, 27 (2006-2007): 151-62.

RodRíGUEZ SALAS, Gerardo. «The Daughters of the Late Colonel: Feminine Temporality in Katherine Mansfield's Short Fiction». The Short Story in English: Crossing Boundaries. Ed. Gema Soledad Castillo García, María Rosa Cabellos Castilla, Juan Antonio Sánchez Jiménez y Vincent Carlisle Espínola. Alcalá de Henares: Servicio de Publicaciones de la Universidad de Alcalá, 2006. 786-98.

—, «"As Old as the Hills”: La "New Woman” en la narrativa de Katherine Mansfield». De habitaciones propias y otros espacios conquistados. Estudios sobre mujeres y literatura en lengua inglesa en homenaje a Blanca López Román. Margarita Carretero González, M. ${ }^{a}$ Elena Rodríguez Martín y Gerardo Rodríguez Salas. Granada: Servicio de Publicaciones de la Universidad de Granada, 2006. 75-87.

- Hijas de la Diosa Blanca: Ginocrítica y feminismo restaurador en la obra de Katherine Mansfield. Oviedo: Septem Ediciones, 2007.

—, "Adiós a Cenicienta: "The Tiredness of Rosabel" de Katherine Mansfield». Proceedings of the 30th International Aedean Conference. Ed. María Losada Friend, Pilar Ron Vaz, Sonia Hernández Santano, Jorge Casanova. Huelva: Editorial Universidad de Huelva, 2007. CDROM. 
—, «The Boundless Ocean of Silence: an Alternative to Language in Katherine Mansfield's Doll's House». Babel A.F.I.A.L., 16 (2007): 51-64.

—, «The Margin in Catherine Mansfield: an Interview with Gillian Boddy-Geer». Estudios en Honor de Rafael Fente Gómez. Ed. Miguel Ángel Martínez-Cabeza Lombardo, Neil McClaren y Luis Quereda Rodríguez-Navarro. Granada: Editorial Universidad de Granada, 2007. 431-40.

—, «"Doy vida a mis personajes": maternidad agridulce y reescritura del cuerpo femenino en Katherine Mansfield». Cuerpos de mujeres: miradas, representaciones e identidades. Coord. Ana María Muñoz Muñoz, Carmen Gregorio Gil y Adelina Sánchez Espinosa. Granada: Universidad de Granada, 2007. 367-380.

ROMERo JóDAR, Andrés. «Bernard Cohen's Snowdome: Somewhere in a Postmodern Time». Revista alicantina de estudios ingleses, 20 (2007): 185-94.

\section{ESTUDIOS SOBRE LITERATURA CANADIENSE}

Arce Alvarez, Maria Laura. «Too visible: Race, Gender and Resistance in the Construction of a Canadian Identity in the Poetry of Himani Bannerji». Miscelánea: a Journal of English and American Studies, 36 (2007): 11-23.

ARzÚA AZURMENDI, Carmen. «Healing the Colonial Wounds: Autobiographical Migration in the Work of Lee Maracle». Proceedings of the 30th International Aedean Conference. Ed. María Losada Friend, Pilar Ron Vaz, Sonia Hernández Santano, Jorge Casanova. Huelva: Editorial Universidad De Huelva, 2007. CD-Rom.

CARmona Rodríguez, Pedro. «Gender and Post- Theories as Counter-Cultural Discourse in Black Canadian Women's Writing». Proceedings of the 30th International Aedean Conference. Ed. María Losada Friend, Pilar Ron Vaz, Sonia Hernández Santano, Jorge Casanova. Huelva: Editorial Universidad de Huelva, 2007. CD-ROM.

—, «No Law and a Mighty Congregation of Indians: Westering Processes and the Performativity of the American Nation in Guy Vanderhaege's The Englishman Boy». Proceedings of the 30th International Aedean Conference. Ed. María Losada Friend, Pilar Ron Vaz, Sonia Hernández Santano, Jorge Casanova. Huelva: Editorial Universidad de Huelva, 2007. CD-ROM.

Darias Beautell, Eva. «Blood Road Leads to Promise: A Gendered Approach to Canada's Past in Gail Anderson-Dargatz's The Cure for Death by Lightning». Canon Disorders: Gendered Perspectives on Literature and Film in Canada and the United States. Eds. María Jesús Hernáez Lerena y Eva Darias Beautell. Logroño. Servicio de Publicaciones de la Universidad de la Rioja/Universidad de La Laguna, 2007. 45-70.

—, «Margaret Atwood's Hack Wednesday: The Canadianness of the Uncanadian». The Short Story in English: Crossing Boundaries. Ed. Gema Soledad Castillo García, María Rosa Cabellos Castilla, Juan Antonio Sánchez Jiménez y Vincent Carlisle Espínola. Alcalá de Henares: Servicio de Publicaciones de la Universidad de Alcalá, 2006. 280-90.

Delgado, Ana Beatriz. «Paradigms of Canadian Literary Biography: Who Will Write Our History?». Transculturing Auto/Biography: Forms of Life Writing. Ed. Rosalia Baena. London, New York: Routledge, 2007. 330-43.

DíAZ DueÑas, Mercedes. «El uso irónico de la imagen de Europa en Wilderness Tips de Margaret Atwood». De habitaciones propias y otros espacios conquistados. Estudios sobre mujeres y literatura en lengua inglesa en homenaje a Blanca López Román .Ed. Margarita Carretero González, M. ${ }^{a}$ Elena Rodríguez Martín y Gerardo Rodríguez Salas. Granada: Publicaciones Universidad de Granada. Campus de la Cartuja, 2006. 133-44. 
—, «Immigration in Canadian Contemporary Fiction: Dealing with Memory and Distance». Estudios en Honor de Rafael Fente Gómez. Ed. Miguel Ángel Martínez Cabeza, Neil Mc Laren y Luis Quereda. Granada: Editorial Universidad de Granada, 2007. 463-74.

DíETZ GuERRERO, Berndt. «La Mirada del Norte: Escritores Canadienses en Canarias». El Viaje Literario y... la Cueva: Imágenes de la Memoria. Ed. Santiago J. Henríquez Jiménez. Las Palmas de Gran Canaria: Cabildo de Gran Canaria, 2007. 53-80.

—, «Margaret Atwood's Hack Wednesday: The Canadianness of the Uncanadian». The Short Story in English: Crossing Boundaries. Ed. Gema Soledad Castillo García, María Rosa Cabellos Castilla, Juan Antonio Sánchez Jiménez y Vincent Carlisle Espínola. Alcalá de Henares: Servicio de Publicaciones de la Universidad de Alcalá, 2006. 280-90.

FERRI, Laura. «Crossing Borders in Alice Munro's Short Stories». The Short Story in English: Crossing Boundaries. Ed. Gema Soledad Castillo García, María Rosa Cabellos Castilla, Juan Antonio Sánchez Jiménez y Vincent Carlisle Espínola. Alcalá de Henares: Servicio de Publicaciones de la Universidad de Alcalá, 2006. 359-67.

Gibert MACEDA, M. a Teresa. «Pragmatism, Ethics and Aesthetics in the Narratives of the JapaneseCanadian Displacement». Transport(s) in the British Empire and the Commonwealth. Ed. Michèle Lurdos y Judith Misrahi-Barak. Les Carnets du Cerpac n. ${ }^{\circ}$ 4. Montpellier: Service des Publications Université Paul Valéry Montpellier III, 2007.

—, «Turning Histories of Childhood into Stories for Children: Autobiographical Fiction about the Internment of Japanese Canadians during WW II». Stories for Children, Histories of Childhood. 2 vols. Ed. Rosie Findlay y Sébastien Salbayre. GRAAT 36. Tours: Presses Universitaires François Rabelais, 2007.

GonZÁlez RodrígueZ, María Luz. «La textualización del cuerpo femenino en los relatos de Alice Munro». Revista canaria de estudios ingleses, 54 (2007): 13-24.

Hernáez Lerena, María Jesús. «Surviving the Metaphorical Condition in Elle: Douglas Glover's Impersonation of the First French Female in Canada». Canon Disorders: Gendered Perspectives on Literature and Film in Canada and the United States. Ed. María Jesús Hernáez Lerena y Eva Darias Beautell. Logroño: Servicio de Publicaciones de la Universidad de la Rioja, 2007. 71-92.

—, y Darias Beautell, Eva, eds. Canon Disorders: Gendered Perspectives on Literature and Film in Canada and the United States. Logroño. Servicio de Publicaciones de la Universidad de la Rioja/ Universidad de La Laguna, 2007.

MCLENNAN, Rob. «Un apunte sobre las antologías de poesía canadiense». Nerter, 10 (2007): 63 70.

OLIVA, Juan Ignacio. «Gendered Constructions of a Multicultural Identity in South Asian-Canadian Short-Story Writing». The Short Story in English: Crossing Boundaries. Ed. Gema Soledad Castillo García, María Rosa Cabellos Castilla, Juan Antonio Sánchez Jiménez y Vincent Carlisle Espínola. Alcalá de Henares: Servicio de Publicaciones de la Universidad de Alcalá, 2006. 674-83.

Pisa CAÑETE, María Teresa. «Don Quichotte en Sudbury. Observaciones sobre una representación teatral en una comunidad franco-ontariana». Don Quijote por tierras extranjeras: Estudios sobre la recepción internacional de la novela cervantina. Coord. Hans Christian Hagedorn. Cuenca: Ediciones de la Universidad de Castilla-La Mancha, 2007. 183-99.

SÁnCheZ-PARdo GonZÁlez, Esther. «Transitional Spaces: Constructions of the Modernist I in Miriam Waddington's Poetry». Revista canaria de estudios ingleses, 54 (2007): 169180.

SÁnchez Soto, Cristina I. «Mythical Realities and Real Myths in the Short Story and the Visual Arts: Crossing Boundaries of Gender, Genre, and Story-Telling. A Study of Alice Munro and Mary Pratt; Alistair MacLeod and David Blackwood». The Short Story in English: Crossing 
Boundaries. Ed. Gema Soledad Castillo García, María Rosa Cabellos Castilla, Juan Antonio Sánchez Jiménez y Vincent Carlisle Espínola. Alcalá de Henares. Servicio de Publicaciones de la Universidad de Alcalá, 2006. 829-40.

\section{ESTUdiOS SOBRE LITERATURA CARIBEÑA}

Alonso BRETo, M. ${ }^{a}$ Isabel. «On Women's Bonds and Diaspora Rearrangements: Aspects of Makeda Silvera's The Heart does not Bend». Proceedings of the 30th International Aedean Conference. Ed. María Losada Friend, Pilar Ron Vaz, Sonia Hernández Santano, Jorge Casanova. Huelva: Editorial Universidad de Huelva, 2007. CD-ROM.

FraILE, Ana María. «Looking Backwards into the Future: Family and Ancestors as the Key to Caribbean Identity in Elizabeth Nunez's Beyond the Limbo Silence». Family Reflections. The Contemporary American Family in the Arts. Ed. Carmen Flys Junquera y Maurice A. Lee. Alcalá de Henares: Servicio de Publicaciones Universidad de Alcalá, 2007. 255-74.

LóPez Ropero, M. ${ }^{a}$ Lourdes. The Anglo-Caribbean Migration Novel: Writing from the Diaspora. Alicante: Servicio de Publicaciones Universidad de Alicante, 2007.

Seguin Pedraill, Zenaida. «A Big Boy/Anancy Tale: the Trickster Motif Propelling a Narrative of Resistance in Olive Senior's Ascot». Odisea: Revista de estudios ingleses, 8 (2007):173-86.

—, «The Caribbean Story Teller/Writer: Asserting Popular Culture in Summer Lightning, by Olive Senior». The Short Story in English: Crossing Boundaries. Ed. Gema Soledad Castillo García, María Rosa Cabellos Castilla, Juan Antonio Sánchez Jiménez y Vincent Carlisle Espínola. Alcalá de Henares: Servicio de Publicaciones de la Universidad de Alcalá, 2006. 84151.

Vega González, Susana. «Exiled Subjectivities: The Politics of Fragmentation in Edwidge Danticat's The Dew Breaker»: Revista canaria de estudios ingleses, 54 (2007):181-94.

—, «Watertime Fiction: Danticat's Children of the Sea and Nineteen Thirty-Seven». The Short Story in English: Crossing Boundaries. Ed. Gema Soledad Castillo García, María Rosa Cabellos Castilla, Juan Antonio Sánchez Jiménez y Vincent Carlisle Espínola. Alcalá de Henares: Servicio de Publicaciones de la Universidad de Alcalá, 2006.1005-13. 


\section{TRADUCCIÓN}

NORBERTO CEREZAL SIERRA

UNED. Madrid

ncerezal@flog.uned.es

Abuín GonZÁLEZ, Marta. El proceso de interpretación consecutiva. Un estudio del binomio problemalestrategia. Granada: Comares, 2007.

ACeves-Pérez, Rita M., Montes y Gómez, M., y Villaseñor-Pineda, Luis. «Fusión de respuestas en la búsqueda de respuestas multilingüe». Procesamiento del lenguaje natural, 38 (2007): 3543.

ACUÑa PARTAL, Carmen. «Sobre las aportaciones de la edición traductológica de las retraducciones de "el origen de las especies" al estudio de la recepción de Charles Darwin en España: el texto de Enríque Godínez (1877)». Traductores y traducciones de literatura y ensayo (18351919). Ed. Juan Jesús Zaro Vera, Granada: Comares, 2007.

Aguado de Cea, Guadalupe, Montiel Ponsoda, Elena y Ramos Gargantilla, José Ángel. «Multilingualidad en una aplicación basada en el conocimiento». Procesamiento del lenguaje natural, 38 (2007): 77-98.

Agulló Vives, Carmen. «Casasayas, traductor del «Quijote”: recursos estilísticos». Tonos Digital, 13 (Julio 2007).

AIJMER, Karin. «The meaning and functions of the Swedish discourse marker alltså-Evidence from translation corpora». Catalan Journal of Linguistics, 6 (2007).

Alba Quiñones, Virginia de y Torre García, Mercedes de la. «La corrección en los usos lingüísticos entre los alumnos de traducción».Panace@: Boletín de Medicina y Traducción, 9.26 (2007).

Alonso, Fernando. «Algo más que suprimir barreras: conceptos y argumentos para una accesibilidad universal». TRANS: Revista de traductología, 11 (2007).

Alonso, Juan Alberto. «Els sistemes de traducció automática». Llengua i ús: Revista técnica de política lingüística, 38 (2007): 23-32.

Amador Domínguez, Nidia. «Diez errores usuales en la traducción de artículos científicos». $P a$ nace@: Boletín de Medicina y Traducción, 9.26 (2007).

ARIAS TORRES, Juan Pablo. «Bibliografía sobre las traducciones del Alcorán en el ámbito hispano». TRANS: Revista de traductología, 11 (2007).

BARRADA, Adil. «Intertextualidad y traducción: la alusión como elemento primordial en la traducción de los textos literarios del árabe al español». Tonos Digital, 13 (Julio 2007).

Bernal-Merino, Miguel Á. «Challenges in the Translation of Video Game». Tradumática 5.12 (noviembre 2007).

Blas, Marta de, MeIUs Ferrés, Marta Estella, y SÁnchEZ, Imma. «Projecte Restad: recursos de suport a la traducció automatizada aplicats a la docéncia». Llengua i ús: Revista técnica de política lingüística, 38 (2007): 41-46.

BLASCO MAYOR, María Jesús. La comprensión oral en el desarrollo de la pericia de la interpretación de conferencias. Granada: Comares, 2007.

Bobadilla PÉrez, María. «Relevance and Complexities of Translating Titles of Literary and Filmic Works». Huarte de San Juan. Filología y Didáctica de la Lengua, 9 (2007): 117124.

BoRDA LAPÉBIE, Juan Miguel. Estructuras léxicas en la traducción francés-español / españolfrancés, con ejercicios. Granada: Comares, 2007. 
BORREGo ROPERO, Rafael y DíAz, Víctor. «Una herramienta para la manipulación de corpora bilingüe usando distancia léxica». Procesamiento del lenguaje natural, 39 (2007): 33.

Borrego Ropero, Rafael, y DíAZ MAdrigal, Víctor Jesús. «Alineamiento de entidades con nombre usando distancia léxica». Procesamiento del lenguaje natural, 38 (2007): 61-66.

Botella TeJera, Carla. «Aproximación al estudio del doblaje y la subtitulación». Murcia: Universidad de Murcia: Tonos Digital, 13 (Julio 2007).

BRAga RIERA, Jorge. «The Non-Verbal in Drama Translation: Spanish Classical Theatre in English. El componente no verbal en la traducción dramática: el teatro áureo español en inglés». Estudios ingleses de la Universidad Complutense, 15 (2007): 119-137.

BUENO GARCíA, Antonio. «Nuevas iniciativas en torno a la formación e investigación en traducción biosanitaria».Panace@: Boletín de Medicina y Traducción, 9.26 (2007).

Campillo Arnárz, Laura. «La traducción de Hamlet, Príncipe de Dinamarca de Guillermo Macpherson». Traductores y traducciones de literatura y ensayo (1835-1919). Ed. Juan Jesús Zaro Vera. Granada: Comares, 2007.

CARLuCCI, Laura. «Translate in English, or Perish in Italian? La traducción biomédica en la combinación lingüística español-italiano: aplicaciones didácticas».Panace@. IX.26 (2007).

Carrero García, Francisco, Gómez Hidalgo, José María, Buenaga Rodríguez, Manuel de, MATA, Jacinto, y MAÑA LÓPEZ, Manuel J. «Acceso a la información bilingüe utilizando ontologías específicas del dominio biomédico». Procesamiento del lenguaje natural, 38 (2007): 107-118.

CARRIó PASTOR, María Luisa. «La variación en el uso de las expresiones de certeza en los textos científicos». Bells: Barcelona English Language and Literature Studies, 16 (2007).

CAstillo García, Gema Soledad. La (auto)traducción como mediación entre culturas. Alcalá de Henares: Servicio de Publicaciones de la Universidad de Alcalá, 2006.

CONTRERAS BlANCO, Fernando. «En busca de especialización: modelo de máster profesional». $\mathrm{Pa}$ nace@: Boletín de Medicina y Traducción, 9.26 (2007).

CRESPO FERNÁNDEZ, Eliecer. El eufemismo y el disfemismo. Procesos de manipulación del tabú en el lenguaje literario inglés. Alicante: Universidad de Alicante, 2007.

CRESPO HIDALGO, Juan. «Políticas de traducción en la España del siglo XIX». Traductores y traducciones de literatura y ensayo (1835-1919). Ed. Juan Jesús Zaro Vera. Granada: Comares, 2007.

CuAdrado Esclápez, Georgina y Berge Legrand, Heliane. «Aportaciones al estudio de la metáfora en la física cuántica a partir de textos en inglés y en español» Ibérica: Revista de la Asociación europea de lenguas para fines específicos (A.E.L.F.E.), 13 (2007): 85-108.

DAYrell, Carmen. «A Quantitative Approach to Compare Collocational Patterns in Translated and Non-Translated Texts». International Journal of Corpus Linguistics, 12.3 (2007): 375414.

DeZA Blanco, Pablo. «Los conectores en noticias de sucesos: retórica contrastiva en textos de periodistas españoles y alumnos taiwaneses». Círculo de lingüística aplicada a la comunicación, 30 (2007): 24-44.

DíAZ CINTAS, Jorge. «Por una preparación de calidad en accesibilidad audiovisual». TRANS: Revista de traductología, 11 (2007).

ECKKRAMMER, Eva Martha.«La comparación en los lenguajes de especialidad».Panace@: Boletín de Medicina y Traducción, 9.26 (2007).

ELENA GARCía, Pilar. «El papel de la información textual en el proceso de lectura del texto especializado».Panace@: Boletín de Medicina y Traducción, 9.26 (2007).

FERNÁNDEZ GoNZÁLEZ, Vicente y GARCíA RAMírEZ, Leandro. «Pautas conceptuales, terminológicas y estilísticas para la traducción de mis obras: esbozo». TRANS: Revista de traductología, 11(2007). 
FERNÁNDEZ GONZÁLEZ, Vicente y GARCía RAMÍREZ, Leandro. «Sobre la traducción y edición de literatura griega moderna y contemporánea en España (1993-2005)». TRANS: Revista de traductología, 11 (2007): 179-196.

FERnÁNDEZ SÁnChEZ, M. ${ }^{a}$ Manuela y MuÑoz Martín, Ricardo. Aproximaciones cognitivas al estudio de la traducción y la interpretación. Granada: Comares, 2007.

Ferrández, Oscar, Micol, Daniel, Muñoz, Rafael y Palomar, Manuel. «Técnicas léxicosintácticas para el reconocimiento de implicación textual». Procesamiento del lenguaje natu$\mathrm{ral}, 38$ (2007): 53-60.

Ferrández, Sergio, Ferrández, Antonio, Roger, Sandra y LóPez-Moreno, Pilar. «Búsqueda de respuestas bilingüe basada en ILI, el sistema BRILI». Procesamiento del lenguaje natural, 38 (2007): 27-34.

FERRANDO, Antoni. «La traducció catalana de la Història de les amors de París e Viana». Caplletra: Revista internacional de filología, 42 (2007): 59-73.

FiJo LeÓn, M. ${ }^{a}$ Isabel. «La enseñanza de la terminología a los alumnos de Traducción e Interpretación: el caso de la Universidad Pablo de Olavide».Panace@: Boletín de Medicina y Traducción, 9.26 (2007).

FRANCO AlVAREZ, Guillermina. «Hacia un "nuevo discurso" visual: la transmutación de la imagen analógica a digital en prensa». Discurso: Revista internacional de semiótica y teoría literaria, 19-20 (2007): 23-37.

FranKenberg-Garcia, Ana y SANTOS, Diana. «The corpus, its users and their needs: a useroriented evaluation of COMPARA». International Journal of Corpus Linguistics, 12.3 (2007): 335-374.

FUlQUET, Josep Maria. «Sobre la teoria i la pràctica de la tradució. Les aportacions d' Itamar Even-Zohar i Gideon Toury al voltant de la teoria del polisistema (1960-1980)». Ars Brevis: Anuario de la Càtedra Ramon Llull Blanquerna, 13 (2007): 72-81.

GALLARDO SAN SALVADOR, Natividad. «Breve repaso a la enseñanza de la traducción científica».Panace@: Boletín de Medicina y Traducción, 9.26 (2007).

GARCÍA CES, Patricia. «Terminología y terminótica en la formación de traductores e intérpretes en Argentina».Panace@: Boletín de Medicina y Traducción, 9.26 (2007).

García GonzÁLEZ, José Enrique. «Waverley ve la luz en España. Consideraciones sobre la traducción publicada por Oliva»». Traductores y traducciones de literatura y ensayo (18351919). Ed. Juan Jesús Zaro Vera. Granada: Comares, 2007.

GARCíA JiMÉNEZ, Rocío. «Algunas revistas electrónicas sobre traducción: breve aproximación». TRANS: Revista de traductología, 11 (2007).

GuZMAN, Josep R. «Traduccions i usos sintàctics de l'expressió de l'abstracció» Caplletra: Revista internacional de Filología, 43 (2007): 59-87.

Hellín del CASTILlo, Javier. «El laboratorio de análisis clínicos dilucidado: la página web Lab Tests OnlineES ® en español».Panace@: Boletín de Medicina y Traducción, 9.26 (2007).

HEREDERO, José Luis. «Macros y atajos para el traductor».Panace@: Boletín de Medicina y Traducción, 8.25 (2007).

HERNÁNDEZ RAMírez, Haliuska y SÁIz NoEdA, Maximiliano. «Ontologías mixtas para la representación conceptual de objetos de aprendizaje». Procesamiento del lenguaje natural, 38 (2007): 99-106.

IzQuierdo, Rubén, Ferrández, Oscar, FerRández, Sergio, TomÁs, David, ViñEdo, José Luis Martínez, Patricio y SuÁrez Cueto, Armando. «QALL-ME: Question-Answering Learning Technologies in a MultiLingual and Multimodal Enviroment». Procesamiento del lenguaje natural, 38 (2007): 43-48.

JIMÉNEZ CARRA, Nieves. «Edición electrónica y traducción». Traductores y traducciones de literatura y ensayo (1835-1919). Ed. Juan Jesús Zaro Vera. Granada: Comares, 2007. 
LANERO, Juan José. «Historia de un traductor, prologuista y anotador. Tyndale y los primeros pasos de la Biblia en inglés». Estudios humanísticos. Filología, 29 (2007): 121-48.

LÓPEZ MORA, Pilar. «La intertextualidad como característica esencial del discurso publicitario». Círculo de lingüística aplicada a la comunicación, 30 (2007): 45-67.

MANIEZ, François. «Using the Web and Computer Corpora as Language Resources for the Translation of Complex Noun Phrases in Medical Research Articles».Panace@:Boletín de Medicina y Traducción, 9.26 (2007).

Martí Antonín, María Antonia, TAulé Delor, Mariona, MárqueZ i Villodre, Lluís y Bertrán, Manuel. «Anotación semiautomática con papeles temáticos de los corpus CESS-ECE». Procesamiento del lenguaje natural, 38 (2007): 67-76.

MARTín RUANO, M. Rosario. «Entre la convención y el futuro: la traducción en la época de la diferencia». TRANS: Revista de traductología, 11 (2007).

Martínez LóPez, Ana Belén y Ortega ARJonilla, Emilio. «Recursos bibliográficos sobre traducción, redacción y terminología en los ámbitos científico-técnico, audiovisual y multimedia». TRANS: Revista de traductología, 11 (2007): 287-298.

Martínez Santiago, Fernando, Montejo RÁEz, Arturo y García Cumbreras, Miguel Ángel. «Representación formal de la estructura lógica de sitios web, y su aplicación a un navegador web multilingüe basado en diálogo». Procesamiento del lenguaje natural, 38 (2007): 17-26.

Matamala, Anna. «The translation of "oh" in a corpus of dubbed sitcoms». Catalan Journal of Linguistics, 6 (2007).

MAYOR SERRANO, M. ${ }^{a}$ Blanca. «La importancia de la tipología textual pragmática para la formación de traductores médicos».Panace@:Boletín de Medicina y Traducción, 9.26 (2007).

MÉNDEZ CEndón, Beatriz y MéNDEZ CEndón, José Carlos. «Glosario español-inglés de imágenes de resonancia magnética».Panace@:Boletín de Medicina y Traducción, 9.26 (2007).

MonTALT I RESURRECCió, Vicent. «La enseñanza virtual de la traducción médica en el Espacio Europeo de Educación Superior (EEES)».Panace@:Boletín de Medicina y Traducción, 9.26 (2007).

Monterde Rey, Ana María. «Estudio terminológico en textos aeronáuticos de tres niveles de especialización». Ibérica: Revista de la Asociación europea de lenguas para fines específicos (A.E.L.F.E.), 13 (2007): 39-64.

MuÑoz Martín, Fco. Javier y VALDivieso BlanCo, María. «Autoridad y cambio lingüístico en la traducción institucional». Murcia: Universidad de Murcia: Tonos Digital, 13 (Julio 2007).

—. «Interferencia lingüística y traducción. ¿Pierde el traductor su papel o ha perdido los papeles?». Panace@.Boletín de Medicina y Traducción, 8.25 (2007).

MuÑoz SÁnCHEZ, PABLo. «La Web 2.0 en el aula de traducción».Panace@:Boletín de Medicina y Traducción, 9.26 (2007).

—. «Electronic Tools for Translators in the 21st Century». Translation Journal, 10,4 (2006).

NAVARro, Fernando A. «Minidiccionario crítico de dudas (n. $\left.{ }^{\circ} 16\right)$. (Critical mini-dictionary and guide to usage)».Panace@.Boletín de Medicina y Traducción, 8.25 (2007).

Navas Quintana, Gracia. «Silas Marner de George Eliot en versión de Isabel Oyarzábal de Palencia». Traductores y traducciones de literatura y ensayo (1835-1919). Ed. Juan Jesús Zaro Vera. Granada: Comares, 2007.

NEVES, Josélia y LORENZO, Lourdes. «La subtitulación para sordos, panorama global y prenormativo en el marco ibérico». TRANS: Revista de traductología,11 (2007).

NOMDEDEU RULL, Antoni. «La representación del conocimiento especializado mediante las marcas de especialidad: del DRAE-1992 al DRAE-2001».Panace@:Boletín de Medicina y Traducción, 8.25 (2007).

O'Hagan, Minako. «Video games as a new domain for translation research: From translating text to translating experience». Tradumática 5.12 (Noviembre 2007). 
ORERO, Pilar. «La accesibilidad en los medios: una aproximación multicisciplinar». TRANS: Revista de traductología,11 (2007).

-, Pereira, Ana María y Utray, Francisco. «Visión histórica de la accesibilidad en los medios en España». TRANS: Revista de traductología, 11 (2007).

ORTS LlOPIS. M. ángeles. Aproximación al discurso jurídico en inglés. Las pólizas de seguro marítimo de Lloyd's. Madrid: Edisofer, 2006.

PARAPAR, Javier y Moskowich-SPIEgel FAndiÑo, Isabel. «The Coruña Corpus Tool». Procesamiento del lenguaje natural, 39 (2007): 41.

PeÑa Pérez, Gloria. «Elementos contextuales en el discurso publicitario». Círculo de lingüística aplicada a la comunicación, 31 (2007): 34-51.

PÉrez RoMero, Carmen. «Problemas de la traducción poética: Juan Ramón Jiménez en inglés». Anuario de estudios filológicos, 30 (2007): 281-300.

PIERINIQ, Patrizia. «Simile in English: from Description to Translation». Círculo de lingüística aplicada a la comunicación, 29 (2007).

PonCe Márquez, Nuria. «El apasionante mundo del traductor como eslabón invisible entre lenguas y culturas». Murcia: Universidad de Murcia: Tonos Digital, 13 (Julio 2007).

RAmíreZ ARLANDI, Juan. «Siro García del Mazo, traductor "en vista" de Spencer. Apuntes sobre la recepción y traducción de textos ensayísticos a finales del siglo XIX». Traductores y traducciones de literatura y ensayo (1835-1919). Ed. Juan Jesús Zaro Vera. Granada: Comares, 2007.

REIMERINK, Arianne. «Sciscribe: una aplicación de software para redactar y traducir artículos de investigación».Panace@.Boletín de Medicina y Traducción, 8.25 (2007).

Remael, Aline y Vercauteren, Gert. «Audio Describing the Exposition Phase of Films. Teaching Students What to Choose». TRANS: Revista de traductología, 11 (2007).

RIGO, Antònia y GENESCÀ, Gabriel. «El nou paper del "traductor" en l'adopció de la terminologia econòmica». Llengua i ús: Revista tècnica de política lingüística, 40 (2007): 33-35.

Rioja BARrocal, Marta. «Translated Novels Affected by External Censorship from Corpus 0 TRACEni (1962-1969)». Proceedings of the 30 ${ }^{\text {th }}$ International AEDEAN Conference. Ed. María Losada Friend, Pilar Ron Vaz, Sonia Hernández Santano, Jorge Casanova. Huelva: Editorial Universidad de Huelva, 2007.

RODRÍGUEZ ESPINOSA, Marcos. «La clave mexicana y la mediación francesa en las primeras traducciones al español (1860-1915) de La feria de las vanidades de William Makepeace Thackeray». Traductores y traducciones de literatura y ensayo (1835-1919). Ed. Juan Jesús Zaro Vera . Granada: Comares, 2007.

RUIZ Noguera, Francisco y ZARo Vera, Juan Jesús. Retraducir: una nueva mirada. La retraducción de textos literarios audiovisuales. Málaga: Miguel Gómez Ediciones, 2007.

RuIZ RosENDO, Lucía «Introducción a la interpretación de conferencias».Panace@: Boletín de Medicina y Traducción, 9.26 (2007).

-, «Propuesta de formación en interpretación en el ámbito de la medicina».Panace@: Boletín de Medicina y Traducción, 9.26 (2007).

SARALEGI, Xavier y ALEGRIA, Iñaki. «Similitud entre documentos multilingües de carácter científico-técnico en un entorno web». Procesamiento del lenguaje natural, 39 (2007): 9.

SHASHOK, Karen. «Up-skilling for Translators, Editors and other Communications Professionals (with a Nod to Academic Researchers and a Wink to Historians)».Panace@: Boletín de Medicina y Traducción, 9.26 (2007).

Simoes, Alberto y Almeida, José. «Parallel Corpora-based Translation Resources Extraction». Procesamiento del lenguaje natural, 39 (2007): 32.

ST. Clair, Robert N. «The Sedimentation Theory of Cultural Time and Space». Círculo de lingüística aplicada a la comunicación, 31 (2007): 52-90. 
TORRES FERnÁNDEZ, Milagros de. «La distribución de uso (diglosia) del español y el inglés en el ámbito de la empresa, la ciencia y la tecnología en áreas hispanohablantes». Linguax: Revista de lenguas aplicadas, 4 (2007).

VÁZQUEZ Y DEL ARBOL, Esther. «Aspectos de la traducción científico-técnica: errores en la traducción de manuales de instrucciones del italiano al inglés». Babel A.F.I.A.L.: Aspectos de filología inglesa y alemana, 16 (2007): 17-32.

Venegas LagüEns, M. ${ }^{a}$ Luisa. «Translating Repetition in Ulysses». The Scallop of Saint James: An Old Pilgrim's Hoard. Reading Joyce from the Peripheries / Leyendo a Joyce desde las periferias. Ed. Susana Domínguez Pena, Margarita Estévez Saá y Anne MacCarthy. Weston, Florida: Netbiblo, 2006. 140-54.

VÉLEZ BERTOMEU, Fabio. «Traductores, traidores y otros malhechores. la falla descubierta por 'la tarea del traductor'». Murcia: Universidad de Murcia: Tonos Digital, 14 (Diciembre 2007).

Vicente-Díez, María Teresa, Pablo-SÁnchez, César de, y Martínez, Paloma. «Evaluación de un sistema de reconocimiento y normalización de expresiones temporales en español». Procesamiento del lenguaje natural, 39 (2007): 14.

Zaro Vera, Juan Jesús, ed. Traductores y traducciones de literatura y ensayo (1835-1919). Granada: Comares, 2007.

—, «La creación de un archivo digitalizado de traducciones». Traductores y traducciones de literatura y ensayo (1835-1919). Ed. Juan Jesús Zaro Vera. Granada: Comares, 2007. 


\section{E. CUltura Y CINE}

ANTONIA SAGREdo SANTOS asagredo@flog.uned.es

M. ${ }^{\mathrm{a}}$ LUZ ARROYo VÁZQUEZ larroyo@flog.uned.es

UNED. Madrid

ÍNDICE

1. Cultura

2. Cine

\section{Cultura}

AguirRe Durán, Marcelo E. «Devoción en la independencia americana». Historia 16, 378 (2007): 28-49.

AL-AED AL-HAQ, Fawwaz. «Cultural Signs in the Teaching and Learning of a Foreign Language». Approaching Cultures through English. Ed. Elizabeth Woodward Smith. A Coruña: Universidade da Coruña, Servicio de Publicaciones, 2007. 1-16.

Alameda HernÁNDEZ, Angela. «Colony vs. Metropolis: Opposing Discursive Representations of a Colony's National Identity in the Printed Press». Odisea: Revista de estudios ingleses, 8 (2007): 19-33.

ALBERRO, Manuel. Lebor gabala: libro de las invasiones de Irlanda. Asturias: Ediciones TREA, S.L., 2007.

Altuna García de Salazar, Asier. «The Irish Language and Issues on Post-colonialism: an Approach». Postcolonial and Gender Perspectives in Irish Studies. Ed. Marisol Morales Ladrón. A Coruña: Netbiblo, 2007. 21-41.

Álvarez CallejA, M. ${ }^{a}$ Antonia. «The US-Mexican Borderlands: Language and Identity». Approaching Cultures through English. Ed. Elizabeth Woodward Smith. A Coruña: Universidade da Coruña, Servicio de Publicaciones, 2007. 17-24.

Álvarez Recio, Leticia. Rameras de Babilonia. Historia cultural del anticatolicismo en la Inglaterra Tudor. Salamanca: Ediciones Universidad de Salamanca, 2006.

Amenedo Costa, Mónica. «Foreign Immigration: The Economic Situation of Some British Workers in Ferrol in the Eighteenth Century». Approaching Cultures through English. Ed. Elizabeth Woodward Smith. A Coruña: Universidade da Coruña, Servicio de Publicaciones, 2007. 25-32.

ANES, Gonzalo, y GARRIGUES, Eduardo, eds. La ilustración española en la independencia de los Estados Unidos. Madrid: Marcial Pons, 2007.

ARIAS, David. Las raíces hispanas de los Estados Unidos. León: Ediciones Leonesas, 2006.

ARMADA, Alfonso. El rumor de la frontera: viaje por el borde entre Estados Unidos y México. Barcelona: Ediciones Península, S.A., 2006.

Armental Romero, María. «Challenging the Father's Voice. Murray Bail's Approximation to Feminine Speech in Eucalyptus». Approaching Cultures through English. Ed. Elizabeth Woodward Smith. A Coruña: Universidade da Coruña, Servicio de Publicaciones, 2007. 33-39. 
Arroyo VÁzqueZ, M. ${ }^{a}$ Luz. «Introducing Historical and Cultural Background into the Language Classroom». Approaching Cultures through English Diversity in Context. Ed. Elizabeth Woodward Smith. A Coruña: Universidade da Coruña, Servicio de Publicaciones, 2007. 41-48.

—, «Federica Montseny en la prensa española: su visión sobre la política estadounidense coetánea». Escritoras y pensadoras Europeas. Ed. Mercedes Arriaga Flórez et al. Sevilla: Arcibel Editores, 2007. 23-37.

—, «Rosa Parks. Pionera e icono del movimiento por los derechos civiles en los Estados Unidos». Proceedings of the 30th AEDEAN International Conference. Eds. María Losada Friend, Pilar Ron Vaz, Sonia Hernández Santano y Jorge Casanova. Huelva: Servicio de Publicaciones de la Universidad de Huelva, 2007. CD-ROM.

AsHe, Geoffrey. Merlin: historia y leyenda de la Inglaterra del rey Arturo. Barcelona: Crítica, 2007.

BAEnA, Rosalía, ed. Transculturing Auto/Biography: Forms of Life Writing. London, New York: Routhledge, 2007.

BeCERra Franco, Ricardo Lucas. «Language, Culture and Communication: A Dilemma? Periphery and Centre II. Ed. Rubén Jarazo Álvarez. A Coruña: Nino S. L., 2006. 375-79.

BELKACEM, Belmekki. «The impact of British Rule on the Indian Muslim Community in the Nineteenth Century». E.S.: Revista de Filología Inglesa, 28, (2007- 2008): 27-46.

Bello PIÑón, Nuria. «The Language of Advertisements: A Case Study of Adverts of Healt Products». Periphery and Centre II. Ed. Rubén Jarazo Álvarez. A Coruña: Nino S. L., 2006. 365-74.

Borge, Francisco J. A New World for a New Nation. The Promotion of America in Early Modern England. Bern: Peter Lang, 2007.

Bringas LóPEZ, Ana. «Cristina García’s Female Exiles: The Mother/Land as a Feminist Trope in Dreaming in Cuban». Approaching Cultures through English Diversity in Context. Ed. Elizabeth Woodward Smith. A Coruña: Universidade da Coruña, Servicio de Publicaciones, 2007. 49-57.

BRITO, Manuel. «Publishing American Poetry Today: a New Multilayered Tone». Approaching Cultures through English Diversity in Context. Ed. Elizabeth Woodward Smith. A Coruña: Universidade da Coruña, Servicio de Publicaciones, 2007. 59-68.

Bueno Alonso, Jorge L. La épica de la Inglaterra anglosajona: Historia y textos desde el auge de Mercia al declive de la monarquía (760-1016). Vigo: Servizio de Publicacións da Universidade de Vigo, 2007.

BURKe, Peter. «¿Qué es la historia cultural?» Barcelona: Paidos ibérica, 2006.

Calvo Buezas, Tomás. Hispanos en Estados Unidos, inmigrantes en España: ¿amenaza o nueva civilización? Madrid: Los Libros de la Catarata, 2006.

—, El gigante dormido. El poder hispano en los Estados Unidos. Madrid: Los libros de la Catarata, 2007.

CARIDAD BARREIRo, María Mercedes. «Nature and Entertainment in Eighteenth-Century Britain». Approaching Cultures through English. Ed. Elizabeth Woodward Smith. A Coruña: Universidade da Coruña, Servicio de Publicaciones, 2007. 69-77.

CARDElús, Borja. La huella de España y de la cultura hispana en los Estados Unidos. Madrid: Agencia Española de Cooperación Internacional, 2007.

CELADA, Antonio R., et al., eds. Las Brigadas Internacionales: 70 años de memoria histórica. Salamanca: Amarú Ediciones, 2007.

Couto LoREnzo, Gerardo. «Cultural Bias through the Centuries: Shylock and the Rule of Law». Approaching Cultures through English. Ed. Elizabeth Woodward Smith. A Coruña: Universidade da Coruña, Servicio de Publicaciones, 2007. 79-85.

Crespo García, Begoña. «The Socio-Cultural Development of Modern Science: An Overview». Approaching Cultures through English. Ed. Elizabeth Woodward Smith. A Coruña: Universidade da Coruña, Servicio de Publicaciones, 2007. 87-92. 
Crossman, Sylvie y Barau, Pierre. Saberes indígenas. Estudios sobre los tibetanos, los navajos y los aborígenes australianos. Castellón: Ellago Ediciones, 2007.

Dachs Ventura, Agnés. «Accessing Another Culture: South African Tales for Children». Approaching Cultures through English. Ed. Elizabeth Woodward Smith. A Coruña: Universidade da Coruña, Servicio de Publicaciones, 2007. 93-101.

DAvidson, M. ${ }^{a}$ Guadalupe. The Rhetoric of Race: Toward a Revolutionary Construction of Black Identity. Valencia: Publicacions Universtitat de Valencia, 2007.

Davis, Rocío G. Begin Here: Reading Asian North American Autobiographies of Childhood. Honolulu: University of Hawai Press, 2007.

-, Aume Aurell y Ana Beatriz Delgado, eds. Ethnic Life Writing and Histories: Genres, Performance, and Culture. Hamburg: LIT Verlag, 2007.

DiETZ, Bernd. «El anticomunismo como memoria histórica: Auden y sus hermanos», Nexus, 2 (2007): 95-102.

EsPeJo, Ramón, et al. eds. Critical Essays on Chicano Studies. Bern: Peter Lang, 2007.

FERNÁNDEZ MÉNDEZ, Cristina. «Gender Relations between Male Colonisers and Colonised Females in Stevenson's The Beach of Falesá: The Subversion of the Transcultural Romance Plot». Approaching Cultures through English. Ed. Elizabeth Woodward Smith. A Coruña: Universidade da Coruña, Servicio de Publicaciones, 2007. 131-38.

FERnÁNDEZ RodrígueZ, Carmen. «Feeding Fancies with the Pen: The Female Artis in Fanny Burney's The Wanderer (1814)». Approaching Cultures through English. Ed. Elizabeth Woodward Smith. A Coruña: Universidade da Coruña, Servicio de Publicaciones, 2007. 139-47.

FERnÁNDEZ SuÁrez, M. ${ }^{a}$ Yolanda. «The Hedge-Schoolmaster. Trespasser of Socio-cultural Barriers». Re-writing Boundaries. Ed. Asier Altuna y Cristina Andreu. Barcelona: Promocions i Publicacions Universitàries, 2007. 105-10.

FERNÁNDEZ SuÁrez, José Ramón. «Some Notes on the Battle of Rioseco (1808): Opinions of English and Spanish Historians». E.S.: Revista de Filología Inglesa, 28 (2007-2008): 89-96.

Filgueira Figueira, Marina y Moreno Álvarez, Alejandra. «Searching for an Identity in an America-Latino Context: Fragmented Female Subjects in Spanglish». Approaching Cultures through English. Ed. Elizabeth Woodward Smith. A Coruña: Universidade da Coruña, Servicio de Publicaciones, 2007. 149-55.

FLOYD, Alan. «The Paradoxes and Estereotypes of The Third Man». Approaching Cultures through English. Ed. Elizabeth Woodward Smith. A Coruña: Universidade da Coruña, Servicio de Publicaciones, 2007. 157-65.

Flys JunQuera, Carmen y LeE, Maurice A., eds. Family Reflections. The Contemporary American Family in the Arts. Alcalá de Henares: Universidad de Alcalá, 2007.

Frías, María; Liste, José y Simal, Begoña, eds. Ethics and Ethnicity in the Literature of the United States. Valencia: Universidad de Valencia, 2006.

Gallardo, Miguel. «Nueva York era el referente de lo nuevo», Quimera, 284-285 (2007). 42-46.

GEORGE, Susan. El pensamiento secuestrado. Cómo la derecha laica y la religiosa se han apoderado de Estados Unidos. Barcelona: Icaria, 2007.

GonZÁlez DE Miguel, Jesús. «Los brigadistas de la batalla del Jarama». Historia 16, 358 (2006): $72-81$.

GutiérRez RodríGuez, Marta María. «The Afflicted Girls of Salem Village: ¿Victims or Victimizers? Periphery and Centre II. Ed. Rubén Jarazo Álvarez. A Coruña: Nino S. L., 2006. 89-97.

HEAvner, Tracy. «The Origin and Evolution of Jazz». Approaching Cultures through English. Ed. Elizabeth Woodward Smith. A Coruña: Universidade da Coruña, Servicio de Publicaciones, 2007. 167-72.

IbARRARAN Bigalondo, Amaia. «How to be a Chicana Role Model, or How to be a $21^{\text {st }}$ Century Chicana». ES: Revista de filología inglesa, 28 (2007-2008). 97-106. 
Jaime De Pablos, M. ${ }^{a}$ Elena, ed. Análisis de género en los estudios irlandeses. Almería. Servicio de Publicaciones de la Universidad de Almería, 2007.

Jarazo Álvarez, Rubén, ed. Periphery and Centre II. A Coruña: Nino, S. L., 2006.

—, «Introduction to Paleography: Applying the Study of Ancient Texts to Welsh Literature». Approaching Cultures through English. Ed. Elizabeth Woodward Smith. A Coruña: Universidade da Coruña, Servicio de Publicaciones, 2007. 181-96.

LABIo BeRnAl, Aurora. Comunicación, periodismo y control informativo: Estados Unidos, Europa y España. Barcelona: Anthropos, 2006.

LamarCa MARGalef, Jordi. «Cartas Irlandesas y Húngaras by José María Lizana. A Vision of the Irish Question». Re-writing Boundaries. Ed. Asier Altuna y Cristina Andreu. Barcelona: Promocions i Publicacions Universitàries, 2007. 225-30.

LASA ÁlvareZ, Begoña. «Literary Patrons and Women Writers at the End of the Eighteenth and Beginning of the Nineteenth Century: A Demanding Relationship». Approaching Cultures through English. Ed. Elizabeth Woodward Smith. A Coruña: Universidade da Coruña, Servicio de Publicaciones, 2007. 197-205.

LASAGABASTER HERRATE, Iñaki. Las lenguas de la diáspora vasca en el oeste de los Estados Unidos. Bilbao: Autor-Editor, 2006.

Ledo FernándeZ, Mónica. «The Parish in Patrick Kavanagh: Towards a New Mythology». Approaching Cultures through English. Ed. Elizabeth Woodward Smith. A Coruña: Universidade da Coruña, Servicio de Publicaciones, 2007. 207-16.

Lezama Morales, Karen Yanuba. «Rewriting Stereotypes over the Boundaries of Terror». Rewriting Boundaries. Ed. Asier Altuna y Cristina Andreu. Barcelona: Promocions i Publicacions Universitàries, 2007. 111-22.

Lojo RodríGuez, Laura. «The Politics of Gender: Eavan Boland's Construction of Subjectivity». Approaching Cultures through English. Ed. Elizabeth Woodward Smith. A Coruña: Universidade da Coruña, Servicio de Publicaciones, 2007. 217-25.

LóPez LiQuete, María Felisa, ed. Postcolonial American Mirrors. Leioa: Universidad del País Vasco, 2007.

LosAdA PÉREZ, Ana María. «"Excavating the Self”: Irish Landscape and Subjectivity in Seamus Haney's Early Poetry». Approaching Cultures through English. Ed. Elizabeth Woodward Smith. A Coruña: Universidade da Coruña, Servicio de Publicaciones, 2007. 235-42.

LLORENS, Vicente. Liberales y románticos. Una emigración española en Inglaterra (1823 - 1834). Madrid: Editorial Castalia, S.A., 2006.

ManZANAS, Ana María, ed. Border Transits: Literature and Culture Across the Line. Amsterdam \& New York: Rodopi, 2007.

—, «La frontera de México-Estados Unidos como paradigma intercultural II: tres entierros y una interculturalidad». Anthropos, 216 (2007): 109-17.

MARTín Rodríguez, Manuel M. «La frontera de México-Estados Unidos como paradigma intercultural III: la otra historia de la literatura chicana». Anthropos, 216 (2007): 128-37.

MarTínez SARIEGo, Mónica María. «Travestismo y music hall en la época victoriana: modelos de mujer vestida de hombre en Tipping the Velvet». Periphery and Centre II. Ed. Rubén Jarazo Álvarez. A Coruña: Nino S. L., 2006. 99-110.

MeJíA, Glenda. «Aculturation and Hispanic Adolescents: Language and Identity», Cultura, Lenguaje y Representación. Revista de Estudios Culturales de la Universidad Jaume I, 4 (2007): 169-84.

Mingo SERRANO, Juan Bautista. «España en la independencia de EE.UU.». Historia 16, 372 (2007): 22-29.

Montero Ameneiro, Lidia María. «The Poetry of Regret: The Ruins of the Ascendancy». Approaching Cultures through English. Ed. Elizabeth Woodward Smith. A Coruña: Universidade da Coruña, Servicio de Publicaciones, 2007. 253-61. 
Morado Sobrido, María Elena y SERÉn Bouzas, Cristina. «Irish Superstitions and Traditions in 'A Costa da Morte'». Periphery and Centre II. Ed. Rubén Jarazo Álvarez. A Coruña: Nino S. L., 2006. 37-48.

Moreno Alonso, Manuel. Las «cosas de España» en Inglaterra. Un país ante la mirada de otro. Sevilla: Junta de Andalucía, 2007.

NAdAles Ruiz, Marta. «Augusto Assía: An Impresión of England and the English». Approaching Cultures through English. Ed. Elizabeth Woodward Smith. A Coruña: Universidade da Coruña, Servicio de Publicaciones, 2007. 263-70.

NAYA Montero, Paula. «South Asian Women in Diaspora: The Difficult Search for a Place Away from Home». Approaching Cultures through English. Ed. Elizabeth Woodward Smith. A Coruña: Universidade da Coruña, Servicio de Publicaciones, 2007. 271-77.

NúÑEz PUENTE, Carolina. «Orientalism in the English Eighteenth Century: The "Other Woman" of Women Writers' Texts». Approaching Cultures through English. Ed. Elizabeth Woodward Smith. A Coruña: Universidade da Coruña, Servicio de Publicaciones, 2007. 279-87.

OrTega, María Luisa. «La frontera de México-Estados Unidos como paradigma intercultural: la herida abierta. Cine e interculturalidad». Anthropos, 216 (2007). 109-17.

Pedreda LóPez, Gema. «The Small Smile Again: New Lives in July's Village». Approaching Cultures through English. Ed. Elizabeth Woodward Smith. A Coruña: Universidade da Coruña, Servicio de Publicaciones, 2007. 301-6.

Ramblado-Minero, María Cinta y Pérez-Vides, Auxiliadora, eds. Single Motherhood in Twentieth-Century Ireland. Cultural, Historical, and Social Essays. Lewiston, Queenston and Lampeter: The Edwin Mellen Press, 2006.

RIBAS Segura, Catalina. «The influence of Spanish, Italian and Greek Migrants in Australia». Approaching Cultures through English. Ed. Elizabeth Woodward Smith. A Coruña: Universidade da Coruña, Servicio de Publicaciones, 2007. 317-24.

RIVERO TARAVILlO, Antonio. Viaje sentimental por Inglaterra. Córdoba: Editorial Alamuzara, 2007.

Rosende PÉREZ, Aida. «Transgressing Corporeal Boundaries: The Female Body and Representation in the Work of Contemporary Irish Women Artists». Re-writing Boundaries. Ed. Asier Altuna y Cristina Andreu. Barcelona: Promocions i Publicacions Universitàries, 2007. 127-40.

Rouse, Andrew C. «The Concept of Time in England before and after 1851». Approaching Cultures through English. Ed. Elizabeth Woodward Smith. A Coruña: Universidade da Coruña, Servicio de Publicaciones, 2007. 335-48.

RUTHERFURD, Edward. Rebeldes de Irlanda. Barcelona: Roca Editorial, 2007.

—, Príncipes de Irlanda. Barcelona: Roca Editorial, 2006.

SAGREDo SANTOS, Antonia. «Líderes marginados en el New Deal estadounidense y su presencia en los medios de comunicación». Periphery and Centre II. Ed. Rubén Jarazo Álvarez. A Coruña: Nino S. L., 2006. 321-29.

—, «The Origins of Special Days and Festivities among English-speaking Peoples». Approaching Cultures through English. Ed. Elizabeth Woodward Smith. A Coruña: Universidade da Coruña, Servicio de Publicaciones, 2007. 349-58.

—, « La influencia de los "colleges” norteamericanos en la Residencia de Señoritas de María de Maeztu». Escritoras y pensadoras europeas. Ed. Mercedes Arriaga Flórez et al. Sevilla: Actibel Editores, 2007. 599-614.

—, «¿Por qué incorporar los contenidos culturales en nuestras clases de idiomas?». TESOL-Spain Newsletter, 31 (June 2007): 10-12.

—, «Personal Connections between Spaniards and Americans in the Revolutionary Era: Pioneers in Spanish-America Diplomacy». Legacy: Spain and the United States in the Age of Independence, 1763-1848. Ed. Carolyn Kinder Karr, coord. Washington D. C. \& Madrid: Smithsonian Institution, SEACEX \& Fundación Consejo Estados Unidos, 2007. 45-63. 
—, «Mary M. Bethune y su lucha por los derechos civiles en los Estados Unidos». Procedings of the 30th AEDEAN Internacional Conference. Ed. María Losada Friend, Pilar Ron Vaz, Sonia Hernández Santano y Jorge Casanova. Huelva: Servicio de Publicaciones de la Universidad de Huelva, 2007. CD-ROM.

-, y Arroyo VÁzquez, M. ${ }^{a}$ Luz. History and Culture of the United States. Madrid: Universidad Nacional de Educación a Distancia, 2007.

SÁNCHEZ-PARDO, Esther. «El silencio de Auden y el clamor de la historia», Nexus, 2 (2007): 87-93.

SeCo GonzÁlez, Carlos. «Modern Irish: Moving from a Peripheral to a Global Language». Periphery and Centre II. Ed. Rubén Jarazo Álvarez. A Coruña: Nino S. L., 2006. 333-41.

SERÉN BouZAS, Cristina. «Celtic Religión: A Brief Study». Approaching Cultures through English. Ed. Elizabeth Woodward Smith. A Coruña: Universidade da Coruña, Servicio de Publicaciones, 2007. 359-66.

SмIтн, Elizabeth W., ed. Approaching Cultures through English. A Coruña: Universidade da Coruña, 2007.

—, «British Character on Film: Little Old Ladies Rule!». Approaching Cultures through English. Ed. Elizabeth Woodward Smith. A Coruña: Universidade da Coruña, Servicio de Publicaciones, 2007. 383-94.

—, «The Vicar of Nibbleswicke: un desafío cultural e lingüístico». Traducción e política editorial de literatura infantil e xuvenil. Coord. Ana Luna Alonso, Silvia Montero Küpper. A Coruña: Tórculo, 2006. 243-52.

Toro Santos, Antonio Raúl de y Alonso GiRáldez, José Miguel. «New Representations of Irishness in Contemporary Irish Poetry: George Watson and Seamus Heaney's Concept of "Sense of Place" in Northern Ireland». Approaching Cultures through English. Ed. Elizabeth Woodward Smith. A Coruña: Universidade da Coruña, Servicio de Publicaciones, 2007. 103-10.

Trainor, Patricia. «Maud Gonne: la Juana de Arco de Irlanda». Análisis de género en los estudios irlandeses. Ed. María Elena Jaime de Pablos. Almería: Servicio de Publicaciones de la Universidad de Almería, 2007. 121-30.

UNCETA GÓMEZ, Luis. «Mito clásico y cultura popular: reminiscencias mitológicas en el cómic estadounidense». EPOS. Revista de filología, 23 (2007): 333-344.

VAlera Tembra, Juan José. «A Brief Account of the Catholic Faith in New Zeeland». Approaching Cultures through English. Ed. Elizabeth Woodward Smith. A Coruña: Universidade da Coruña, Servicio de Publicaciones, 2007. 367-72.

VÁZQUEZ MAROÑO, M. ${ }^{a}$ Luz. «The Importance of Forensic Linguistics and the Análisis of Court and Police Documents in English-Speaking Countries». Approaching Cultures through English. Ed. Elizabeth Woodward Smith. Coruña: Universidade da Coruña, Servicio de Publicaciones, 2007. 373-81.

VILAR, Mar. «To Build or Not To Build, New Walls to Language Diversity». Periphery and Centre II. Ed. Rubén Jarazo Álvarez. A Coruña: Nino S. L., 2006. 343-50.

VILlAR-ARgÁIz, Pilar. «Latter-day Mother Irelands: The Role of Women in Michael Collins sand The Wind that Shakes the Barley». Estudios Irlandeses, 2 (2007). 183-204.

Weng, Pei Shi. «The Impact of Different Social Class Mother's Verbal Input on Children's Language Acquisition». Periphery and Centre II. Ed. Rubén Jarazo Álvarez. A Coruña: Nino S. L., 2006. 351-64.

WILSON, Janet K. «The Traditional American Family Structure: Prime-time Television versus the U. S. Census Bureau». Family Reflections. The Contemporary American Family in the Arts. Ed. Carmen Flys Junquera y Maurice A. Lee. Alcalá de Henares: Servicio de Publicaciones Universidad de Alcalá, 2007. 83-92. 


\section{CINE}

Agullera, Christian. Milos Forman: el cineasta del inconformismo. Córdoba: Editorial Berenice, 2006. Alonso, Juan J., Mastache, Enrique A. y Alonso, Jorge. La edad media en el cine. Madrid: T \& B Editores, 2007.

Álvarez, Juan Luis. Bogart y Bacall. Dos estrellas y un destino. Madrid: T \& B Editores, 2007.

Azcona Montoliú, María del Mar. «Nine Short Stories into a Long One: Narrative Strategies in Robert Altman's Short Cuts (1993)». The Short Story in English: Crossing Boundaries. Ed. Gema Soledad Castillo García, María Rosa Cabellos Castilla, Juan Antonio Sánchez Jiménez, Vincent Carlisle Espínola. Alcalá de Henares: Servicio de Publicaciones de la Universidad de Alcalá, 2006. 75-85.

BALLESTER, Cesar. Milos Forman. Barcelona: Cátedra, 2006.

BARBER, Stephen. Ciudades proyectadas. Cine y espacio urbano. Barcelona: Gustavo Gili, 2006.

Berruete Rodríguez, María Pilar. «Family still Matters in The sound of music and Star wars». Family Reflections. The Contemporary American Family in the Arts. Ed. Carmen Flys Junquera y Maurice A. Lee. Alcalá de Henares: Servicio de Publicaciones Universidad de Alcalá, 2007. 39-54.

BERTHONe, Jean Pierre. Orson Wells en acción. Madrid: Akal, 2007.

Bou, Nuria: Diosas y tumbas. Mitos femeninos en el cine de Hollywood. Barcelona: Icaria, 2006. CAGiga, Nacho. David Mamet. Madrid: Akal, 2007.

CAIRNS, Graham. La visión espacial del cine. El arquitecto detrás de la cámara. Madrid: Abada, 2007.

CANTERO, Marcial. Steven Spielberg. Barcelona: Cátedra, 2006.

CAPRA, Frank. Autobiografía de Frank Capra. El nombre delante del título. Madrid: T \& B Editores, 2007.

CARRASCO CARrasco, Rocío. «Peripheral Bodies in Cyberworlds: Cronenberg's e-XistenZ (1999)». Periphery and Centre II. Ed. Rubén Jarazo Álvarez. A Coruña: Nino S. L., 2006. 157-62.

—, New Heroes on Screen. Huelva: Servicio de Publicaciones de la Universidad de Huelva, 2007.

—, y Domínguez Romero, Elena. «The Enemy from Within: Wilcox's Forbidden Planet (1956) and the Shakesperean Trace». Approaching Cultures through English Diversity in Context. Ed. Elizabeth Woodward Smith. La Coruña: Tórculo, 2007. 111-19.

CARRERA SUÁREZ, Isabel. «El rostro femenino de Europa: Casablanca, Ingrid Bergman y el orientalismo del cine clásico de Hollywood». Diosas del celuloide: arquetipos de género en el cine clásico. Coord. Carmen Rodríguez Fernández. Madrid: T \& B Editores, 2007. 45-66.

CARretero, Margarita y RodrígueZ, M. ${ }^{a}$ Elena. «Fragmented Women, Fragmented Discourses: The Hours and its Film Adaptation». Estudios en Honor de Rafael Fente Gómez. Ed. Miguel Ángel Martínez-Cabeza Lombardo, Neil McClaren y Luis Quereda Rodríguez-Navarro. Granada: Editorial Universidad de Granada, 2007. 507-15.

Casanova Varela, Basilio. Leyendo a Hitchcock: Análisis textual de North by Northwest. Valladolid: Castilla Ediciones, 2007.

CASAS, Quim. David Lynch. Barcelona: Cátedra, 2007.

—, Películas clave del Western. Barcelona: Robinbook, 2007.

CASCAJOSA VIRINo, Concepción Carmen. El espejo deformado. Versiones, secuelas y adaptaciones en Hollywood. Sevilla: Universidad de Sevilla, 2006.

—, «Miedos y sueños en Sunnydale: una aproximación a Joss Whedon como autor televisivo en Bufy, cazavampiros». Garoza: Revista de la Sociedad Española de Estudios Literarios de Cultura Popular, 6 (2006): 4.

CASTRo, Sixto J. «Woody Allen y Dostoievski: ¿existe una estructura moral trascendente? (A propósito de Delitos y faltas)». Anthropos, 216 (2007). 138-149. 
CHANDLER, Charlotte. Sólo es una película: Alfred Hitchcock, una biografía personal. Barcelona: Ma Non Troppo, 2006.

CHAPARRo, Hugo. Alfred Hitchcock: el miedo hecho cine. Madrid/Bogotá: Panamericana Editorial, 2007.

CoHEN, Clélia. El western: el cine americano por excelencia, la conquista del Oeste, el nacimiento de un género, artistas y modelos: Ford, Wayne, Mann, Stewart. Barcelona : Paidós Ibérica, 2006.

Coleman, Philip. «William Austin, the Missing Man». The Short Story in English: Crossing Boundaries. Ed. Gema Soledad Castillo García, María Rosa Cabellos Castilla, Juan Antonio Sánchez Jiménez, Vincent Carlisle Espínola. Alcalá de Henares: Servicio de Publicaciones de la Universidad de Alcalá, 2006. 230-40.

Colmenares, Dario. Billy Wilder: el arte de la ironía. Madrid/Bogotá: Panamericana Editorial, 2007.

ComA, Javier. Las películas de la caza de brujas. Madrid: Notorious Ediciones, 2007.

Comas, Ángel. Coppola. Madrid: T \& B. Editores, 2007.

Cornut-Gentille D’Arcy, Chantal. El cine británico de la era Thatcher. ¿Cine nacional o «nacionalista»? Zaragoza: Prensas Universitarias de Zaragoza, 2006.

Corral, Juan M. Humphrey Bogart. De la A a la Z. Madrid: Jaguar, 2006.

COURSODON, Jean-Pierre y TAVERNIER, Bertrand. 50 años de cine norteamericano. Barcelona: Akal, 2006.

Cueto, Roberto y Palacios, Jesús, eds. Asia Noir. Serie negra al estilo oriental. Madrid: T \& B Editores, 2007.

Dañobeitia, M. ${ }^{a}$ Luisa. «Parker's Angel Heart: Some Basic Considerations on Intertextuality». Estudios en Honor de Rafael Fente Gómez. Ed. Miguel Ángel Martínez-Cabeza Lombardo, Neil McClaren y Luis Quereda Rodríguez-Navarro. Granada: Editorial Universidad de Granada, 2007. 515-38.

Darias Beautell, Eva y Hernáez Lerena, M. Jesús, eds. Canon Disorders: Gendered Perspectives on Literature and Film in Canada and the United States. Logroño: Universidad de la Rioja/Universidad de La Laguna, 2007.

DíAZ-CuEstA, José. «Duel: Richard Matheson versus Steven Spielberg». The Short Story in English: Crossing Boundaries. Ed. Gema Soledad Castillo García, María Rosa Cabellos Castilla, Juan Antonio Sánchez Jiménez, Vincent Carlisle Espínola. Alcalá de Henares: Servicio de Publicaciones de la Universidad de Alcalá, 2006. 301-11.

Domínguez Romero, Elena. «The enemy from within: Wilcoxs Forbidden Planet (1956) and the Shakespearean trace». Approaching Cultures through English. Ed. Elizabeth Woodward Smith. A Coruña: Universidade da Coruña, Servicio de Publicaciones, 2007. 111-20.

EChaZARreta Soler, Carmen. «Sin City: cuando el cine se rinde a los pies del cómic». Aula de innovación educativa, 148 (2006): 65-76.

-, y Romea CAStro, Celia. Literatura universal a través del cine I/II. Barcelona: Horsori, 2006.

—, Literatura universal a través del cine II/II. Barcelona: Horsori, 2007.

EPSTEIN, Edward Jay. La gran ilusión. Dinero y poder en Hollywood. Barcelona: Tusquets, 2007.

Evans, Peter. «La enseñanza del cine en el sistema educativo británico». Comunicar XV (2007): 2729.

Faro ForteZa, Agustín. Películas de libros. Zaragoza: Prensas Universitarias de Zaragoza, 2006.

FERNÁNDEZ, Victor. Desmuntant a Woody Allen: Les Millors Frases. Barcelona: Columna Ediciones, 2007.

FERnÁNDEZ Morales, Marta. «"Civil War inside my Body”: Two Narratives of Dying in Contemporary Anglophone Film». Miscelánea: A Journal of English and American Studies, 36 (2007): 39-54. 
FERNÁNDEZ-SANTOS, Ángel. La mirada encendida. Escritos sobre cine. Barcelona: Debate [Random House Mondadori], 2007.

—, Más allá del Oeste. Barcelona: Debate [Random House Mondadori], 2007.

Fez, Desirée de. Películas clave del cine de terror moderno. Barcelona: Robinbook, 2007.

FONTE, Jorge. Woody Allen. Barcelona: Ediciones Cátedra, 2007.

GALLEGO, Carmen, coord. Tiempos modernos. Ensayos de tecnociencia y cine. Madrid: Equipo Sirius, 2007.

GARcía GómEZ, Francisco. El miedo sugerente. Val Lewton y el cine fantástico y de terror de la RKO. Málaga: Diputación Provincial de Málaga, 2007.

Giovanni, Elena, di. «Disney Films Reflections of the Other and the Self», Cultura, Lenguaje y Representación, 4 (2007): 91-110.

GÓMEZ TARÍn, Francisco Javier. Más allá de las sombras. Lo ausente en el discurso fílmico desde los orígenes hasta el declive del clasicismo (1895-1949). Castellón: Publicaciones de la Universitat Jaime I, 2006.

GonzÁlez Casademont, Rosa. «Postcolonial Ireland on Screen». Postcolonial and Gender Perspectives in Irish Studies. Ed. Marisol Morales Ladrón. A Coruña: Netbiblo, 2007. 203-40.

GonzÁlez-Fierro SAntos, José Manuel y GonzÁlez-Fierro Santos, Francisco Javier. Robert Altman: el independiente de Hollywood. Madrid: Arkadin Ediciones, 2006.

GonzÁlez Requena, Jesús. S. M. Eisenstein. Barcelona: Cátedra, 2006.

—, Douglas Sirk. Barcelona: Cátedra, 2007.

GotTFRIED, Martin. Bob Fosse: Vida y muerte. Barcelona: Alba Editorial, 2006.

Grobel, Lawrence. Conversaciones con Al Pacino. Barcelona: Belacqva, 2007.

GuijarRo GonZÁLEZ, J. Ignacio. «Don’t Know Much About (Multicultural) History: Teaching the Texan Conflicts in John Sayles' Film Lone Star». Masculinities, Femininities and the Power of the Hybrid in U.S. Narratives: Essays on Gender Borders. Ed. Nieves Pascual, Laura AlonsoGallo y Francisco Collado-Rodríguez. Heidelberg: Universitätsverlag, 2007.

HAAS, Anita. Eli Wallach. Vitalidad y picardía. Almería: Diputación de Almería, 2006.

Huerta Floriano, Miguel Ángel. Celuloide en llamas. El cine estadounidense tras el 11-S. Madrid: Notorious Ediciones, 2006.

IbARROLA ARMENDÁRIZ, Aitor. «Bridging the Gap between Short Story Cycles and Film: A Case Study». The Short Story in English: Crossing Boundaries. Ed. Gema Soledad Castillo García, María Rosa Cabellos Castilla, Juan Antonio Sánchez Jiménez, Vincent Carlisle Espínola. Alcalá de Henares: Servicio de Publicaciones de la Universidad de Alcalá, 2006. 468-85.

IgLESIAS DíAZ, Guillermo. «Cinematographic Na(rra)tions from the Edge: Transpotting». Approaching Cultures through English. Ed. Elizabeth Woodward Smith. A Coruña: Universidade da Coruña, Servicio de Publicaciones, 2007. 173-80.

JARAZO ÁlVAREZ, Rubén. «Al márgen de la transposición fílmica: El éxito de las Uvas de la Ira en Hollywood». Periphery and Centre II. Ed. Rubén Jarazo Álvarez. A Coruña: Nino S. L., 2006. 189-235.

JULLIER, Laurent. El sonido en el cine. Barcelona: Paidós Ibérica, 2007.

KIRSHENSON, Janet y Jenkins, Jane. La aventura de dirigir un casting. Cómo se hicieron los repartos de las grandes producciones de Hollywood. Barcelona: Alba, 2007.

LARA RALLO, Carmen. «From Image to Word, and Back to Image Again: Textualising and Filming Vermeer's Paintings in Girl with a Pearl Earring». Proceedings of the 30th International AEDEAN Conference. Ed. María Losada Friend, Pilar Ron Vaz, Sonia Hernández Santano, Jorge Casanova. Huelva: Editorial Universidad de Huelva, 2007. CD-ROM.

LEDO FERNÁNDEZ, Mónica. «Film and Play Versions of Lillian Hellman's Female Characters in The Children's Hour. The Impact of Meeting "Deviation"». Periphery and Centre II. Ed. Rubén Jarazo Álvarez. A Coruña: Nino S. L., 2006. 163-70. 
Marcos Azca, Marcos. Tim Burton. Barcelona: Ediciones Cátedra S. A., 2007.

Martín Alegre, Sara. Expediente X: en honor a la verdad. Madrid : Imágica, 2006.

-, y BAllesteros, Antonio. Siete relatos góticos/ Seven Gothic Stories: Del papel a la pantalla / from Paper to the Screen. Madrid: Jaguar Ediciones, 2006.

MARTín RENES, Cornelis. «The Quiet Man and Angela's Ashes: Hollywood Representations of Irish Emigration as Male Quest Narrative». Estudios Irlandeses, 2 (2007). Revista electrónica.

Martínez Cabeza, Miguel A. «How not to Adapt a Book to the Screen Successfully: The Orchid Thief». Estudios en Honor de Rafael Fente Gómez. Ed. Miguel Ángel Martínez-Cabeza Lombardo, Neil McClaren y Luis Quereda Rodríguez-Navarro. Granada: Editorial Universidad de Granada, 2007. 499-506.

McGuilligan, Patrick. Backstory 4. Conversaciones con guionistas de los años 70 y 80. Madrid: Plot, 2007.

—, George Cukor. Una doble vida. Madrid: T \& B Editores, 2007.

Memba, Javier. La Hammer. Su historia, sus películas, sus mitos. Madrid: T \& B Editores, 2007.

MENÉNDEZ Flores, Javier. Arte en vena. 50 creadores se confiesan. Barcelona: Ediciones B, 2007.

MerivirTA-ChaKrabarti, Raita. «Between Irish National Cinema and Hollywood: Neil Jordan's Michael Collins». Estudios Irlandeses, 2 (2007): 121-27.

Nabal Aragón, Eduardo. El marica, la bruja y el armario. Misoginia gay y homofobia femenina en el cine. Madrid: Egales, 2007.

Navarro, Antonio José, ed. El demonio en el cine. Máscara y espectáculo. Madrid: Valdemar, 2007.

Nelson, Nancy. Conversaciones con Gary Grant. A través de sus palabras y de quienes mejor le conocieron. Madrid: Notorious Ediciones, S. L., 2007.

OCAÑA, Javier. «Hollywood años 40». Cinemanía, 126 (2006): 91-95.

Oliete AldEA, Elena. «Representing hybridity as the bridge between cultures in Ivory's 1982 film Heat and Dust». ES: Revista de filología inglesa, 27 (2006-2007). 135-50.

OostdiJK, Diederik. «Changing Family Values: The Cosby show and The Simpsons». Family Reflections. The Contemporary American Family in the Arts. Ed. Carmen Flys Junquera y Maurice A. Lee. Alcalá de Henares: Servicio de Publicaciones Universidad de Alcalá, 2007. 93106.

ORIA GómEZ, Beatriz. «The Life Independent with Wes Anderson». Periphery and Centre II. Ed. Rubén Jarazo Álvarez. A Coruña: Nino, 2006. 151-56.

—, «Genre and ideology in Woody Allen's Another Woman (1988)». Revista alicantina de estudios ingleses, 20 (Nov. 2007). 167-83.

ORTEGA, Maria Luisa: Espejos rotos. Aproximaciones al documental norteamericano contemporáneo. Madrid: Ocho y medio, 2007.

—, «La frontera de México-Estados Unidos como paradigma intercultural: la herida abierta. Cine e interculturalidad». Anthropos, 216 (2007). 109-17.

PACHÓN RAMíREZ, Alejandro. Música y cine: géneros para una generación. Badajoz: Diputación de Badajoz, 2007.

Pagán, Alberte. A mirada impasible. As películas de Andy Warhol. Primeira parte. Santiago de Compostela: Editorial Santiago, 2007.

Palacios, Jesús ed. Euronoir. Serie negra con sabor europeo. Madrid: T \& B Editores, 2007.

PAREDES BADÍA, Israel. Imágenes del cuerpo. Cáceres: Filmoteca de Extremadura y Ocho y medio, 2007.

PRIETO, Miguel Angel. ;Malditas películas! Las leyendas negras en el cine de terror. Madrid: T \& B Editores, 2007.

QUIROGA, Horacio: Cine y literatura. Madrid: Losada, 2007.

RENES, Cornelis Martin. «The Quiet Man and Angela's Ashes: Hollywood Representations of Irish Emigration as Male Quest Narrative». Estudios Irlandeses, 2 (2007): 93-106. 
Ríos CARratalá, Juan A. Una arrolladora simpatía. Edgar Neville: de Hollywood al Madrid de la posguerra. Barcelona: Ariel, 2007.

—, coord. Universo Neville. Ayuntamiento de Málaga. Málaga, 2007.

RodríGuez FERnÁNDEZ, M. a del Carmen, coord. Diosas del celuloide. Arquetipos de géneros en el cine clásico. Madrid: Jaguar, 2006

RodríGuez Martín, María Elena. «Lecturas fílmicas de las obras de Jane Austen». De habitaciones propias y otros espacios conquistados. Estudios sobre mujeres y literatura en lengua inglesa en homenaje a Blanca López Román. Margarita Carretero González, M. ${ }^{a}$ Elena Rodríguez Martín y Gerardo Rodríguez Salas. Granada: Servicio de Publicaciones de la Universidad de Granada, 2006. 265-81.

RodríGuez RamíReZ, María del Carmen. «Minimalism to the Maximum: Short Story as the Starting Point in Memento». The Short Story in English: Crossing Boundaries. Ed. Gema Soledad Castillo García, María Rosa Cabellos Castilla, Juan Antonio Sánchez Jiménez, Vincent Carlisle Espínola. Alcalá de Henares: Servicio de Publicaciones de la Universidad de Alcalá, 2006. 775-85.

ROHMER, Eric. Elisabeth. Madrid: Ediciones J C, 2007.

ROMEA CASTRO, M.Celia. «El cine en el aula. La literatura en el aula». Aula de innovación educativa, 156 (2006): 6-11 .

—, «Literatura española y cine (1990-2007). Mirada desde la literatura infantil y juvenil». Letras peninsulares, 20.1 (2007): 57-90.

Ruiz Pardos, Manuela. «Representing the Nuclear Family in the Nuclear Age: Identity and Fatherhood in The Seven Year Itch». Family Reflections. The Contemporary American Family in the Arts. Ed. Carmen Flys Junquera y Maurice A. Lee. Alcalá de Henares: Servicio de Publicaciones Universidad de Alcalá, 2007. 27-38.

SALISBURY, Mark. Tim Burton por Tim Burton. Barcelona: Alba Editorial, 2006.

SÁNCHEZ, Sergi. Películas clave del cine de ciencia-ficción. Barcelona: Robinbook, 2007.

SÁnChEz NorIEGA, José Luis, ed. Historia del cine. Madrid: Alianza Editorial, 2006.

—, Historia del cine en películas 1990-1999. Bilbao: Mensajero, 2007.

SÁncheZ-PAlEncia CARAzo, Carolina. "“The Way you Wear your Hat": Performativity and Selfinvention in Jackie Kay's Trumpet and Duncan Tucker's Transamerica». Proceedings of the 30th International AEDEAN Conference. Ed. María Losada Friend, Pilar Ron Vaz, Sonia Hernández Santano, Jorge Casanova. Huelva: Editorial Universidad de Huelva, 2007. CD-ROM.

Sansweet, Stephen J. Star Wars. El legado. Caelus-Urano. Madrid: Ocho y Medio, 2007.

SeCo GonzÁlez, Carlos. «Michael Collins, Film and Myth: How a Peripheral Colony Became a Nation of the World». Periphery and Centre II. Ed. Rubén Jarazo Álvarez. A Coruña: Nino S. L., 2006. 171-80.

Seco Salvador, Olga. «The Same Old Store: The Representation of Peripheral Identities in the Australian Cinema of the 1990s». Periphery and Centre II. Ed. Rubén Jarazo Álvarez. A Coruña: Nino S. L., 2006. 181-87.

-, «The popularisation of Interracial Teen Romance in Contemporary Hollywood Cinema. Save the Last Dance (Thomas Carter, 2001)». ES.: Revista de filología inglesa 28, (2007-2008): 197-212.

SERRANo Cueto, José Manuel. Horrormanía. Enciclopedia de cine de terror. Madrid: Imágina y Alberto Santos, 2007.

—, De monstruos y hombres. Los reyes del terror de la Universal. Madrid: T \& B Editores, 2007.

SERVER, Lee. Ava Gardner: una diosa con pies de barro. Madrid: T \& B Editores, 2007.

Simmons, Carner. Sam Peckinpack: vida salvaje. Madrid: T \& B Editores, 2007.

Simsolo, Noël. El cine negro. Pesadillas verdaderas y falsas. Trad. Alicia Martorell Linares. Madrid: Alianza, 2007. 
STENGEL, Wayne. «Expelled from Eden: Welles and Coppola Women, the Violence of Family Secrets, and the Domestication of the African-American Family in Maya Angelou's Down in the Delta». Family Reflections. The Contemporary American Family in the Arts. Ed. Carmen Flys Junquera y Maurice A. Lee. Alcalá de Henares: Servicio de Publicaciones Universidad de Alcalá, 2007. 55-64.

Stourdzé, Sam, et al. Chaplin en imágenes. Barcelona: Fundación la Caixa, 2007.

Strauss, Frédéric y Huet, Anne. Hacer una película. Barcelona: Paidós Ibérica, 2007.

TARANCón, Juan A. «Se habla en español: A Certain Tendency in the Western film». Miscelánea: A Journal of English and American Studies, 36 (2007). 101-20.

TASENDE, J. M. ¡Acción! Memorias de un espectador. El cine de John Ford. Barcelona: Polígrafa, 2007.

Tejero García, Juan. John Wayne. El vaquero que conquistó Hollywood. Parte I (1907-1955). Madrid: T \& B Editores, 2007.

—, John Wayne. El vaquero que conquistó Hollywood. Parte II. Madrid: T \& B Editores, 2007.

ToteBERG, Michael. Fritz Lang (Lo esencial de...). Madrid: T \& B Editores, 2006.

Tovar PAz, Francisco Javier. Un río de fuego y agua: lecciones sobre mitología y cine. Cáceres: Servicio de Publicaciones de la Universidad de Extremadura, 2007.

URKIJO, Francisco Javier. John Frankenkeimer. Barcelona: Cátedra, 2006.

VALERo Garcés, Carmen. «Overripe Mangos, Eggshells and Miracle Glow: the Latino and the Anglo-American Families as Cultural Manifestations Represented in Films». Family Reflections. The Contemporary American Family in the Arts. Ed. Carmen Flys Junquera y Maurice A. Lee. Alcalá de Henares: Servicio de Publicaciones Universidad de Alcalá, 2007. 65-82.

VILLAR ARGÁIZ, Pilar. «Latter-day Mother Irelands: the Role of Women in Michael Collins and The Wind that Shakes the Barley». Estudios Irlandeses: Spanish Journal of Irish Studies, 2 (2007): 183-204.

VILLEGAs LóPEZ, Manuel. Grandes clásicos del cine: pioneros, mitos e innovadores. Madrid: Ediciones J C, 2005.

WALTERS, Ben. Orson Welles. Madrid: Ediciones Tutor, 2006. 